\title{
GESTÃO ESTRATÉGICA DO CONHECIMENTO: ESTUDO EXPLORATÓRIO EM EMPRESAS INSTALADAS NOS PARQUES TECNOLÓGICOS DO ESTADO DE SÃO PAULO
}

Dissertação apresentada à Escola de Engenharia de São Carlos da Universidade de São Paulo, como parte dos requisitos para obtenção do título de Mestre em Engenharia de Produção.

Área de concentração: Engenharia de Produção.

Orientador: Prof. Dr. Marcelo Seido Nagano

São Carlos 


\section{AUTORIZO A REPRODUÇÃO E DIVULGAÇÃO TOTAL OU PARCIAL DESTE TRABALHO, POR QUALQUER MEIO CONVENCIONAL OU ELETRÔNICO, PARA FINS DE ESTUDO E PESQUISA, DESDE QUE CITADA A FONTE.}

Ficha catalográfica preparada pela Seção de Tratamento da Informação do Serviço de Biblioteca - EESC/USP

Cruz, Claudia Andressa

C957g Gestão estratégica do conhecimento : estudo exploratório em empresas instaladas nos parques tecnológicos do estado de São Paulo / Claudia Andressa Cruz ; orientador Marcelo Seido Nagano. -- São Carlos, 2007.

Dissertação (Mestrado) - Programa de Pós-Graduação e Área de Concentração em Engenharia de Produção -- Escola de Engenharia de São Carlos da Universidade de São Paulo.

1. Gestão estratégica do conhecimento. 2. Gestão do conhecimento. 3. Dimensões estratégicas. 4. Parques tecnológicos. I. Título. 
Candidata: Engenheira CLAUDIA ANDRESSA CRUZ

Dissertação defendida e julgada em 15/03/2007 perante a Comissão Julgadora:

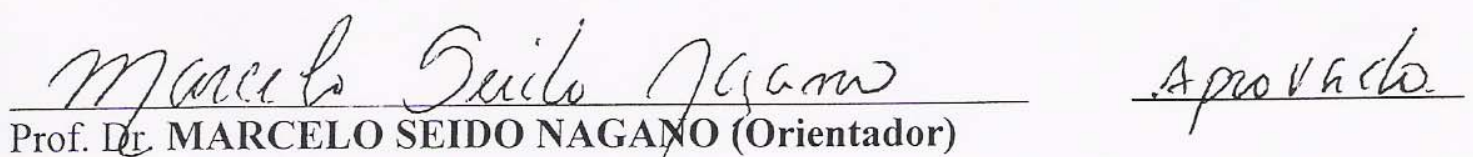

(Escola de Engenharia de São Carlos/USP)

$\frac{C O C O D C}{\text { Prof. Dr. EDMUNDO ESCRIVÂA FILHO }}$

APRSVADO

(Escola de Engenharia de São Carlos/USP)

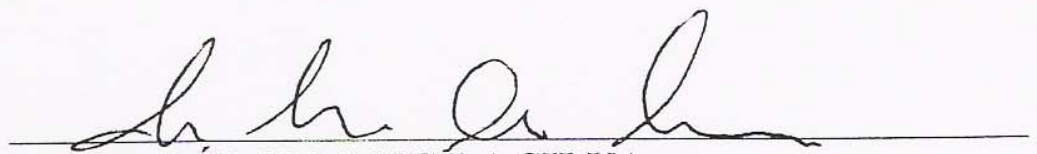

Prof. Dr. SÉRGIO LUIS DA SILVA

(Universidade Federal de São Carlos/UFSCar)
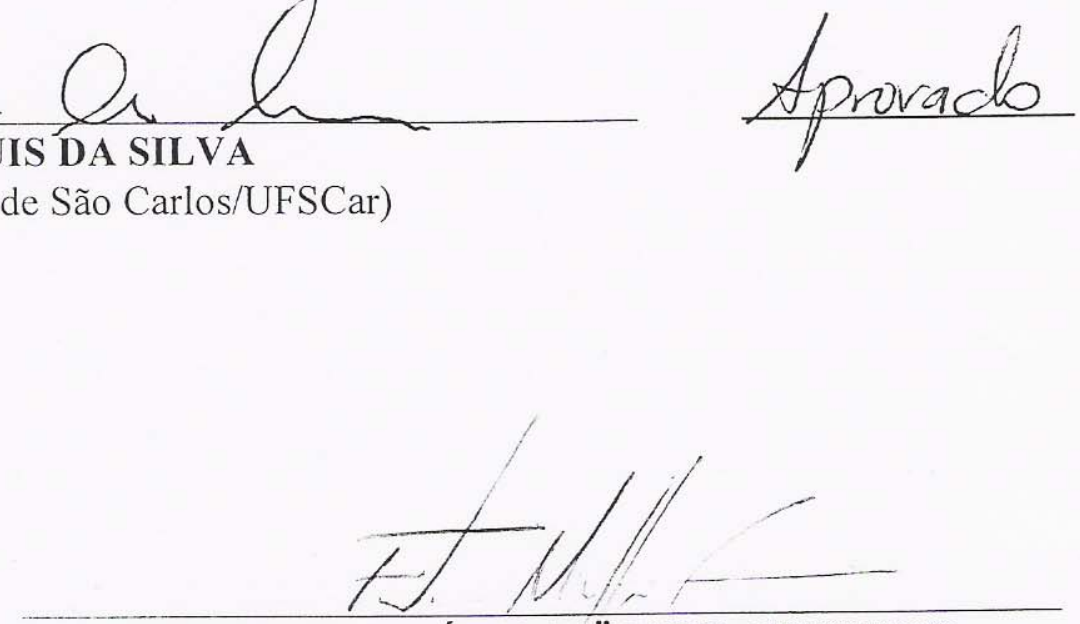

Prof. Associado FÁBIO MÜLLER GUERRINI

Coordenador do Programa de Pós-Graduação em

Engenharia de Produção

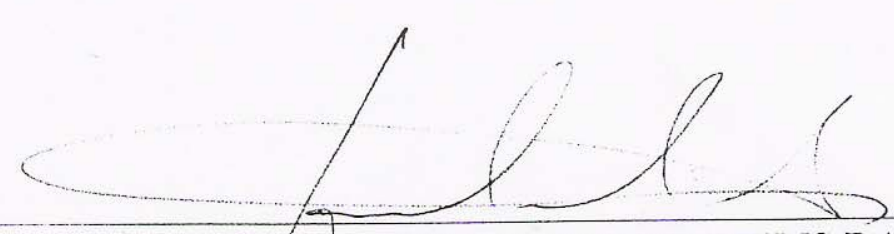

Prof. Associado GERALDO ROBERTO MARTINS DA COSTA

Presidente da Comissão da Pós-Graduação da EESC 


\section{DEDICATÓRIA}

Dedico este trabalho para aqueles que mais amo.

Primeiramente, à Deus e ao Santo Expedito, meus protetores.

Aos meus pais, Eustáquio e Paula, pelo amor e apoio incondicional.

Ao meu irmão, Allan, por sua sabedoria.

Ao Alex, meu amor, com gratidão e admiração por sua compreensão, carinho, presença e incansável apoio ao longo do período de elaboração desta pesquisa. 



\section{AGRADECIMENTOS}

Ao Prof. Dr. Marcelo Seido Nagano, pela atenção, confiança, ajuda criteriosa e cuidadosa indispensáveis durante o processo de definição e orientação, sou muito grata por todo o aprendizado que me proporcionou.

Aos professores Renato Vairo Belhot e Sérgio Luis da Silva pela contribuição impecável na banca de qualificação.

Ao Prof. Dr. Edmundo Escrivão Filho por sua extrema generosidade, agradeço muito pelas contribuições em minha formação como ser humano e pesquisadora.

Ao Prof. Dr. Francisco José da Costa Alves, meu amigo Chiquinho, por seu incentivo já na iniciação científica, despertando meu interesse pela academia, e por me ensinar a não ser inerte a determinados acontecimentos.

Agradeço ao Sr. Toninho, Odila e Frank, pela gentileza e delicadeza com que sempre me acolheram em inúmeros momentos.

À minha melhor amiga, Aninha, por auxiliar em minhas decisões e argumentar de modo sempre tão sutil e carinhoso.

Às queridas Edna e Verinha sempre confiantes e otimistas ao extremo, passando em todos os momentos uma energia muito positiva, imprescindível no primeiro ano desta pesquisa.

Sou muito grata aos meus grandes amigos de hidroginástica, em especial, Cris, Maurício e Sílvia, por ouvirem os desabafos e proporcionarem momentos de muita alegria.

Às eternas amigas de república e amigos de graduação que mesmo distantes sempre torceram pela conclusão deste trabalho, em especial: Aline, Pri, Chris, Tati, Helga, Marcelo e Muris.

Agradeço a todos os colegas com os quais cursei disciplinas e convivi no laboratório que em muito contribuíram para minha formação. Muito obrigada, em especial, à: Jana, Alessandra (Baby), Mary, Aline, Kris e Eli pelos bons momentos de descontração, acompanhados de muitos chocolates. 
Muito obrigada aos dirigentes das empresas instaladas nos parques que gentilmente atenderam às solicitações, dispostos a colaborarem com a pesquisa. Agradeço em especial ao gerente do ParqTec, Sr. Luis Antonio Pereira, sempre muito atencioso com as inúmeras dúvidas surgidas ao longo deste trabalho.

Ao José Luis, Silvana e Fábio, funcionários do Departamento de Engenharia de Produção a quem recorri inúmeras vezes e sempre se mostraram dispostos e gentis em ajudar.

Agradeço também a CAPES pela concessão da bolsa de mestrado e à Universidade de São Paulo por toda a infra-estrutura que tornou este trabalho possível, e à Fundação de Amparo à Pesquisa do Estado de São Paulo pela concessão do auxílio financeiro.

Enfim, agradeço a todos que acreditaram neste trabalho e que me deram verdadeiras demonstrações de amizade. 
"O valor das coisas não está no tempo que elas duram, mas na intensidade com que acontecem. Por isso, existem momentos inesquecíveis, coisas inexplicáveis e pessoas incomparáveis".

Fernando Pessoa 



\section{RESUMO}

CRUZ, C. A. Gestão estratégica do conhecimento: estudo exploratório em empresas instaladas nos parques tecnológicos do Estado de São Paulo. 2007. 164f. Dissertação (Mestrado) - Escola de Engenharia de São Carlos, Universidade de São Paulo, São Carlos, 2007.

Este trabalho tem como principal objetivo evidenciar e analisar o relacionamento entre os elementos que constituem a gestão estratégica do conhecimento: os fatores inerentes a gestão do conhecimento e as dimensões estratégicas organizacionais que apóiam esta gestão; no contexto das empresas residentes em parques tecnológicos do Estado de São Paulo, apresentando mecanismos que sejam capazes de direcionar ao estabelecimento de posições de vantagem competitiva a situação peculiar destas empresas. Com intuito de atingir o objetivo proposto foi realizada uma ampla revisão bibliográfica que abrangeu muitos estudos sobre o processo de gestão do conhecimento e administração estratégica, buscou-se com isso: identificar os principais fatores do processo de gestão do conhecimento, por meio de atributos que os qualificassem e identificar as dimensões estratégicas que de alguma forma estavam relacionadas a gestão do conhecimento. Com isso, foi possível analisar a relação entre os fatores supracitados no contexto organizacional das empresas instaladas no: Parque Científico e Tecnológico de Campinas - Ciatec e o Parque Tecnológico de São Carlos - ParqTec. A pesquisa é caracterizada como exploratória e descritiva, por realizar descrições categóricas da situação, visando descobrir as relações existentes entre os elementos componentes da mesma, e por explorar um assunto pouco abordado. Para a pesquisa empírica, aplicou-se na coleta de dados um questionário fechado, por meio de correio eletrônico aos dirigentes das empresas, o questionário empregava a escala Likert e visou mensurar a percepção dos dirigentes em relação aos elementos da gestão estratégica do conhecimento. Com base nesses resultados foi possível realizar: a análise descritiva, a análise de correspondência, o teste binomial e o diagrama de correlação que permitiu avaliar a associação entre as variáveis investigadas. De modo geral, observou-se nos resultados que o comportamento dos parques em relação ao processo de gestão do conhecimento difere de forma significativa, demonstrando que aspectos como: a influência do ambiente, diferentes estilos de administração e distintos tamanhos de equipes de trabalho, entre outros, influenciam fortemente no gerenciamento das empresas. No que concernem as estratégias empregadas pelas empresas que subsidiam a gestão do conhecimento, uma maior proximidade de comportamentos foi verificada, indicando que elementos como: a equivalência na área de atuação das empresas e necessidades parecidas de mão-de-obra qualificada, requer estratégias similares. E por fim, a análise do relacionamento entre os fatores que caracterizam a gestão do conhecimento e as dimensões estratégicas expressou que esta relação gestão do conhecimento e dimensões estratégicas estava mais estruturada nas empresas instaladas no Parque Científico e Tecnológico de Campinas, apesar de tratar-se de uma infra-estrutura recente de incorporação de empresas.

Palavras-chave: Gestão estratégica do conhecimento; Gestão do conhecimento; Dimensões estratégicas; Parques tecnológicos. 


\begin{abstract}
CRUZ, C. A. Strategic knowledge management: exploratory study in park technological companies located in the São Paulo's state. 2007. 164p. Master Dissertation. - Escola de Engenharia de São Carlos, Universidade de São Paulo, São Carlos, 2007.
\end{abstract}

The main objective of this work is to evidence and to analyse the relationship between the elements that characterized the strategic knowledge management: the knowledge management factors and strategical dimensions; in the context of companies located in technological parks in São Paulo's state, presenting mechanisms that it may be capable to direct to the establishment of competitive advantage to the peculiar situation of these companies. It was realized an ample bibliographical revision about many studies of knowledge management process and strategical management, searched: to identify the main factors of the knowledge management process, by attributes that characterize them; to identify the strategical dimensions related to the knowledge management. So it was possible to analyze the relation between the above mentioned factors in the organizational context of the companies resident in: Scientific and Technological Park of Campinas - Ciatec and the São Carlos Technological Park - ParqTec. The research is characterized as exploratory - descriptive, for carrying through categorical descriptions of the situation, aiming at to discover the existing relations between the elements, and for exploring a subject little discussed. For the empirical research, a closed questionnaire was applied in the collection of data, by e-mail to the companies managers, the questionnaire used the Likert scale and aimed at to calculated the perception of managers in relation to the strategical knowledge management. With these results, it was possible to realize: the descriptive analysis, correspondence analysis, the binomial test and the correlation diagram that allowed evaluating the association between the investigated variables. In general way, it was observed in the results that the behavior of the parks in relation to the knowledge management process differs from significant form, demonstrating that aspects as: the influence of the environment, different styles of administration and distinct sizes of work teams, etc, influences strongly companies management. In related to the strategies, that subsidize the knowledge management, used for the companies, a stronger proximity of behaviors was verified, indicating that elements as: equivalence in the performance area and similar necessities of qualified manpower requires similar strategies. And finally, the analysis of the relationship between the factors that characterize the knowledge management and strategical dimensions expressed that it was more structuralized in the companies of the Scientific and Technological Park of Campinas, surprising, a time that it deals with a recent infrastructure to the incorporation of companies.

Keywords: Strategic knowledge management; Knowledge management; Strategical dimensions; Technological parks. 


\section{LISTA DE FIGURAS}

Figura 1: Lacuna entre os fatores em comum a gestão do conhecimento e a estratégia.......40

Figura 2: Construção triangular de duplo sentido do conhecimento ...................................48

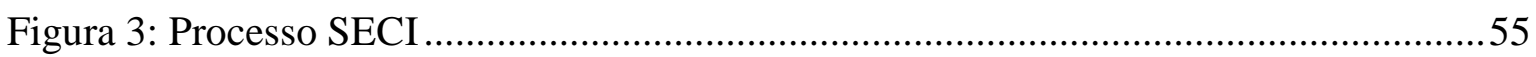

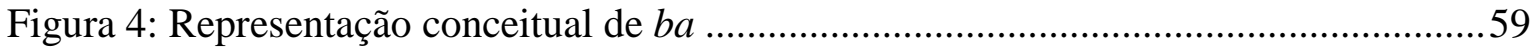

Figura 5: Dimensões da gestão do conhecimento............................................................ 76

Figura 6: Interdependência entre as dimensões estratégicas da gestão do conhecimento ... 80

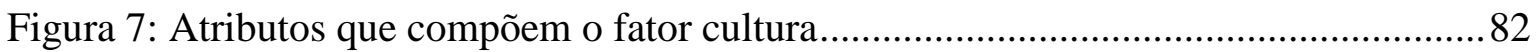

Figura 8: Sub-dimensões que compõem os Sistemas de Informação ................................... 84

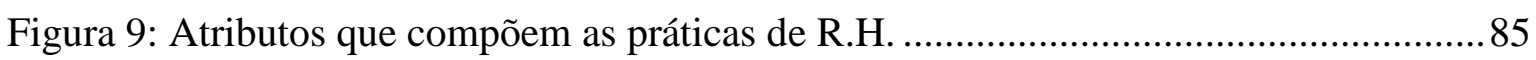

Figura 10: Diagrama de alta correlação entre as variáveis - Ciatec .................................. 114

Figura 11: Diagrama de alta correlação entre as variáveis - Ciatec .................................. 117

Figura 12: Diagrama de alta correlação entre as variáveis - ParqTec................................118

Figura 13: Diagrama de alta correlação entre as variáveis - ParqTec ................................ 119

Figura 14: Diagrama de correlação inversa entre as variáveis - ParqTec ........................... 120

Figura 15: Esquema representativo da gestão estratégica do conhecimento no ParqTec.. 128

Figura 16: Esquema representativo da gestão estratégica do conhecimento no Ciatec..... 130 


\section{LISTA DE GRÁFICOS}

Gráfico 1: A presença das micro e pequenas empresas na economia brasileira 37

Gráfico 2: Estágio das empresas que ingressam no parque 39

Gráfico 3: Análise de correspondência para a Socialização 102

Gráfico 4: Análise de correspondência para a Externalização 103

Gráfico 5: Análise de correspondência para a Combinação 104

Gráfico 6: Análise de correspondência para a Internalização 105

Gráfico 7: Análise de correspondência para a Cultura 105

Gráfico 8: Análise de correspondência para a Práticas de Recursos Humanos 106

Gráfico 9: Análise de correspondência para os Sistemas de Informação 107

Gráfico 10: Análise de correspondência para SECI 108

Gráfico 11: Análise de correspondência para Estratégia 109 
xviii 


\section{LISTA DE QUADROS}

Quadro 1: Especificidades das pequenas e médias empresas 38

Quadro 2: Fatores e atributos do Processo SECI 62

Quadro 3: Quatro estratégias do conhecimento 73

Quadro 4: Relacionamento entre os fatores do processo SECI e as dimensões estratégicas 


\section{LISTA DE TABELAS}

Tabela 1 - Matriz de hipóteses que relacionam o processo de gestão do conhecimento e as dimensões estratégicas

Tabela 2 - Perfil dos Princípios Organizacionais da Era Industrial e da Era do Conhecimento

Tabela 3 - Tipos de estratégias de Gestão do Conhecimento

Tabela 4 - Impacto da estratégia de alavancagem sobre as metas estratégicas

Tabela 5 - Impacto da estratégia de expansão sobre as metas estratégicas

Tabela 6 - Impacto da estratégia de investigação sobre as metas estratégicas

Tabela 7 - Impacto da estratégia de apropriação sobre as metas estratégicas

Tabela 8 - Atributos relacionados aos grupos de questões

Tabela 9 - Comparação: Parque de São Carlos e Campinas

Tabela 10 - Análise das variáveis de alta correlação do Ciatec - Correlação 1

Tabela 11 - Análise das variáveis de alta correlação do Ciatec - Correlação 2

Tabela 12 - Análise das variáveis de alta correlação do Ciatec- Correlação 3

Tabela 13 - Análise das variáveis de alta correlação do Ciatec - Correlação 4

Tabela 14 - Análise das variáveis de alta correlação do Ciatec - Correlação 5

Tabela 15 - Análise das variáveis de alta correlação do ParqTec - Correlação 1

Tabela 16 - Análise das variáveis de alta correlação do ParqTec - Correlação 2

Tabela 17 - Análise das variáveis de correlação inversa do ParqTec

Tabela 18 - Porcentagem de cada questão para o Parque de São Carlos

Tabela 19 - Porcentagem de cada questão para o Parque de Campinas

Tabela 20: Matriz de correlação referente as respostas dadas pelas empresas instaladas no Ciatec

Tabela 21: Matriz de correlação referente as respostas dadas pelas empresas instaladas no ParqTec 
xxii 


\title{
LISTA DE SIGLAS
}

\author{
ANPROTEC Associação Nacional de Entidades Promotoras de Empreendimentos de \\ Tecnologias Avançadas \\ Ciatec Companhia de Desenvolvimento do Pólo de Alta Tecnologia de Campinas \\ Cietec Centro Incubador de Empresas Tecnológicas \\ GC Gestão do Conhecimento \\ GEC Gestão Estratégica do Conhecimento \\ MPE's Micro e Pequenas Empresas \\ Parqtec Parque Tecnológico de São Carlos \\ R.H. Recursos Humanos \\ S.I. Sistemas de Informação \\ SECI Socialização - Externalização - Combinação - Internalização \\ SGC Sistemas de Gestão do Conhecimento \\ T.I. Tecnologia de Informação \\ TPC Tipo de Processo do Conhecimento
}


xxiv 


\section{SUMÁRIO}

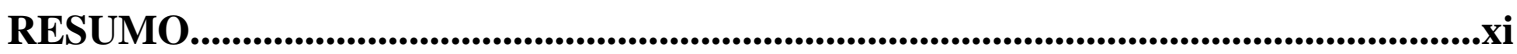

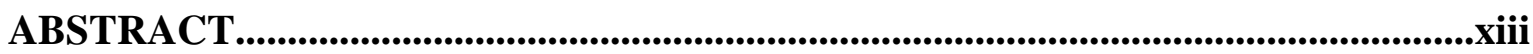

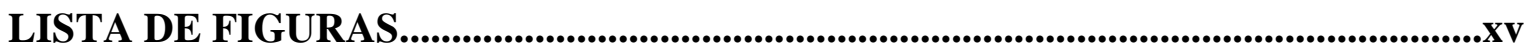

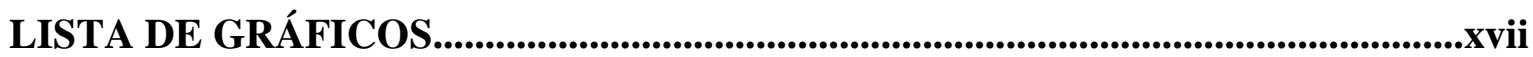

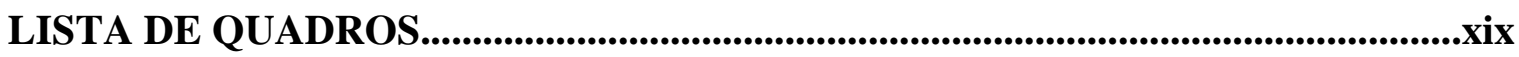

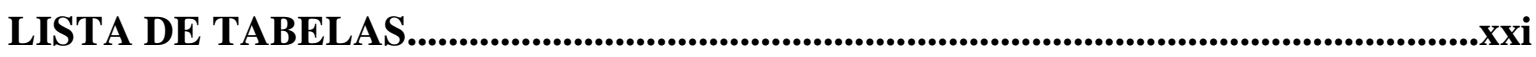

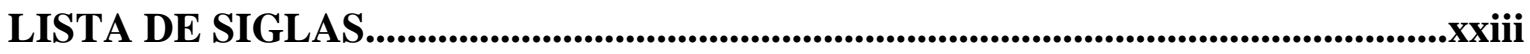

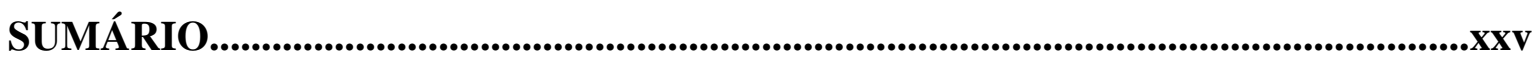

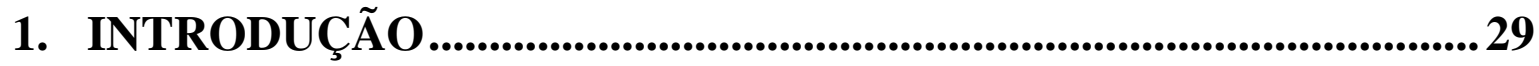

1.1. Problema de PeSQUISA............................................................. 32

1.2. DeclaraçÃo dos ObJetivos de PESQuiSA....................................... 35

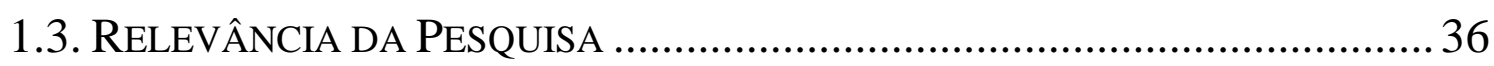

1.4. MÉTOdO DE PESQUISA .............................................................. 40

1.5. ESTRUTURA DO TRABALHO................................................... 42

2. GESTÃO DO CONHECIMENTO...................................................... 45

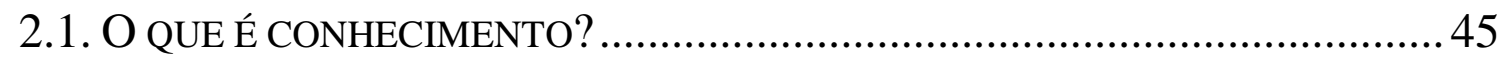

2.2. ANÁLISE SEMÂNTICA ENTRE DADOS, INFORMAÇÕES E CONHECIMENTO. 47

2.3. CRIAÇÃO E GESTÃo do CONHECIMENTO ........................................... 49

2.4. PROCESSO SECI.................................................................... 54

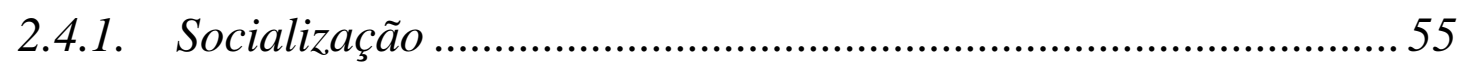




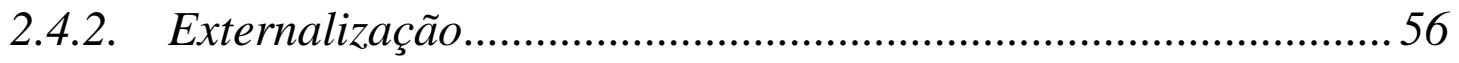

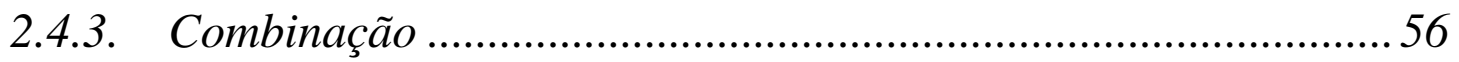

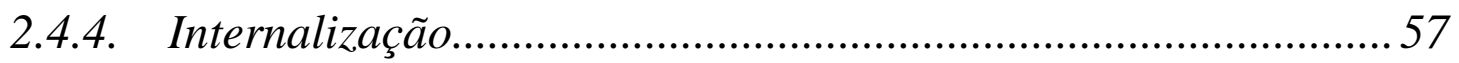

3. GESTÃO ESTRATÉGICA DO CONHECIMENTO ...........................65

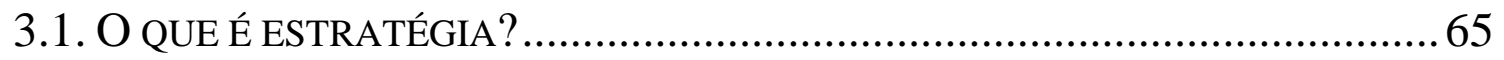

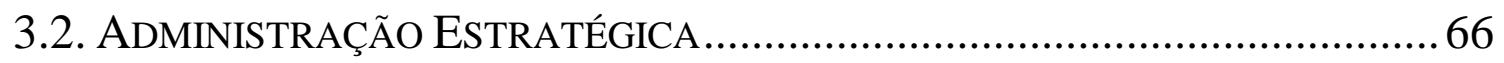

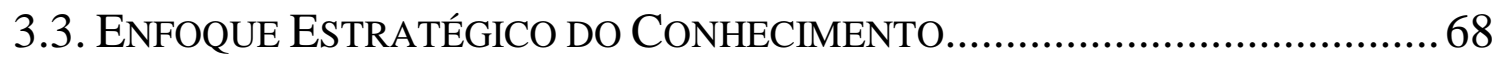

3.3.1. Abordagem de Hansen, Nohria e Tierney.................................. 71

3.3.2. Abordagem de von Krogh, Nonaka e Aben................................ 72

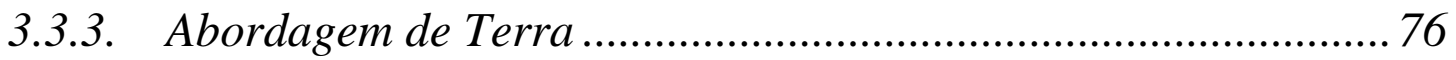

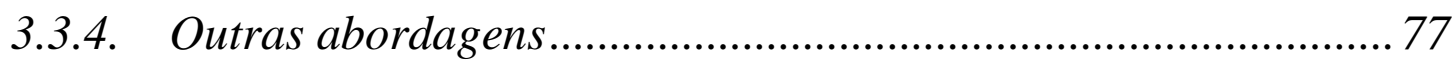

3.3.5. Critérios de classificação das possíveis formas assumidas na GEC $\quad 78$

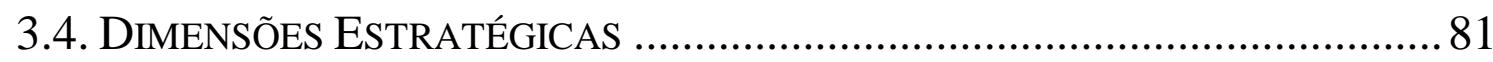

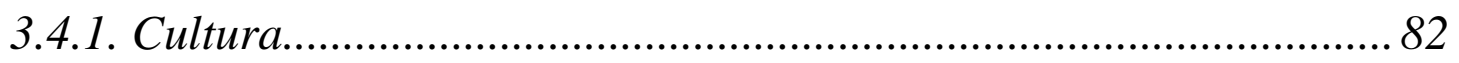

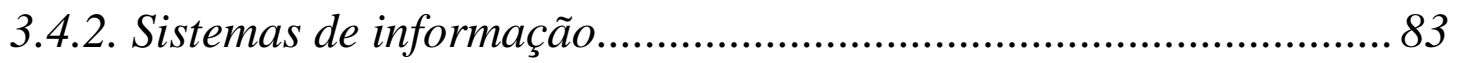

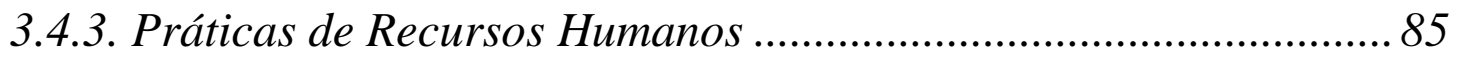

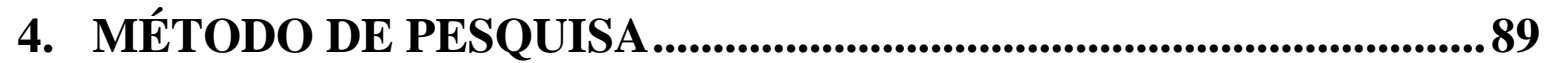

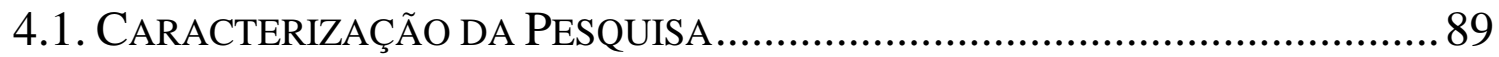

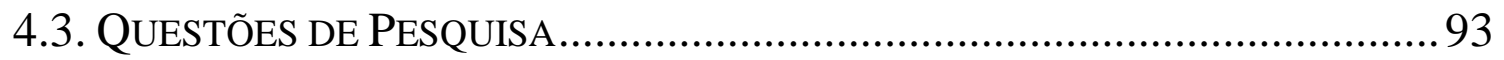

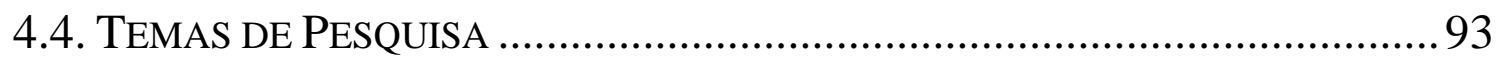




\section{ANÁLISE DA GESTÃo ESTRATÉGICA DO CONHECIMENTO99}

5.1. DESCRIÇÃO DO COMPORTAMENTO DAS VARIÁVEIS 99

5.2. MAPEAMENTO DAS PERCEPÇÕES DOS DIRIGENTES. 101

5.3. COMPARAÇÃO dOS PARQUES TECNOLÓGICOS PERANTE OS ELEMENTOS DA GESTÃO ESTRATÉGICA DO CONHECIMENTO

APÊNDICE A - Carta de apresentação.

APÊNDICE B - Modelo do questionário utilizado no trabalho de campo. 
xxviii 


\section{INTRODUÇÃO}

Notadamente, a administração é consagrada por diversos estudos gerenciais que, embora incorporem aspectos organizacionais distintos, possuem a mesma finalidade, proporcionar lucratividade às organizações.

De acordo com Wren (1994), o pensamento administrativo pode ser caracterizado por três grandes Eras, em que cada uma é caracterizada de acordo com o predomínio das idéias naquele momento: a primeira, a Administração Científica, em que há busca por eficiência e racionalização do trabalho; a segunda Era, por sua vez, denominada Era Social ou Humana marca o segundo período em que predomina o movimento das relações humanas, em que noções de liderança e os grupos informais foram introduzidos; e, o terceiro grande momento, a Era Moderna em que a relação com o ambiente é introduzida na tomada de decisões.

Há ainda, acrescentado por alguns autores como Morgan (1996), o movimento da contingência o qual caracteriza o período subseqüente. Este movimento surgiu mediante um estudo de empresas que diferiam quanto ao ramo industrial. Foi constatado que em circunstâncias diferentes, há necessidade de adotar enfoques administrativos diferentes, ora mecanicista (com a racionalização do trabalho), ora orgânico (com a incorporação de perspectivas humanísticas). Em síntese, a contingência é marcada pela adaptação constante ao ambiente, mediante a introdução de práticas diferentes para casos distintos.

Neste âmbito, as teorias contemporâneas constituídas por perspectivas interorganizacionais e intraorganizacionais surgem como uma alternativa em termos de como a produção de bens e 
serviços está sendo projetada e implementada. O aumento na taxa de criação e mortalidade de empresas, ao mesmo tempo em que a inovação, as competências e estruturação organizacional tornaram-se necessárias à sobrevivência das empresas caracterizam este novo período (TERRA, 2001). Observa-se assim uma transição na qual o poder de gerar toda a riqueza e o poder da sociedade atual deixa de provir, exclusivamente, dos fatores tradicionais de produção, tais como: capital, terra e trabalho, advindo também de bens intangíveis como o conhecimento organizacional (LEONARD-BARTON, 1998; SANTIAGO Jr., 2002).

Neste contexto, muitas empresas deparam com o desafio de competir num mundo em que conhecimento e não apenas os recursos naturais e mão-de-obra abundante e barata constituem vantagem competitiva (EDWARDS et al., 2003). Nonaka (1991) corrobora quando menciona que se vive numa época em que a única certeza é a incerteza e a única fonte de vantagem competitiva duradoura é o conhecimento. Desse modo, buscando vantagens competitivas, surgem teorias e abordagens visando gerenciar o conhecimento estrategicamente.

A gestão estratégica do conhecimento (GEC) deve ser entendida neste trabalho, como um processo constituído pelo processo de gestão do conhecimento (GC) somado às dimensões estratégicas organizacionais, ou melhor, funções organizacionais que viabilizem a gestão do conhecimento nas empresas. Segundo Nonaka, Peltokorpi e Tomae (2005), a gestão estratégica pode ser vista como um processo mecanicista ou orgânico que corresponde, respectivamente, a escola do posicionamento que produz serviços e produtos baseado na análise de mercado, portanto ambiente externo (PORTER, 2003); e, a visão baseada em recursos (VBR) que prioriza o acúmulo de recursos internos (WERNERFELT, 1984). Dessa forma, gestão estratégica do conhecimento analisa que tanto os fatores exógenos (externos) quanto endógenos (internos) devem ser considerados na fase de formulação estratégica das empresas. 
A gestão do conhecimento, especificamente, visa conquistar acertos organizacionais por meio de estratégia dirigida pela motivação e facilitação do conhecimento dos trabalhadores. Essa estratégia visa criar, disseminar, armazenar e incorporar às rotinas de trabalho todo o conhecimento desenvolvido na organização, utilizando a capacidade dos trabalhadores para interpretação de dados e informações (por recursos disponíveis de informação, experiências, habilidades, cultura, características, personalidade, sentimentos entre outros) mediante um processo fornecedor de significado à estes dados e informações (uit BEIJERSE, 1999). Gerenciar o conhecimento é analisado por Nonaka (1991), como um ciclo de criação contínuo do conhecimento, por isso o autor introduziu o termo criação do conhecimento organizacional, destacando que as companhias bem sucedidas são aquelas que criam novos conhecimentos, disseminam-nos amplamente por toda organização e, rapidamente os incorporam em novos produtos, serviços e tecnologias. A teoria de criação do conhecimento é caracterizada como um processo que envolve interações entre os vários níveis organizacionais, a partir da transformação do conhecimento tácito (pessoal e informal) em conhecimento explícito (formal e sistemático), processo este denominado SECI Socialização, Externalização, Combinação e Internalização.

O processo de gestão de conhecimento, SECI, compõe assim os fatores exógenos e endógenos das empresas, por considerar não apenas o processo interno de gestão do conhecimento, mediante o desenvolvimento de práticas que promovam um ciclo contínuo de ampliação do conhecimento, mas também os processos inerentes à organização como os mecanismos de transferência externa, a partir de fornecedores, clientes e parceiros.

Somando-se a isso, as dimensões estratégicas configuram os fatores endógenos que subsidiam este processo, e as que se destacam neste trabalho são: uma cultura organizacional que permeie a confiança para o compartilhamento do conhecimento individual; sistemas de informação, como provedores de suporte técnico e funcionalidade que oferecem ao processo 
de gestão do conhecimento; e as práticas de recursos humanos vislumbrando um alto comprometimento da empresa com os membros organizacionais, visando atrair, reter, motivar e encorajar os membros da organização.

Neste contexto, o presente estudo enfoca a caracterização do processo de gestão do conhecimento e seu relacionamento com as dimensões estratégicas, configurando a gestão estratégica do conhecimento (GEC), denotada no problema de pesquisa.

\subsection{Problema de Pesquisa}

Após a concepção universalista e hegemônica de fábricas tayloristas-fordistas de produção em massa, altamente verticalizadas, observa-se a emergência de um complexo sistema de novos conceitos para a organização de negócios (FLEURY e FLEURY, 2003). E a dificuldade em explicitar as razões pela qual uma empresa estabelece resultados superiores aos de outra indica um sinal de intangibilidade dos recursos que conferem vantagem competitiva a ela. Esses podem resultar de processos por meio dos quais uma empresa cria ou adquire conhecimento sobre suas ações (FLEURY e OLIVEIRA Jr., 2001).

Neste âmbito, o avanço científico-tecnológico impôs novos padrões de desenvolvimento econômico. A flexibilização e a automação do processo produtivo provocaram alterações significativas nas denominadas economias de escala. A necessidade de mudanças organizacionais, em virtude da concorrência acirrada ou diferentes estágios do ambiente empresarial, remete à reflexão de que uma gestão estratégica do conhecimento pode ser uma alternativa na busca por vantagem competitiva.

Uma consequiência desses novos padrões de desenvolvimento é a criação dos parques tecnológicos ambientes que visam promover o desenvolvimento econômico e a inovação a partir da retenção de empregos de alto valor agregado, comercialização de novas tecnologias e promover relações entre a indústria, o governo e a academia. Desse modo, a análise sobre 
gestão estratégica do conhecimento neste trabalho é realizada em empresas instaladas em parques tecnológicos, afinal elas são uma das formas eficazes para promover o desenvolvimento tecnológico, além de estar apoiada na parceria pesquisa-empresa-governo. Não obstante se bem conduzida pode garantir a qualidade de vida da maioria da população e não apenas de uma elite privilegiada (MEDEIROS et al., 1992).

A fim de melhor conduzir esta parceria encontrada nos parques tecnológicos, a gestão estratégica do conhecimento assume um papel importante. Pois, o conhecimento organizacional, assim como os ativos intangíveis, não pode ser negociado ou facilmente replicado por competidores, à medida que estão enraizados na história e na cultura organizacional. Estes ativos são acumulados lentamente ao longo do tempo. Quanto mais específico à empresa for o ativo intangível, mais durável ele será e mais difícil será para os competidores imitá-los. Esta característica confere ao conhecimento o caráter de ativo estratégico (FLEURY e OLIVEIRA Jr., 2001).

Fleury e Oliveira Jr. (2001) acrescentam que a gestão estratégica do conhecimento, a qual tem por tarefa identificar, desenvolver, disseminar e atualizar o conhecimento estrategicamente relevante para a empresa, seja por meio de processos externos ou internos às empresas, deve servir como linha-mestra norteadora das ações estratégicas das empresas que pretendem permanecer competitivas.

Assim, a gestão estratégica do conhecimento apresenta uma importante contribuição para a compreensão de como recursos intangíveis podem constituir a base de uma estratégia competitiva, bem como para a identificação dos ativos estratégicos que irão assegurar resultados superiores para a empresa no futuro (DAVENPORT e PRUSAK, 2003; McCANN III e BUCKNER, 2004).

Com base na identificação dos elementos necessários ao estudo da gestão estratégica do conhecimento, denotados no presente trabalho como: fatores SECI e dimensões estratégicas; e 
nos atributos que os caracterizam, como pode ser observado nos próximos capítulos, foi construída a Tabela 1 que explicita a origem das hipóteses de pesquisa.

Tabela 1 - Matriz de hipóteses que relacionam o processo de gestão do conhecimento e as dimensões estratégicas

\begin{tabular}{|l|l|l|l|}
\hline & Cultura & Práticas de R.H. & Sistemas de informação \\
\hline Socialização & & & \\
Externalização & Hipótese 1 & Hipótese 2 & Hipótese 3 \\
Combinação & & & \\
Internalização & & & \\
\hline
\end{tabular}

A hipótese 1 pressupõe que uma cultura organizacional comprometida com o crescimento profissional e pessoal do funcionário promove um aumento na confiança dos funcionários para o compartilhamento do conhecimento por meio de interações individuais e coletivas, tanto face-a-face, quanto virtual.

Esta hipótese tem por objetivo analisar se a cultura, uma das dimensões estratégicas, está diretamente relacionada com a eficácia das interações individuais, coletivas e face-a-face, virtuais, características do SECI, indispensáveis ao processo de gestão do conhecimento. Nesta hipótese, a proposição é de que quanto mais a cultura organizacional for comprometida com o crescimento e desenvolvimento de seus membros, maior será o número de interações do processo SECI.

A hipótese 2 parte do pressuposto que as práticas de reconhecimento, recompensas e de desenvolvimento das habilidades dos membros da empresa por meio de treinamentos promove uma maior socialização, anseio por inovação, aumento da utilização das redes de comunicação e do know how técnico.

Esta segunda hipótese objetiva, portanto, evidenciar se as práticas de recursos humanos subsidiam o processo de conversão do conhecimento, SECI, principalmente no que concerne 
aos incentivos técnicos (treinamento e recompensa) ao compartilhamento do conhecimento, verificando se uma relação direta é estabelecida pelo grupo de variáveis.

E, por fim, a hipótese 3 propõe que uma infra-estrutura adequada em sistemas de informação com sistemas integrados promove a confiança entre os membros organizacionais para interações virtuais, acesso a banco de dados e armazenamento de informações e conhecimento.

Almeja-se nesta última hipótese identificar se sistemas de informação apropriados implicam necessariamente no aumento da criação, compartilhamento, armazenamento e incorporação do conhecimento organizacional.

Diante deste contexto, é formulado o seguinte problema de pesquisa:

Como os fatores do processo de gestão do conhecimento estão relacionados com as dimensões estratégicas em empresas residentes a parques tecnológicos, considerando suas especificidades de gestão?

\subsection{Declaração dos Objetivos de Pesquisa}

O principal objetivo desta pesquisa é evidenciar e analisar o relacionamento entre os fatores relativos a gestão do conhecimento e as dimensões estratégicas em empresas residentes em parques tecnológicos, apresentando mecanismos que sejam capazes de direcionar ao estabelecimento de posições de vantagem competitiva destas empresas.

Desdobrando em objetivos secundários, têm-se:

i) identificar os principais fatores do processo de gestão do conhecimento, por meio de atributos que os qualifiquem;

ii) identificar as dimensões estratégicas que de alguma forma estejam relacionadas com a gestão do conhecimento; 
iii) analisar a relação entre os fatores supracitados no contexto organizacional das empresas residentes em parques tecnológicos, considerando suas particularidades mediante inferências quantitativas e qualitativas.

\subsection{Relevância da Pesquisa}

As empresas residentes em parques tecnológicos, em sua maioria, possuem aspectos pertinentes ao universo das micro e pequenas (MPE's). Entende-se na presente pesquisa como microempresa aquela que possui um quadro com até 19 funcionários e como pequena empresa o correspondente de 20 a 99 funcionários (SEBRAE, 2004). Tendo em vista a extrema heterogeneidade das pequenas empresas e a dificuldade de estabelecer um critério comum para a análise destas, JULIEN (2001), a classificação quantitativa por número de funcionários foi a escolhida.

As empresas de pequeno porte, no Brasil e no mundo, representam um papel importante na economia, uma vez que apresentam grande participação na distribuição de renda, na absorção de grande parte da mão-de-obra, na geração de novos postos de trabalho (PREVIDELLI e MEURER, 2005).

No contexto sócio-econômico brasileiro, as MPE's são extremamente relevantes, pois são identificadas como fator de promoção social, devido a sua capacidade de gerar empregos e incorporar tecnologia (TERENCE, 2002).

Segundo o IBGE (2005), no Brasil existem 4,6 milhões de empresas, desse total, 99\% são micros e pequenas empresas. Os pequenos negócios (formais e informais) respondem por mais de dois terços das ocupações do setor privado, conforme mostra o Gráfico 1, entretanto as MPE’s são responsáveis por apenas $20 \%$ do PIB. 


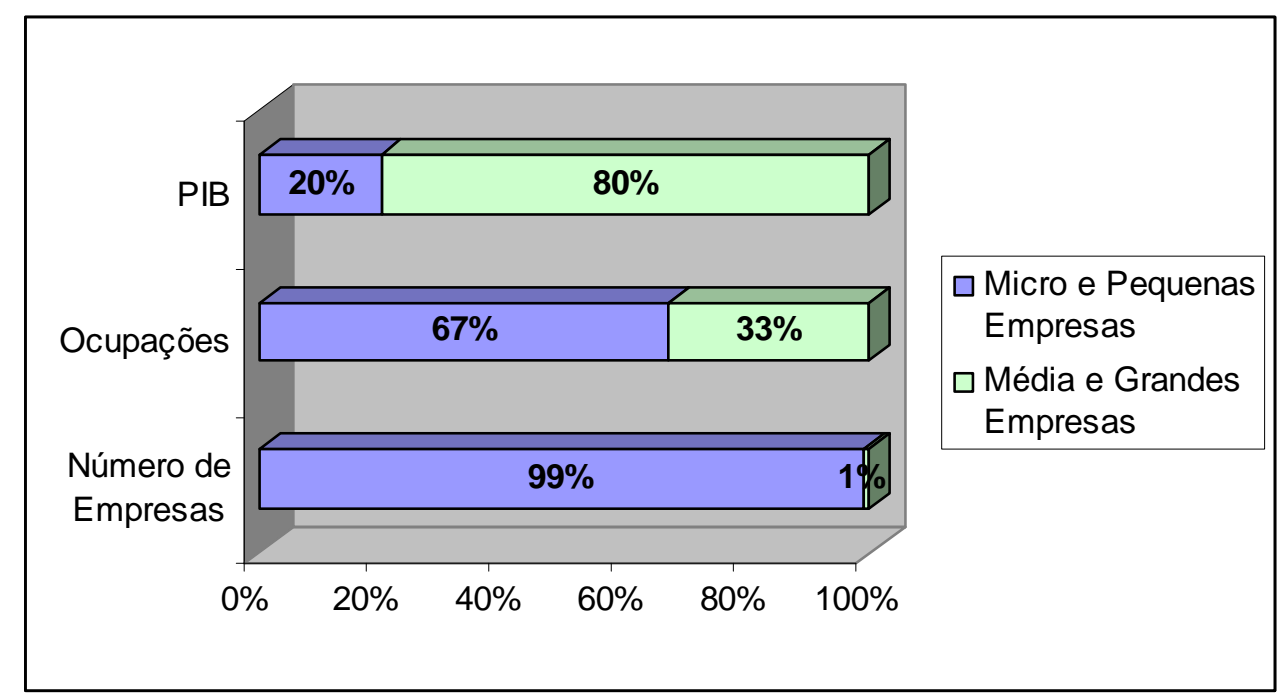

Gráfico 1: A presença das micro e pequenas empresas na economia brasileira Fonte: Adaptado de IBGE (2005)

Apesar das micro e pequenas empresas desempenharem um papel relevante para o desenvolvimento econômico e social do Brasil, há fatores que limitam o crescimento destas, no que concerne ao seu porte e a sua expansão, em termos de unidades empresariais, ressaltando que tais fatores variam de região para região, em virtude do desenvolvimento social, político, econômico e cultural (SILVA et al., 2005).

De acordo com Leone (1999), as pequenas empresas possuem problemas distintos aos das grandes empresas, merecendo desse modo uma teoria específica ao seu contexto. Assim, a autora propõe um agrupamento das especificidades que caracterizam estas empresas, em três grupos, apresentados no Quadro 1: organizacionais, decisionais e individuais. 


\begin{tabular}{|c|c|c|}
\hline $\begin{array}{l}\text { ESPECIFICIDADES } \\
\text { ORGANIZACIONAIS }\end{array}$ & $\begin{array}{l}\text { ESPECIFICIDADES } \\
\text { DECISIONAIS }\end{array}$ & $\begin{array}{l}\text { ESPECIFICIDADES } \\
\text { INDIVIDUAIS }\end{array}$ \\
\hline $\begin{array}{l}\text { - Escassez de recursos; } \\
\text { - Gestão centralizadora; } \\
\text { - Situação extra-organizacional } \\
\text { incontrolável; } \\
\text { - Fraca maturidade organizacional; } \\
\text { - Fraqueza das partes no mercado; } \\
\text { - Estrutura simples e leve; } \\
\text { - Ausência de um planejamento } \\
\text { formal de trabalho; } \\
\text { - Fraca especialização; } \\
\text { - Estratégia intuitiva e pouco } \\
\text { formalizada; } \\
\text { - Sistema de informações simples. }\end{array}$ & $\begin{array}{l}\text { - Tomada de decisão intuitiva; } \\
\text { - Horizonte temporal curto prazo; } \\
\text { - Inexistência de dados } \\
\text { quantitativos; } \\
\text { - Alto grau de autonomia decisória; } \\
\text { - Racionalidade econômica, política } \\
\text { e familiar. }\end{array}$ & $\begin{array}{l}\text { - Onipotência do proprietário- } \\
\text { dirigente; } \\
\text { - Identidade entre pessoa física e } \\
\text { jurídica; } \\
\text { - Dependência perante certos } \\
\text { funcionários; } \\
\text { - Influência pessoal do } \\
\text { proprietário-dirigente; } \\
\text { - Simbiose entre patrimônio social } \\
\text { e pessoal; } \\
\text { - Propriedade dos capitais; } \\
\text { - Propensão a riscos calculados. }\end{array}$ \\
\hline
\end{tabular}

Quadro 1: Especificidades das pequenas e médias empresas

Fonte: Adaptado de Leone (1999:94)

Mediante estas especificidades pode-se inferir que muitas dessas fazem parte do contexto das pequenas empresas, de maneira quase inconsciente, são princípios de excelência (LEONE, 1999).

Contudo, possivelmente, algumas destas especificidades das pequenas empresas devem ser compatíveis com aquelas encontradas nos parques tecnológicos, enquanto outras não são a verdade para o universo destas micro e pequenas empresas. Tendo em vista, o ambiente de alta tecnologia e de integração com o conhecimento acadêmico em que estas estão inseridas. Segundo Medeiros et al. (1992), parques tecnológicos são constituídos por empresas reunidas num mesmo local, dentro do campus da universidade, ao lado deste ou em uma área próxima. Conceitua que instaladas nestes parques estão as empresas de base tecnológica caracterizadas por incorporar o conhecimento científico-tecnológico como seu principal insumo de produção e por relacionarem-se intensivamente entre si e com a universidade ou instituto de pesquisa.

De acordo com Dalton (apud PERUSSI FILHO, 2001) um Science Park ou Parque Tecnológico é uma iniciativa que:

1) têm ligações formais com a universidade ou outras instituições de nível superior;

2) é projetado para estimular a formação e crescimento de empresas locais e baseadas no conhecimento; 
3) possui uma função gerencial que está ativamente envolvida na transferência de tecnologia e habilidades de negócio para as organizações locais.

Os parques tecnológicos têm como objetivo a criação de um ambiente propício à inovação, via integração num único ambiente de universidades, empresas tradicionais e de base tecnológica e agentes de fomento (TORKOMIAN, 1992).

Geralmente, as empresas instaladas em um parque tecnológico já são empresas sólidas, conforme demonstra o Gráfico 2, apesar do gráfico trabalhar com a porcentagem acumulada, em que uma empresa num determinado período pode ser existente e também ter provindo de uma incubadora, note que não há necessidade de ter passado por esta, embora a maioria das empresas instaladas nos Parques tenham nascidos em incubadoras (75\%).

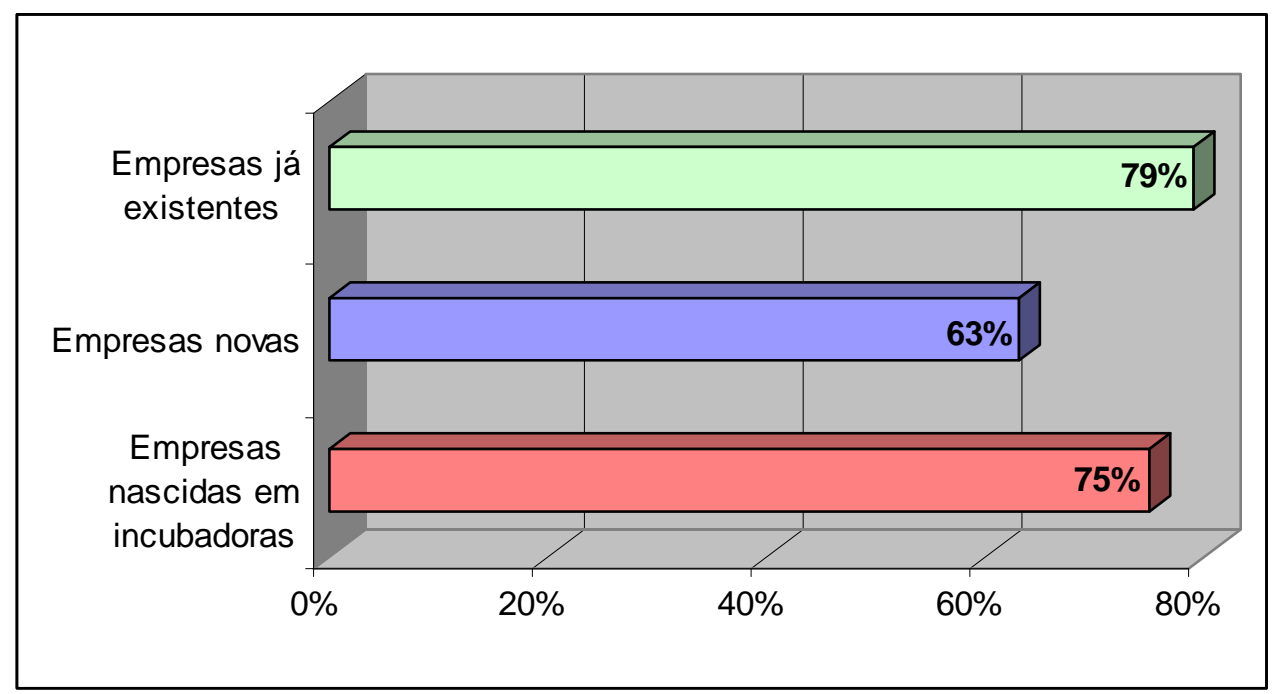

Gráfico 2: Estágio das empresas que ingressam no parque Fonte: Adaptado de ANPROTEC (2005)

De acordo com o Gráfico 2, as empresas já existentes e as nascidas em incubadoras possuem uma maior representatividade no universo dos parques tecnológicos, $79 \%$ e $75 \%$ respectivamente, o que favorece o estudo do processo de gestão do conhecimento, uma vez que estas empresas, provavelmente, estão mais consolidadas em termos de estruturação do seu processo de gestão em relação às nascentes. 
Neste contexto, é possível observar que os parques tecnológicos, objeto de estudo deste trabalho, são considerados ambientes adequados para investigação do processo de gestão do conhecimento, por contribuir com o desenvolvimento e capacitação das empresas residentes.

Outro aspecto relevante desta pesquisa está na busca de elementos que viabilizem o entendimento das relações entre os fatores do processo de gestão do conhecimento e dimensões estratégicas organizacionais, conforme demonstra Figura 1.
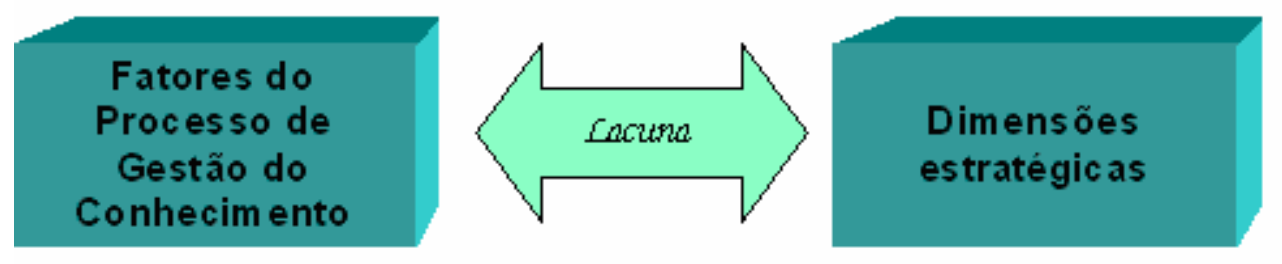

Figura 1: Lacuna entre os fatores em comum a gestão do conhecimento e a estratégia

Em geral, na literatura especializada, os fatores do processo de gestão do conhecimento são analisados independentemente das dimensões estratégicas que os subsidiam, por isso a importância desta pesquisa em entender de forma agregada os mecanismos que preenchem a lacuna entre estes elementos.

A relevância desta pesquisa é dada também, pelo fato de poder contribuir com a Lei de Inovação Tecnológica (Lei Federal n. $\left.{ }^{\circ} 10.973 / 2004\right)$ que tem como objetivo criar um ambiente propício ao aumento do envolvimento das empresas no desenvolvimento de projetos inovadores que levem à geração de novos produtos e processos. Esta lei busca uma elevação do nível de parcerias entre empresas, universidades e institutos científicos e tecnológicos para que ganhem força e estimulem o processo de inovação (MATIAS-PEREIRA e KRUGLIANKAS, 2005).

\subsection{Método de Pesquisa}

A análise do relacionamento entre os fatores relativos a gestão do conhecimento e as dimensões estratégicas em empresas residentes em parques tecnológicos é um tema pouco 
explorado na literatura, o que caracteriza uma pesquisa exploratória e descritiva, pois realiza descrições categóricas da situação, visando descobrir as relações existentes entre os elementos componentes da mesma, e explora um assunto pouco abordado, medindo as características descritas nas questões de pesquisa (CERVO E BERVIAN, 1983; DANE, 1990; GIL, 2002; HAIR JR et al., 2005; LAKATOS e MARCONI, 1992).

Inicialmente, foi realizada uma análise, junto as empresas instaladas em dois parques tecnológicos pertencentes ao Estado de São Paulo: o Parque Científico e Tecnológico de Campinas - Ciatec (Cia. de Desenvolvimento do Pólo de Alta Tecnologia de Campinas), localizado na cidade de Campinas; e o Parque Tecnológico de São Carlos - ParqTec, localizado na cidade de São Carlos.

A escolha de uma amostra de pesquisa constituída por empresas residentes em Parques Tecnológicos remete a magnitude de conhecimento incorporado nestes, tratam-se de empresas que estão constantemente inovando, formada em sua maioria por pessoas altamente especializadas em sua área de atuação, ademais há transferência continua de conhecimento universidades-empresas devido ao contexto que estão inseridas. Não obstante, sabe-se que diferenças estruturais, pessoal e gestão, entre outras são comuns entre as empresas, e a abordagem quantitativa desta pesquisa permitirá visualizar a existência ou não de diferenças significativas em termos de gestão do conhecimento entre os grupos de empresas pesquisadas: ParqTec e Ciatec.

Para a coleta de dados, a técnica adotada foi o envio de um questionário fechado, por meio de correio eletrônico aos dirigentes das empresas. O questionário emprega a escala Likert, contida no intervalo de 1 a 7 , em que 1 corresponde a alternativa discordo totalmente e 7 a concordo plenamente, visando mensurar a percepção dos dirigentes em relação aos elementos da gestão estratégica do conhecimento. 
Com base nos resultados obtidos foram realizadas as análises: análise descritiva, análise de correspondência, o teste binomial e os diagramas de correlações que permitiram avaliar a associação entre os elementos investigados (HAIR JR et al., 2005b).

\subsection{Estrutura do Trabalho}

Este trabalho está estruturado em seis capítulos, no capítulo 1, foi realizada a contextualização geral e específica deste trabalho, caracterizando o tema de pesquisa, a formulação do problema, bem como a declaração dos objetivos e a relevância do estudo.

No capítulo 2, definições e conceitos de conhecimento, é apresentado os principais conceitos do recurso intangível "conhecimento", denotando as principais diferenças entre conhecimento, dados e informações; mostra também os tipos de conhecimento identificados pela literatura, enfatizando a questão filosófica do tema. Ademais, é apresentado o processo de gestão do conhecimento, bem como os elementos integrantes deste processo com ênfase no: modelo SECI, $b a$ e os recursos do conhecimento.

O capítulo 3 mostra os principais aspectos que permeiam a gestão estratégica do conhecimento, imprescindível à continuidade da pesquisa, uma vez que neste capítulo são identificadas as principais dimensões estratégicas a partir da literatura, as quais serão posteriormente correlacionadas com os elementos da gestão do conhecimento.

O capítulo 4, Método de Pesquisa, apresenta o método de pesquisa, questões, variáveis, técnicas de coleta e de análise dos dados.

O capítulo 5, Análise dos Dados, apresenta os resultados investigados mediante a aplicação de questionários estruturados nas empresas residentes nos parques tecnológicos, por meio de análise quantitativa, em que é demonstrado o grau de relacionamento entre os fatores estratégicos e aqueles relativos a gestão do conhecimento. 
Por fim, o capítulo 6 apresenta as considerações finais sobre a gestão do conhecimento nas empresas estudadas e as características que influenciam sua gestão estratégica. Neste capítulo, são discorridos as limitações do trabalho e os resultados de pesquisa, bem como algumas sugestões para futuras pesquisas.

Os capítulos supracitados compõem três fases principais deste trabalho:

i) Fase 1: fundamentação teórica necessária à apresentação dos conceitos, para posterior identificação das variáveis de pesquisa, e esta fase abrange desde o capítulo 1 até 3.

ii) Fase 2: escolha do método de pesquisa para coleta de dados e análise dos resultados, capítulo 4 .

iii) Fase 3: tratamento dos dados, perante o método determinado na fase anterior, analisando os resultados obtidos, capítulo 5.

iv) Fase 4: finalização, apresentando os principais resultados obtidos na pesquisa e as limitações da pesquisa, capítulo 6 . 


\section{GESTÃO DO CONHECIMENTO}

Este capítulo apresenta os principais conceitos que norteiam a chamada era do conhecimento. A princípio é exposta a base teórica que sustenta a temática em questão e os elementos que diferem o recurso conhecimento dos conceitos relativos a dados e informações.

Ademais, é apresentada uma configuração do processo de gestão do conhecimento, bem como os principais elementos integrantes deste, com ênfase no: modelo SECI.

\subsection{O que é conhecimento?}

Desde o período clássico grego, a história da filosofia pode ser vista como o processo de busca a definição da palavra conhecimento. O conceito de conhecimento não é algo consensual.

Conforme ressalta Nonaka (1994), o conhecimento pode ser definido como "uma crença justificadamente verdadeira”. Ou ainda como denota Liebeskind (1996), conhecimento é uma informação cuja validade é estabelecida por meio de testes de veracidade.

Segundo Davenport e Prusak (2003, p.6):

[...] o conhecimento envolve aspectos mais amplos e profundos, conhecimento é uma mistura fluída de experiência condensada, valores, informação contextual e insight experimentado, a qual proporciona uma estrutura para avaliação e incorporação de novas experiências e informações. Ele tem origem e é aplicado na mente dos conhecedores. Nas organizações, ele costuma estar incorporado não só em documentos [...], mas também em rotinas, processos, práticas e normas organizacionais. 
De acordo com Hitt, Ireland e Hoskisson (2002), o conhecimento pode ser visto como informações repletas de experiência, julgamento, insights e valores. Lacombe e Heilborn (2003) corroboram com os autores quando mencionam que o conhecimento também pode ser definido como conteúdo de valor agregado do pensamento humano, derivado da percepção e manipulação inteligente das informações.

Plato (apud MÜLLER- MERBACH, 2004) faz uso de uma analogia com o discurso direto para definir o conhecimento, o discurso direto é entendido como um diálogo dinâmico em que os participantes interpelam uns aos outros, reagem aos argumentos dos parceiros, respondem as questões, tentam convencer os demais, tudo baseado na percepção, convicção, compromissos, talvez até mesmo paixão. Assim, o conhecimento é entendido, como parte da consciência humana.

Embora não consensual, nota-se que as inúmeras definições, em geral, norteiam aspectos similares. Assim, o presente trabalho adota como conceitualização básica do termo conhecimento aquela assumida por Davenport e Prusak, em virtude do seu caráter mais amplo.

Na literatura são apresentadas algumas tipologias que caracterizam o termo conhecimento tais como: implícito, explícito, sistemático, informal, codificável e não codificável, entre outros. A mais comumente utilizada na literatura em geral é a proposta por Polanyi (apud Nonaka e Takeuchi, 1997), em que o autor identifica dois tipos de conhecimento: o conhecimento tácito e o conhecimento explícito.

O conhecimento tácito é altamente pessoal e difícil de formalizar, o que dificulta sua transmissão e compartilhamento. Palpites subjetivos, insights, intuições, valores e emoções fazem parte desta categoria (NONAKA, 1991).

Por outro lado, o conhecimento explícito pode ser expresso em palavras e números, sendo facilmente comunicado e compartilhado sob a forma de dados brutos, fórmulas científicas, 
princípios universais, especificações e manuais. O conhecimento explícito pode ser facilmente transmitido, formalmente e sistematicamente entre indivíduos (NONAKA e KONNO, 1998).

\subsection{Análise Semântica entre dados, informações e conhecimento}

Observa-se que a literatura, muitas vezes, comete erros no que concerne aos conceitos: dados, informações e conhecimento, principalmente no período anterior a década de 90.

A fim de esclarecê-los realizar-se-á nesta seção uma síntese das principais diferenças que norteiam tais definições, antes de apresentar a principal sustentação teórica do presente trabalho focada na gestão do conhecimento organizacional e na gestão estratégica do conhecimento.

Os dados são objetivos factuais. Se classificados, analisados, sumariados e inseridos em um determinado contexto, transformam-se em informações as quais manipuladas de maneira inteligente, por meio de experiências, percepções e valores resultam em conhecimento (CARDOSO, 2003; HITT; IRELAND; HOSKINSSON, 2002; LACOMBE e HEILBORN, 2003). No que concerne a formação do conhecimento, Rodriguez y Rodriguez (2001) afirma que o início deste processo ocorre por meio de eventos que, por sua vez, geram fatos e dados. Estes quando devidamente tratados, manipulados e interpretados, geram informações, que quando testadas, validadas e codificadas transformam-se em conhecimento.

Davenport e Prusak (2003) salientam que todas as organizações independentemente de sua dimensão ou setor de atividade, geram dados nas suas mais diversas formas, mas incorrem no erro de meramente os acumular, dificultando deste modo, a identificação e a atribuição de sentido aos dados que são efetivamente importantes e instrumentais para a geração da informação.

De acordo com Schulz (2001), as noções de conhecimento e de informação têm uma longa tradição nas pesquisas organizacionais, anterior aos estudos de Weber. Contudo, a informação 
tornou-se mais proeminente em meados do século 20, enquanto, mais recentemente com o advento da tecnologia de informação, o processamento de informação está sendo ampliado para a produção e processamento de conhecimento.

Cardoso (2003) propõe uma construção triangular de duplo sentido ao analisar a relação dados-informação-conhecimento, conforme Figura 2.

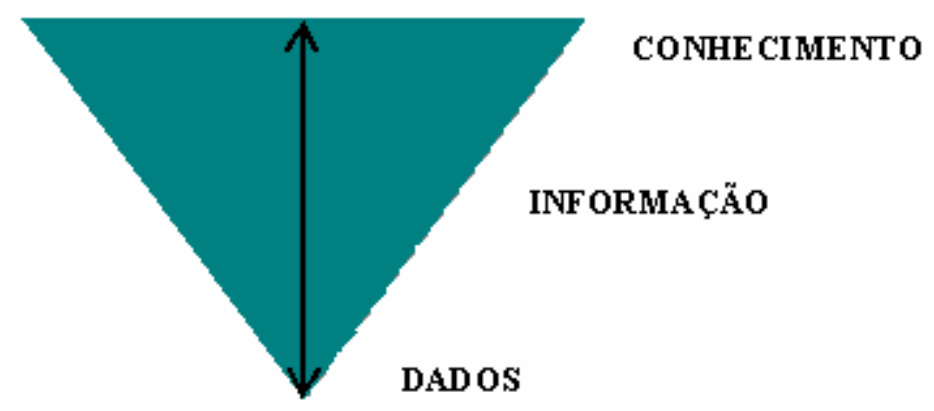

Figura 2: Construção triangular de duplo sentido do conhecimento Fonte: Adaptado de Cardoso (2003:55)

A Figura 2 demonstra a interdepêndencia e a necessidade de alternância entre o conhecimento, informação e dados, observa-se que a base de sustentação do conhecimento são os dados os quais agregados e sistematizados levam a criação da informação e posterior criação do conhecimento, contudo o sentido da triangulação é invertido perante a possível perda de conhecimento, pois o que poderia ser conhecimento passa a ser apenas uma informação que sem ser trabalhada tornar-se apenas mais um dado factual. A inversão da triangulação apresentada nesta figura poderia ser pensada, caso a análise entre dadosinformação-conhecimento fosse realizada em termos de quantidade, dessa forma seria denotado que é necessário muitos dados para a geração de conhecimento.

À luz deste processo, verifica-se que o conhecimento, a informação e os dados não são variáveis independentes, porém interdependentes, sendo necessário gerenciá-las estrategicamente por meio de criação, captação, disseminação e incorporação do conhecimento. 


\subsection{Criação e Gestão do Conhecimento}

A história sobre a criação do termo gestão do conhecimento teve seu início com a automação, por volta de 1970, em que os sistemas de computadores eram denominados "processadores de dados", pretendia-se com esta caracterização conduzir a noção de grupos de dados que alimentavam computadores e os quais processava-nos individualmente ou ainda em pequenos grupos.

Após esta fase iniciou-se um processo em que os dados estavam combinados com uma estrutura e rótulos, o que configurou o "processamento de informações". A principal diferença desta fase com a anterior é que nesta os dados não eram gerenciados de forma isolada, tornouse possível estocá-los em tabelas permitindo operações um pouco mais complexas.

A partir dos anos 90, um novo conjunto de aplicações emergiu, diferindo qualitativamente das fases antecessoras. Iniciou-se um processo de armazenamento de informações de toda parte da organização: financeira, demográfica, clientes, produtos, entre outros. Não surpreendemente, este processo assumiu uma conotação que a distinguisse das demais, denominado de "processamento de conhecimento", neste âmbito o aprimoramento da gestão da informação eleva-se à chamada gestão do conhecimento (DILLON, 2002).

De acordo com Miles et al. (1998) o século XXI incitaria previsões dramáticas nas forças que moldam as organizações e a gestão, resultado dos impactos da globalização e mudanças tecnológicas que estabeleceriam uma outra etapa na nova era de desenvolvimento econômico, em que a variável direcionadora seria o conhecimento.

Notadamente, tanto as especializações em negócios como nas pesquisas entre os acadêmicos, a ênfase dada à gestão do conhecimento aumentou rapidamente nos últimos tempos.

Teece (2000) identifica três objetivos fundamentais, os quais estão alinhados com a evolução abordada por Dillon, que caracterizam o movimento da gestão do conhecimento: 
i) a criação de "depósitos" de conhecimento com informação externa: inteligência competitiva e melhores práticas; e com informação interna: relatórios de pesquisas internas; e, conhecimento interno informal como discussões em bases de dados.

ii) o aprimoramento do acesso ao conhecimento e com isso a reutilização deste por meio do desenvolvimento de ferramentas analíticas com interfaces amigáveis.

iii) valorização do ambiente de conhecimento organizacional, incluindo a espontaneidade dos indivíduos para compartilhar o seu conhecimento e experiências.

Sveiby (1997) traçou um perfil comparativo, conforme Tabela 2, dos princípios da organização da era industrial e a era baseada no conhecimento. Nesta tabela o autor compara a transição dos princípios organizacionais, tais como: pessoas, informação, produção, conhecimento e valores de mercado, da Era industrial para a Era do conhecimento, evidenciando-se assim uma mudança nas perspectivas que ainda não ocorreram em sua totalidade, e apresentam contradições como: a evolução da informação de instrumento de controle para recurso de comunicação, ou ainda; o fluxo de produção regido por máquinas seqüenciais e na era do conhecimento regido por idéias e caótico. Desse modo, embora haja um avanço em termos de tecnologia para a comunicação, por exemplo, o controle que estes mecanismos viabilizam é ainda maior, além disso, mesmo a era do conhecimento sendo regida por idéias, nem todas as práticas são necessariamente caóticas, há aquelas preocupadas com a sistematização do conhecimento. Apesar desta transição era industrial e era do conhecimento, vale ressaltar que muitas práticas da era industrial ainda sobrevivem por adequar-se a determinados contextos organizacionais. 
Tabela 2 - Perfil dos Princípios Organizacionais da Era Industrial e da Era do Conhecimento

$\begin{array}{ccc}\text { PARADIGMA DA ERA } & \text { PARADIGMA DA ERA DO } \\ \text { ITEM } & \text { CONHECIMENTO }\end{array}$

\begin{tabular}{|c|c|c|}
\hline PESSOAS & Geradores de custos e recursos & Geradores de receita \\
\hline $\begin{array}{l}\text { FONTE DE PODER DOS } \\
\text { GERENTES }\end{array}$ & Nível hierárquico na organização & Nível de conhecimento \\
\hline LUTA DE PODER & Operários versus Capitalistas & $\begin{array}{l}\text { Trabalhadores do conhecimento } \\
\text { versus gerentes }\end{array}$ \\
\hline $\begin{array}{l}\text { PRINCIPAL } \\
\text { RESPONSABILIDADE DA } \\
\text { GERÊNCIA }\end{array}$ & Supervisionar os subordinados & Apoiar os colegas \\
\hline INFORMAÇÃO & Instrumento de controle & $\begin{array}{l}\text { Ferramenta para o recurso da } \\
\text { comunicação }\end{array}$ \\
\hline PRODUÇÃO & $\begin{array}{l}\text { Operários processando recursos } \\
\text { físicos para criar produtos tangíveis }\end{array}$ & $\begin{array}{l}\text { Trabalhadores do conhecimento } \\
\text { convertendo conhecimento em } \\
\text { estruturas intangíveis }\end{array}$ \\
\hline FLUXO DE INFORMAÇÃO & Via hierarquia organizacional & Via redes colegiadas \\
\hline GARGALOS NA PRODUÇÃO & $\begin{array}{l}\text { Capital financeiro e habilidades } \\
\text { humanas }\end{array}$ & Tempo e conhecimento \\
\hline FLUXO DE PRODUÇÃO & Regido pelas máquinas; seqüencial & Regido pelas idéias; caótico \\
\hline EFEITO DO TAMANHO & $\begin{array}{l}\text { Economia de escala no processo de } \\
\text { produção }\end{array}$ & Economia de escopo das redes \\
\hline $\begin{array}{l}\text { RELAÇÕES COM OS } \\
\text { CLIENTES }\end{array}$ & Unidirecional pelos mercados & Interativo pelas redes pessoais \\
\hline CONHECIMENTO & $\begin{array}{l}\text { Uma ferramenta ou recurso entre } \\
\text { outros }\end{array}$ & O foco do negócio \\
\hline $\begin{array}{l}\text { PROPÓSITO DO } \\
\text { APRENDIZADO }\end{array}$ & Aplicação de novas ferramentas & Criação de novos ativos \\
\hline $\begin{array}{l}\text { VALORES DE MERCADO } \\
\text { (AÇÕES) }\end{array}$ & Regido pelos ativos tangíveis & Regido pelos ativos intangíveis \\
\hline ECONOMIA & De redução de custos & De aumento e redução de custos \\
\hline
\end{tabular}


Neste âmbito, surgem algumas perspectivas dentro do movimento de gestão do conhecimento: as focadas no desenvolvimento de softwares, visando o armazenamento de conhecimento; as comunidades de prática visando interações mais otimizadas em equipes de trabalho; a gestão do capital intelectual, subsidiando as práticas operacionais; entre outras. $\mathrm{O}$ presente trabalho aprofunda seus estudos na teoria de criação do conhecimento organizacional desenvolvida por Nonaka (1991), notoriamente reconhecida pela literatura por concentrar muitas das melhores práticas denotadas por outras perspectivas de G.C.

Conforme Nonaka (1991), a criação do conhecimento organizacional é observada quando os mercados mudam, os competidores se multiplicam, as tecnologias proliferam e os produtos tornam-se obsoletos praticamente do dia para noite. Ademais, as companhias bem sucedidas são aquelas que criam novos conhecimentos, disseminam-nos amplamente por toda organização e, rapidamente os incorporam em novos produtos, serviços e tecnologias.

De acordo com Inkpen (1996), a criação do conhecimento representa um processo em que o conhecimento dos indivíduos é amplificado e internalizado como parte fundamental da gestão do conhecimento organizacional.

Nonaka e Takeuchi (1997) caracterizam a criação do conhecimento como um processo mutável que envolve interações entre os vários níveis organizacionais, direcionando os indivíduos que amplificam, estendem e disseminam seu conhecimento. Não obstante, a criação do conhecimento é um processo dialético de pensamento e ação, em que várias contradições são sintetizadas através de interações dinâmicas, passíveis de mudança, entre os indivíduos, a organização e o ambiente. Entenda-se síntese como uma integração de aspectos opostos através deste processo dinâmico entre o diálogo e a prática (NONAKA e TOYAMA, 2003).

A teoria de criação do conhecimento está enraizada na crença de que o conhecimento essencial inclui os valores humanos e ideais. Sendo que o processo de criação do 
conhecimento não pode ser capturado apenas como um modelo casual normativo, visto que os valores e ideais humanos são subjetivos e o conceito de verdade depende dos valores, ideais e contextos (NONAKA e TOYAMA, 2005).

Desse modo, conforme ressalta Grant (1996), a importância do elemento humano tem aumentado, uma vez que o conhecimento tem se tornado um ingrediente crítico para obtenção de vantagem competitiva.

A necessidade de administrar o conhecimento surge mediante o fato dele poder conferir para a organização vantagem competitiva, uma vez que por meio de um conjunto de conhecimento e habilidades uma empresa está apta em inovar produtos, processos e serviços, ou ainda aprimorar aqueles existentes de modo eficiente e eficaz (NONAKA; TOYAMA e NAGATA, 2000).

Desta forma Hitt; Ireland e Hoskinsson (2001) corroboram com os autores ao afirmar que os recursos internos (conhecimento e habilidades) das organizações têm sido cada vez mais utilizados na criação de vantagem competitiva.

Entretanto, anterior ao fato de que a gestão do conhecimento pode viabilizar vantagem competitiva a organização, deve-se ter em mente a existência de fatores que são pré-requisitos para uma gestão do conhecimento, os quais segundo Teece (2000) são: os níveis de desenvolvimento econômico, as contratações, as políticas de regulamentações, os sistemas nacional de inovação, o custo e a demanda, as oportunidades tecnológicas e a apropriabilidade dos regimentos. Corroborando com o que Miles (1998) denominou de barreiras operacionais e estratégicas.

Neste contexto, o ideal é gerenciar o conhecimento a fim de que ele seja uma vantagem competitiva sustentável, em que uma empresa terá assegurado esta vantagem quando as outras empresas não conseguirem imitá-la (HITT; IRELAND; HOSKINSSON, 2002). Ademais, desenvolver estratégias de gestão do conhecimento com apropriabilidade que visem amenizar 
e proteger o impacto que os fatores identificados por Teece e Miles possam ter sobre a gestão do conhecimento, que sejam adequadas, customizadas, ao contexto organização e não uma panacéia que atenue a todos os problemas de G.C. (SHIH e CHIANG, 2005).

Segundo Oliveira Jr. (2001), partindo do pressuposto de que o sucesso de uma empresa está baseado em sua capacidade de criar e transferir conhecimento de forma mais eficaz que seus competidores, entender os mecanismos pelos quais o conhecimento pode ser criado e transferido na empresa é ponto de partida para um resultado superior.

Tendo em vista, a importância da gestão do conhecimento organizacional e das inúmeras variáveis que estão relacionadas com este processo, o presente trabalho irá priorizar o entendimento dos mecanismos que norteiam o conhecimento, analisando primeiramente os fatores principais do processo de gestão do conhecimento por meio do denominado processo SECI.

\subsection{Processo SECI}

De acordo com Nonaka e Takeuchi (1997), a organização deve ser capaz de captar, armazenar e transmitir o novo conhecimento organizacional criado a partir da transformação do conhecimento tácito (pessoal e informal) em conhecimento explícito (formal e sistemático).

Conforme Nonaka, Umemoto e Senoo (1996), uma organização cria conhecimento por meio das interações entre o conhecimento explícito e o tácito, estas interações são denominadas "conversão do conhecimento".

Este processo de criação do conhecimento organizacional é denominado de SECI Socialização, Externalização, Combinação e Internalização - e ocorre mediante a interação contínua e dinâmica entre o conhecimento tácito (informal e incorporado em valores e crenças) e o conhecimento explícito (formal e codificável) (NONAKA e KONNO, 1998). 
O processo de criação de conhecimento denominado SECI, ilustrado na Figura 3, é abordado por Nonaka e Toyama (2003), afirmando que o conhecimento é criado mediante a contradição dos recursos internos e o ambiente. Uma vez que, não foca apenas internamente, como no caso da visão baseada em recursos, mas foca também o ambiente externo em que a organização opera.

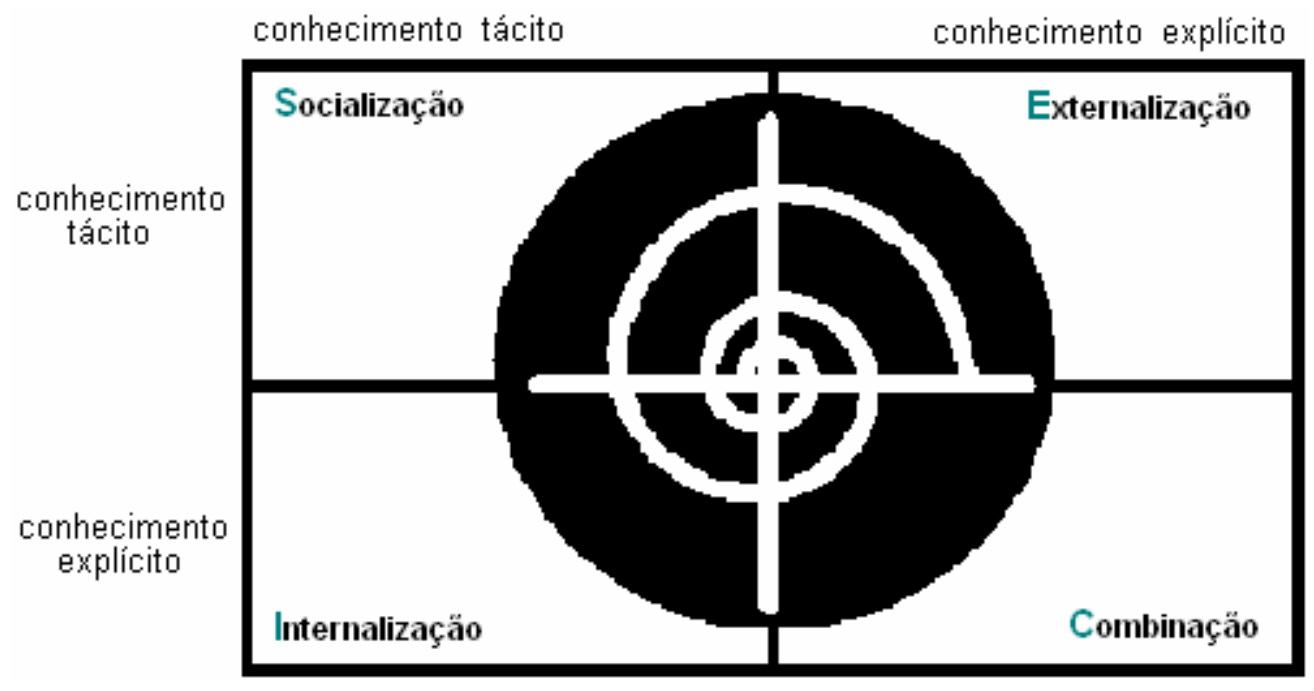

Figura 3: Processo SECI

Fonte: Adaptado de Nonaka e Takeuchi (1997:80)

Quatros modos de conversão do conhecimento podem ser identificados: socialização (de conhecimento tácito para conhecimento tácito); externalização (de conhecimento tácito para conhecimento explícito); combinação (de conhecimento explícito para conhecimento explícito) e a internalização (de conhecimento explícito para conhecimento tácito).

\subsubsection{Socialização}

Este modo de conversão do conhecimento denominado socialização configura o processo de compartilhamento de experiências e viabiliza a criação do conhecimento tácito (Nonaka, 1994). 
Como o conhecimento tácito é difícil de ser formalizado em tempo e lugar específico, este conhecimento pode ser adquirido somente por meio de troca de experiências, via convivência direta. Por exemplo, como ocorria na produção artesanal com os aprendizes e os mestres.

Segundo Silva (2002, p.46), uma frase que sintetiza esta conversão seria: "troca de conhecimentos face-a-face entre as pessoas".

\subsubsection{Externalização}

O processo de externalização consiste na articulação do conhecimento tácito em explícito através de ações que possam ser entendidas pelos outros, seja esta ação um diálogo ou reflexão coletiva (NONAKA e TOYAMA, 2003).

Desse modo, Silva (2002), caracteriza esta conversão como o registro de conhecimento de um determinado indivíduo feito por ele mesmo.

O sucesso da conversão do conhecimento tácito em explícito depende do uso seqüencial de metáforas, analogias e modelos. Por exemplo, por meio de reflexões para construção do conceito de um novo produto (NONAKA, 1994).

\subsubsection{Combinação}

A combinação é o processo de sistematização do conhecimento explícito em um sistema de conhecimento onde os indivíduos trocam e combinam conhecimento explícito de forma sistemática (NONAKA e TAKEUCHI, 1997), ademais configura-se o agrupamento dos registros de conhecimentos (SILVA, 2002).

O conhecimento explícito é coletado dentro e fora da organização e então combinado, editado ou processado a fim de formar um novo conhecimento explícito (NONAKA, TOYAMA e KONNO, 2000). 


\subsubsection{Internalização}

A internalização consiste na incorporação de conhecimento explícito sob a forma de conhecimento tácito.

Este processo ocorre através do "aprender fazendo", pela verbalização, diagramação e modelos mentais. Quando a maioria dos membros da organização compartilha do novo modelo mental, o conhecimento passa a fazer parte da cultura organizacional. E a cada internalização bem sucedida, o ciclo reinicia, levando ao aperfeiçoamento ou à inovação (NONAKA, TOYAMA e KONNO, 2000).

De acordo com Nonaka e Takeuchi (1997), os quatro modos de conversão formam uma espiral, denominada "espiral do conhecimento" e não um círculo, pois ela expande e retrai horizontalmente através da dimensão ontológica, relativo ao que é real, composta por: indivíduo, grupo, organização e interorganização; e, verticalmente através da dimensão epistemológica, relativo aos princípios críticos, envolvendo a conversão entre o conhecimento tácito e explícito.

Mediante a conversão do conhecimento a partir destes quatro modos, a organização mobiliza e amplia o conhecimento individual para toda a organização, cristalizando-o em níveis superiores, como ocorre, por exemplo, nas atividades de desenvolvimento de produto.

Neste âmbito, as empresas devem fornecer um contexto apropriado que facilite as atividades grupais, a fim de que os quatro modos de conversão do conhecimento sejam bem sucedidos, não se restringindo apenas ao estímulo de aprendizagem individual dos funcionários, mas incentivando o compartilhamento de conhecimento em equipes.

De acordo com Senge (2004), as organizações somente aprendem por intermédio de indivíduos que aprendem. Entretanto, o aprendizado individual não garante o aprendizado organizacional. Contudo, sem ele, o aprendizado organizacional não acontece. 
Cabe ressaltar Handy (1994) o qual identificou nove paradoxos no intuito de explicar como a nossa sociedade funciona. Segundo este autor os paradoxos não devem ser resolvidos, mas controlados, pois como a própria definição explica, estes são conceitos que são ou parecem contrários ao comum, sendo que concomitantemente parecem ser companheiros do progresso econômico. Entre os paradoxos, convém enfatizar, o paradoxo da inteligência:

\begin{abstract}
A inteligência é um novo tipo de ativo. Não se comporta como os outros tipos de ativos e nisso reside o paradoxo. Ao contrário dos outros bens, a inteligência não pode ser dada de presente e será sempre conservada, mesmo que compartilhada. Também não é possível possuir a inteligência de outra pessoa, por mais que se seja dono da empresa na qual a pessoa trabalha. Se a pessoa sair da empresa e for embora, levará consigo a inteligência (HANDY, 1994, p.17).
\end{abstract}

A inteligência concentrada, capacidade de adquirir e aplicar conhecimento, e o know-how, de acordo com Handy (1994), são as novas fontes de riqueza, sendo, no entanto impossível transmiti-los a outras pessoas por decreto. Todavia, também é impossível impedir que as pessoas consigam adquiri-los.

Neste contexto, a gestão do conhecimento pode ser considerada como uma alternativa estratégica na criação, transferência, armazenamento e utilização do conhecimento (INKPEN, 1996).

Nonaka e Konno (1998) acrescentam que para criar o conhecimento, disseminá-lo, desenvolvê-lo e incorporá-lo é necessário um local ou um contexto específico, não necessariamente físico. Este local é denominado $b a$, e deve ser pensado como um espaço de compartilhamento onde as relações emergem.

Segundo Nonaka, Toyama e Konno (2000), o $b a$ é a chave para criação, compartilhamento e utilização do conhecimento, visto a energia, qualidade e espaço que este contexto fornece no desenvolvimento das conversões individuais e movimento ao longo da "espiral do conhecimento". Ba é definido como um contexto dinâmico em que o conhecimento é compartilhado, criado e utilizado. De maneira geral, $b a$ pode ser conceitualizado como espaço. 
$B a$ refere-se a um espaço que pode ser:

i) físico (um escritório ou uma biblioteca, por exemplo);

ii) virtual (e-mail, teleconferência, entre outros);

iii) mental (por meio do compartilhamento de idéias e experiências);

iv) ou ainda, uma combinação de todos estes (NONAKA e KONNO, 1998).

$B a$ pode emergir de indivíduos, grupos de trabalho, times de projeto, círculos informais, encontros periódicos, espaço virtuais como: grupos de e-mails e fóruns de discussão.

Conforme a Figura 4, no ba os participantes compartilham seus contextos, criando novos conceitos através de suas interações (NONAKA e TOYAMA, 2003).

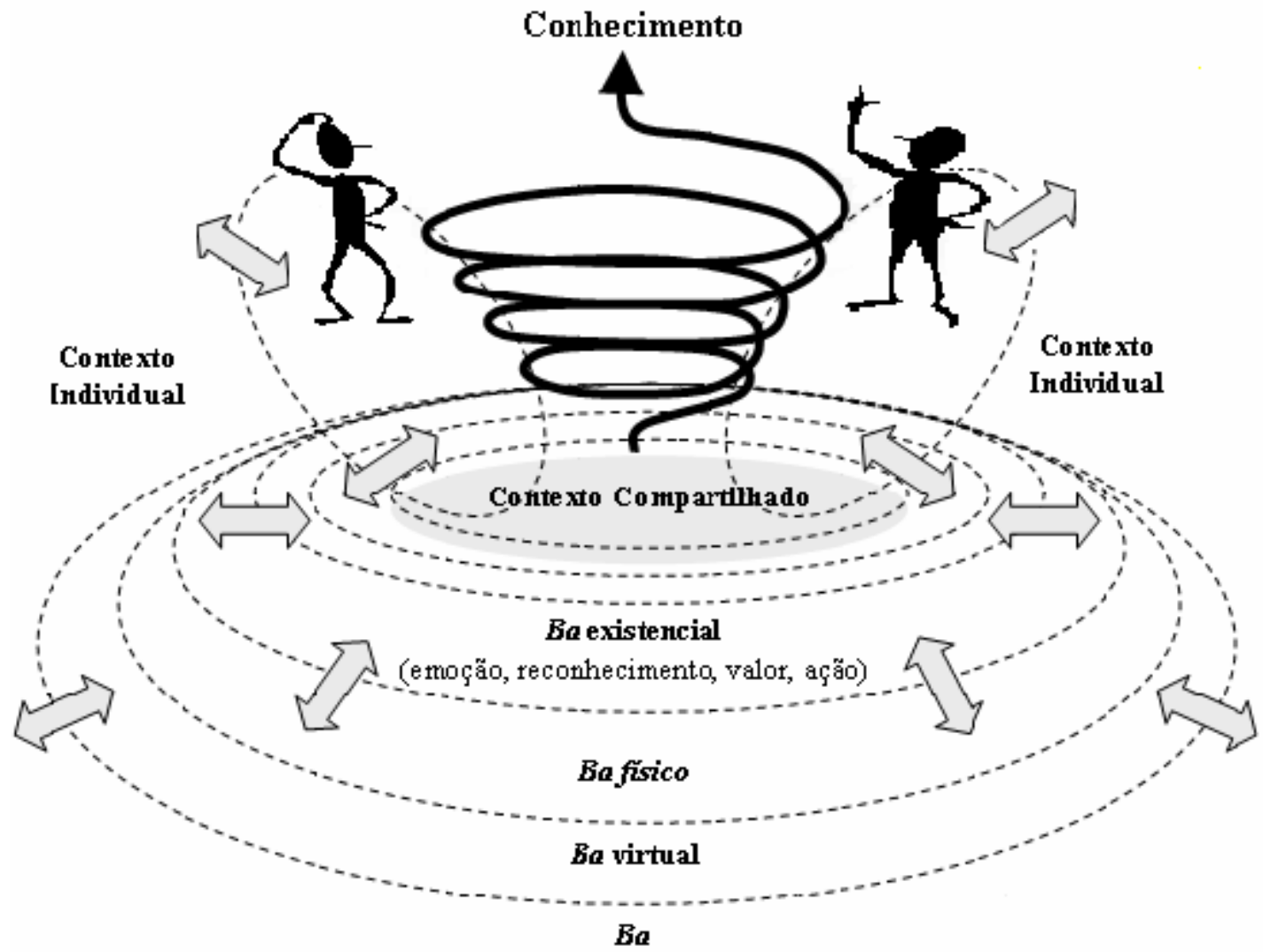

Figura 4: Representação conceitual de $b a$

Fonte: Adaptado de Nonaka e Toyama (2003:7)

A Figura 4 faz a representação conceitual do $b a$, no qual mediante o compartilhamento dos contextos individuais em um contexto compartilhado, seja físico, virtual, mental ou 
existencial, ou uma junção de todos, promove uma realização efetiva dos ciclos da espiral do conhecimento (NONAKA e TOYAMA, 2003).

Uma empresa pode ser vista como uma configuração orgânica de vários $b a$, em que as pessoas interagem entre si e com o ambiente baseado no conhecimento que elas possuem e nos conceitos criados.

De acordo com Nonaka e Konno (1998), o ba existe em muitos níveis e estes podem formar um grande $b a$, denominado basho. Por exemplo, os times são um $b a$ para os indivíduos, a organização é um $b a$ para os times, enquanto o mercado, por sua vez, é um $b a$ para a organização. Assim, o ba é uma "concentração de recursos" composta por ativos do conhecimento organizacional e competências dentro do processo de criação do conhecimento.

O conceito de $b a$ é corroborado por Teece (1998), quando afirma que o conhecimento necessita de contato face-a-face, pois as pessoas sabem mais do que podem dizer. Ademais, o conhecimento codificado é impessoal e técnico, além de depender do canal de comunicação que transmite a informação; e, da familiaridade do receptor com o conhecimento. Então, somente conhecimentos completamente codificados podem ser reproduzidos.

Cohendet e Steinmueller (2000) e Cowan, David e Foray (2000) ressaltam dois aspectos referentes à dificuldade em codificar o conhecimento: a dificuldade de articulação do conhecimento e a necessidade de identificação das capacidades do receptor do conhecimento.

O processo de criação e gestão do conhecimento envolve também as "competências do conhecimento" ou os denominados recursos do conhecimento. De acordo com Nonaka, Toyama e Konno (2000), estas competências são específicas da empresa, indispensáveis para a criação de valor organizacional.

Recursos do conhecimento incluem os inputs, outputs e os fatores moderadores de todo o processo de criação e gestão do conhecimento. Exemplificando, a confiança entre os membros de uma organização é gerada e desenvolvida como um output do processo de criação do 
conhecimento e simultaneamente modera as funções do $b a$ como plataforma de suporte de todo o processo.

Apesar de o conhecimento ser considerado um importante insumo organizacional, não existem sistemas e ferramentas eficazes que possibilitem a avaliação e gestão dos recursos do conhecimento (McCAMPBELL, CLARE e GITTERS, 1999; NONAKA, TOYAMA e KONNO, 2000; NONAKA, TOYAMA e NAGATA, 2000, SCHULZ, 2001; SOO et al., 2002).

A dificuldade em avaliar as competências do conhecimento ocorre em razão de seu caráter intangível, dinâmico e sua natureza tácita. Segundo Teece (2000), a natureza das competências do conhecimento é a de que elas não podem ser prontamente vendidas ou compradas, uma vez que estão incorporadas nas rotinas da empresa.

No âmbito de explicar como as competências do conhecimento são criadas, adquiridas e exploradas; Nonaka, Toyama e Konno (2000) propuseram um modelo em que estas são categorizadas em quatro tipos: recurso experiencial; conceituais; sistêmicos e rotineiros.

As competências de conhecimento experiencial são compostas por conteúdos tácitos compartilhados por meio de experiências comuns, quer entre os diversos membros da organização ou ainda com os clientes, fornecedores ou organizações afiliadas.

Exemplos são: habilidades e know-how adquiridos e acumulados através da experiência individual no local de trabalho; conhecimentos emocionais (cuidado, amor e confiança), energéticos (entusiasmo, tensão), físicos (gestos e expressões) e rítmicos (improvisação) (CARDOSO, 2003).

As competências de conhecimento conceitual, por sua vez, consistem na articulação do conhecimento explícito através de imagens, símbolos e linguagem. A imagem da marca percebida pelos consumidores; e, os conceitos e design de produtos percebidos por membros de uma organização, são exemplos de recursos de conhecimento conceitual. 
Sendo de natureza intangível, as competências de conhecimento conceitual são mais inteligíveis do que as anteriores, embora seja difícil compreender as necessidades dos consumidores e membros organizacionais (NONAKA, TOYAMA e KONNO, 2000).

As competências do conhecimento sistêmico são compostas por conhecimentos explícitos sistematizados e armazenados, tais como: tecnologia de informação, especificações de produtos, manuais ou informações documentadas relativas aos clientes e fornecedores. Ademais, propriedade intelectual protegida legalmente, como: licenças e patentes compõem esta categoria (NONAKA, TOYAMA e NAGATA, 2000).

Os conhecimentos tácitos enraizados na cultura organizacional, procedimentos, Know-how, rotinas e práticas organizacionais formam as denominadas competências de conhecimento de rotina.

Embora sejam aprofundados na literatura de criação do conhecimento, observa-se que o $b a$ e as competências do conhecimento redundam nos elementos denotados pelo processo de conversão do conhecimento, SECI, por isso a essência deste trabalho encontra-se nesse. Desse modo, é possível a identificação de atributos que qualifiquem de maneira sintetizada este processo, Quadro 2, responsável pela conversão do conhecimento organizacional.

\begin{tabular}{|c|c|}
\hline Socialização & Externalização \\
\hline \multirow{3}{*}{$\begin{array}{l}\text { Interaçẫo individual face a face } \\
\text { Treinamento } \\
\text { Confiança } \\
\text { Comprometimento }\end{array}$} & Interaçỗes coletivas face a face \\
\hline & Conceito de produto/Analogia \\
\hline & Incentivo a criatividade e diálogo \\
\hline internalizaçầo & Combinaçã̃o \\
\hline Interaçỗes individuais e virtuais & Interaçốes coletivas e virtuais \\
\hline Cultura organizacional disseminada & Banco de dados \\
\hline Know how técnico & Redes de comunicaçẫo \\
\hline Learning by doing & Elaboraçẫo de relatórios \\
\hline
\end{tabular}


Do exposto pode-se inferir que o processo de socialização caracteriza-se: por interação face-a-face (NONAKA, 1994; SILVA, 2004), indispensável nesta conversão; por uma cultura de confiança e comprometimento (CARDOSO, 2003; NONAKA, TOYAMA E KONNO, 2000), uma vez que atuam como facilitadores no processo de compartilhamento do conhecimento com o próximo; ademais a ação que facilita efetivamente o compartilhamento de conhecimentos tácitos é o treinamento (NONAKA e KONNO, 1998; TEECE, 1998).

A externalização abrange basicamente: interações coletivas e face-a-face (NONAKA E TAKEUCHI, 1997), facilitando as atividades em equipe e permitindo um leque maior de conhecimentos distintos a serem compartilhados; a utilização de analogias e metáforas que transmitam novos conceitos de produtos, o que é amplamente verificado em atividades de desenvolvimento de produtos (NONAKA, 1994; SILVA, 2002), em que a criatividade e o diálogo devem ser incentivados, uma vez que a abstração dos conceitos pode direcionar à inovações importantes de bens e serviços.

No processo de combinação inicia-se a incorporação de alguns aspectos das tecnologias de informação, este processo remete às interações coletivas e virtuais (NONAKA e KONNO, 1998; NONAKA, TOYAMA e NAGATA, 2000) em que ambientes cibernéticos servem como meio para a troca de conhecimento de vários indivíduos. Não obstante, a elaboração de relatórios que armazenem em banco de dados todo o conhecimento aprendido deve ser priorizado nesta etapa, desse modo as redes de comunicação auxiliam no armazenamento, disponibilização e transferência de conhecimento (COHENDER e STEINMUELLER, 2000; COWAN, DAVID e FORAY, 2000; NONAKA e TAKEUCHI, 1997).

E, por fim, os atributos relacionados com a internalização são: interações individuais e virtuais (NONAKA E KONNO, 1998), uma vez que a consulta de registros de conhecimento são indispensáveis para o aprendizado pessoal (SILVA, 2004); o know-how técnico e o learning by doing, facilitadores desta etapa; e como ação gerencial uma cultura 
organizacional favorável e disseminada servindo como motivadora da incorporação de todo conhecimento adquirido (NONAKA e TAKEUCHI, 1997).

Neste contexto, caracteriza-se o processo de gestão do conhecimento abordado por Inkpen (1996), remetendo aos seguintes aspectos principais: a criação, transferência, armazenamento e utilização do conhecimento; os quais correspondem, de maneira geral, respectivamente a socialização, externalização, combinação e internalização, de Nonaka (1994).

Salienta-se ainda que a seleção do processo SECI como parte fundamental deste trabalho remete ao seu caráter primário e de sustentação da prática de gestão do conhecimento. Mediante a identificação dos fatores integrantes do SECI, o próximo passo será identificar as principais dimensões estratégicas que estão relacionadas com a gestão do conhecimento, valendo-se da literatura especializada.

Por conseguinte, o capítulo três apresentará, primeiramente, aspectos teóricos do termo “estratégia", perante a evolução do pensamento administrativo. E, por fim, as abordagens estratégicas do conhecimento serão expostas, com a finalidade de identificar dimensões estratégicas relacionadas com a gestão do conhecimento. 


\section{GESTÃO ESTRATÉGICA DO CONHECIMENTO}

Este capítulo tem o objetivo de identificar as principais dimensões estratégicas que se relacionam com a gestão do conhecimento, para tanto é apresentada, a evolução semântica do termo estratégia sob uma perspectiva global até os aspectos mais específicos do enfoque estratégico do conhecimento.

O enfoque estratégico do conhecimento é estudado mediante a identificação das principais variáveis estratégicas da gestão do conhecimento, as quais serão analisadas conjuntamente àquelas identificadas no capítulo anterior, com intuito de sintetizar os principais elementos a serem trabalhados na pesquisa de campo.

\subsection{O que é estratégia?}

A utilização do conceito de estratégia na administração ocorreu na década de 50, a partir do momento em que o ambiente externo da empresa foi se tornando cada vez mais mutável e descontínuo. A velocidade destas mudanças tornou-se fator de influência na configuração interna do ambiente empresarial. Em conseqüência, surgiu a necessidade de algo que guiasse e reorientasse os objetivos e os caminhos da empresa no seu mercado, buscando adaptação aos novos desafios, ameaças e oportunidades (HAYASHI, NAKAMURA e ESCRIVÃO FILHO, 1995; PORTER, 2003).

Em meados da década de 60, Ansoff considerou estratégia como uma inovação na área administrativa. Não obstante, estudos como os realizados por Mintzberg, Ahlstrand e Lampel 
(2000) acrescentam ainda que, a estratégia é uma ferramenta gerencial imprescindível para as empresas.

Segundo a visão de Grant (1991), estratégia pode ser definida como: uma adaptação realizada por uma organização entre seus recursos internos, habilidades e as oportunidades e riscos criados pelo ambiente externo.

Enquanto para Thompson Jr. e Strickland III (2000), a estratégia da empresa consiste em um conjunto de mudanças competitivas e abordagens comerciais, que os gerentes executam para atingirem o melhor desempenho da empresa, buscando reforçar a posição da organização no mercado, promover a satisfação dos clientes e atingir os objetivos de desempenho.

Neste contexto, surge o chamado processo de administração estratégica, com caráter dinâmico por natureza, o qual visa o gerenciamento das estratégias, levando em consideração: insumos estratégicos; ações como formulação e implementação de estratégia e o feedback dos resultados estratégicos.

\subsection{Administração Estratégica}

De acordo com Teece, Pisano e Shuen (1997), o principal questionamento na temática de administração estratégica é como as empresas obtêm e sustentam vantagens competitivas.

O processo de administração estratégica é representado pelo elenco completo de decisões e ações necessárias para que uma empresa alcance competitividade estratégica, aferindo retornos maiores do que a média. Desse modo, o processo de administração estratégica é empregado para combinar as condições de um mercado em constante transição com a estrutura competitiva dos recursos, capacidades e competências de uma empresa também em constante transição (HITT, IRELAND e HOSKISSON, 2005). 
A área da administração estratégica está atualmente desenvolvendo novos conceitos e ferramentas, a fim de direcionar os gerentes em seus esforços às ondas da economia do conhecimento (von KROUGH, NONAKA e ABEN, 2001).

O processo de administração ou gestão estratégica é composto fundamentalmente por: insumos estratégicos que direcionam a intenção estratégica organizacional; ações estratégicas composto pela formação da estratégia e implementação; e, os resultados estratégicos.

Os insumos estratégicos, mais especificamente o conhecimento, e a estratégia delimitam a gestão estratégica do presente trabalho.

Mediante as escolas de estratégia, Mintzberg; Ahlstrand e Lampel (2000) são considerados os autores que inferem uma abordagems interessante sobre o tema. Dentre as dez escolas de estratégia identificadas por eles, a escola do aprendizado é vista como um processo de estratégia emergente, sendo o processo de criação do conhecimento, um exemplo desta escola.

De acordo com Argyris (apud MINTZBERG; AHLSTRAND e LAMPEL, 2000), os gerentes precisam refletir criticamente sobre seu próprio comportamento, identificar as maneiras pelas quais, inadvertidamente, contribuem para os problemas da organização e então mudar seu modo de agir. Os gerentes devem ensinar as pessoas como raciocinar a respeito de seu próprio comportamento, proporcionando isso de maneira nova e mais eficaz, a fim de que as defesas que bloqueiam o aprendizado sejam derrubadas.

Uma das alternativas estratégicas está no desenvolvimento da capacidade organizacional para adquirir, criar, acumular e explorar o conhecimento. Porém, como o conhecimento é criado somente por indivíduos, o papel da organização é facilitar este aprendizado individual, apoiando e estimulando-o, amplificando-o, cristalizando-o e sintetizando-o em nível de grupo por meio de diálogos, debates, troca de experiências e observações (NONAKA e TAKEUCHI, 1997). 
Mintzberg; Ahlstrand e Lampel (2000) corroboram com a escola do aprendizado, ao afirmar apoiá-la, pois, ela representa um contrapeso a cautela "racional" que, por tanto tempo, dominou a literatura e a prática da administração estratégica. Contudo, deve-se ter cautela para que o aprendizado não seja considerado como um "santo graal" e sim como uma disciplina para a elaboração de uma valiosa noção de direcionamento, uma perspectiva estratégica estabelecida e ocasionalmente modificar esse direcionamento quando necessário.

De acordo com Hitt; Ireland e Hoskinsson (2001), as organizações empregam tanto os bens tangíveis quanto os intangíveis no desenvolvimento e implementação de estratégias, entretanto os bens intangíveis são mais adequados à produção de vantagem competitiva, pois raridade e complexidade são características específicas destes tipos de bens.

\subsection{Enfoque Estratégico do Conhecimento}

O reconhecimento de que as vantagens competitivas nas empresas dependem também da habilidade delas em criar, transferir, utilizar e proteger os bens de imitação tem aumentado. Esta mudança, em que as competências do conhecimento são as bases para vantagem competitiva, tornou-se fato com a liberalização e expansão do mercado tanto doméstico como internacional (TEECE, 2000).

De acordo com Nadler e Tushman (2000), com avanços na área de tecnologia de informação, a capacidade de fazer negócios foi alterada de forma irreversível. A economia que era baseada em manufatura e commodities passou a valorizar mais as informações, assistência e distribuição, o que atribuiu um valor inédito aos denominados "trabalhadores do conhecimento", uma nova classe de pessoas instruídas e com mobilidade.

Segundo Drucker (1994), os "trabalhadores do conhecimento" são compostos por: operadores, especialistas e gerentes do conhecimento os quais devem ser diferenciados na equipe de trabalho, da mesma forma que os capitalistas eram os "proprietários" dos meios de 
produção na sociedade capitalista, os "trabalhadores do conhecimento" são proprietários de seu conhecimento na sociedade pós-capitalista. Estes profissionais são responsáveis pelo acúmulo e geração de conhecimento tácito e explícito, compreendendo os "operadores do conhecimento" que interagem com o conhecimento tácito e os "especialistas do conhecimento" que interagem com o explícito.

Existem ainda os chamados "engenheiros do conhecimento" que têm a responsabilidade de converter o conhecimento tácito em explícito e vice-versa, facilitando o processo SECI. E, por fim os "gerentes do conhecimento" sendo responsáveis pela gestão total do processo de criação do conhecimento em nível empresarial (NONAKA e TAKEUCHI, 1997).

A gestão do conhecimento não é novidade, por centenas de anos proprietários de empresas familiares deixavam parte de suas habilidades para seus filhos, artesões passavam seu conhecimento aos seus aprendizes e trabalhadores têm compartilhado idéias e know-how no trabalho. No entanto, até a década de 90 este tema ainda não estava presente nas discussões dos executivos (HANSEN; NOHRIA e TIERNEY, 1999).

De acordo com Soo et al. (2002), a necessidade de gerenciar estrategicamente o conhecimento cresceu a partir do reconhecimento de que as estruturas organizacionais inflexíveis não conseguem competir quando há uma mudança tão rápida quanto a que ocorre nos mercados atuais. Corroborando com Zack (1999) que denota a essência da gestão estratégica do conhecimento como a identificação dos recursos baseados no conhecimento e as habilidades valiosas, únicas e inimitáveis.

Fleury e Oliveira Jr. (2001), por sua vez, acreditam que o interesse por uma abordagem baseada em recursos como o conhecimento, pode ser entendida como uma tentativa de explicar e prever porque algumas empresas são capazes de estabelecer resultados superiores aos de outra. 
Pelo contexto apresentado, a gestão estratégica do conhecimento (GEC) vem analisar o quanto efetivo é a criação de novos produtos e serviços que incorporam o conhecimento da organização, voltando-se para as atividades de: avaliação, construção, aquisição, aplicação, retenção e compartilhamento de conhecimento. Focando a interface entre o desenvolvimento das capacidades internas e as necessidades estratégicas atuais e futuras da organização (McCANN III e BUCKNER, 2004).

A relevância da gestão estratégica do conhecimento é destacada pelo fato de que, uma vez armazenado o conhecimento na mente dos trabalhadores chave, nos arquivos e banco de dados, este perderá seu valor caso não proveja a pessoa certa na hora certa (TEECE, 2000).

No bojo do processo da gestão estratégica do conhecimento, o papel da alta administração é fundamental, conforme explica Terra (2001), pois cabe a ela fazer com que a empresa mova do paradigma do treinamento para o paradigma do aprendizado.

O paradigma do treinamento baseia-se em programas formais de treinamento voltados unicamente para as especialidades técnicas e funcionais que os cargos exigem. Enquanto, o paradigma do aprendizado, considera além dos programas formais, a utilização de processos informais de captação de conhecimento, tais como aconselhamento e discussão de idéias, baseado não apenas no escopo de suas funções, mas também em técnicas gerenciais, comportamentais e estratégicas, reconhecendo todos os profissionais como fonte de conhecimento.

Poucas abordagens são encontradas na literatura que tratem sobre a gestão estratégica do conhecimento, na maioria das vezes, examina-se de forma isolada ora a gestão do conhecimento ora estratégias organizacionais, ou ainda como na visão baseada em recursos, o conhecimento aparece como um dos insumos estratégicos.

Nas próximas seções serão apresentadas as principais abordagens presentes na literatura relativas a gestão estratégica do conhecimento. 


\subsubsection{Abordagem de Hansen, Nohria e Tierney}

Hansen; Nohria e Tierney (1999) sugerem dois tipos de estratégias para a gestão do conhecimento: a codificada e a personalizada, conforme Tabela 3. A estratégia codificada ocorre quando o conhecimento é codificado e armazenado em uma base de dados, podendo ser acessados e utilizados facilmente por qualquer membro da organização. Enquanto, a estratégia personalizada ocorre quando o conhecimento é disseminado através da proximidade das pessoas, as quais o desenvolvem e partilham por meio de contatos diretos de pessoas para pessoas.

A escolha sobre a melhor estratégia de acordo com os autores depende dos seguintes aspectos:

i) se a empresa oferece um produto padrão ou customizado;

ii) se a empresa trabalha com produto maduro ou inovador;

iii) e, se as pessoas que resolvem os problemas possuem habilidades para lidar com o conhecimento tácito ou explícito.

Na Tabela 3 podem ser observadas as duas estratégias comentadas, é mostrado também como os fatores: modelo econômico; a estratégia de gestão do conhecimento (GC); tecnologia de informação e recursos humanos se comporta perante cada estratégia. 
Tabela 3 - Tipos de estratégias de Gestão do Conhecimento

\section{CODIFICAÇÃ̃O}

Prover alta qualidade, confiança e rapidez na implementação dos sistemas de informação através do reuso do conhecimento codificado.
ESTRATÉGIA Prover criatividade, comunicação

analiticamente rigorosa nos problemas de nível estratégico através da canalização da especialidade individual.

\section{Economia Reutilizável}

Investir uma vez no conhecimento e reutilizá-lo várias vezes.

Usar grandes equipes com alta taxa de parcerias.

Foca na generalização dos rendimentos.

\section{Economia "Expert"}

Investir grandes honorários em soluções altamente customizadas.
MODELO

ECONÔMICO
Usar pequenas equipes com baixa taxa de parcerias.

Foca na manutenção de lucros marginais.

\section{Pessoa-documentos}

Desenvolver um sistema de documentação eletrônica que codifica, armazena, dissemina e permite a reutilização do conhecimento.

\section{Pessoa-Pessoa}

Desenvolver redes para relacionar as pessoas

ESTRATÉGIA DE a fim de que o conhecimento tácito seja GC compartilhado.

\begin{tabular}{|c|c|c|}
\hline $\begin{array}{l}\text { Investir pesadamente em tecnologia de } \\
\text { informação; a meta é possibilitar a } \\
\text { interface das pessoas com } \\
\text { conhecimento codificável reutilizável. }\end{array}$ & $\begin{array}{l}\text { TECNOLOGIA DE } \\
\text { INFORMAÇÃ̃O }\end{array}$ & $\begin{array}{l}\text { Investir moderadamente em tecnologia de } \\
\text { informação; a meta é facilitar conversas e } \\
\text { compartilhamento de conhecimento tácito. }\end{array}$ \\
\hline $\begin{array}{lcc}\text { Admitir recém graduados os quais se } & \text { ged a } \\
\text { adequam a } & \text { reutilização } & \text { do } \\
\text { conhecimento e implementação } & \text { de } \\
\text { soluções. } & & \end{array}$ & & $\begin{array}{l}\text { Admitir M.B.A's, os quais gostam de } \\
\text { solucionar problemas e podem tolerar } \\
\text { ambigüidade. }\end{array}$ \\
\hline $\begin{array}{l}\text { Treinar pessoas em grupos e através de } \\
\text { ensino a distância. }\end{array}$ & $\begin{array}{l}\text { RECURSOS } \\
\text { HUMANOS }\end{array}$ & $\begin{array}{l}\text { Treinar pessoas por meio de mentores um a } \\
\text { um. }\end{array}$ \\
\hline $\begin{array}{l}\text { Recompensar as pessoas que utilizam e } \\
\text { contribuem com banco de dados. }\end{array}$ & & $\begin{array}{l}\text { Recompensar pessoas que compartilham } \\
\text { conhecimento diretamente com outros. }\end{array}$ \\
\hline
\end{tabular}

Fonte: Adaptado de Hansen, Nohria e Tierney (1999).

Embora, os autores tenham realizado uma análise individual de cada estratégia, eles afirmam que as empresas deveriam optar não apenas por uma das estratégias, mas pelo uso de ambas, uma vez que elas são complementares.

\subsubsection{Abordagem de von Krogh, Nonaka e Aben}

De acordo com von Krogh, Nonaka e Aben (2001), a escolha de uma estratégia deve basear-se: no balanço entre o conhecimento existente e o novo; processos centrais do conhecimento e as metas da organização. Os autores identificam quatro estratégias genéricas 
do conhecimento, a fim de auxiliar a alocação de recursos: alavancagem, expansão, investigação e apropriação. Conforme Quadro 3.

A estratégia de alavancagem remete a transferência de conhecimento existente. Enquanto, a estratégia de apropriação direciona-se para a transferência de novos conhecimentos. A estratégia de expansão examina o processo de criação do conhecimento, a partir de conhecimento existente. Por outro lado, a estratégia de investigação foca a criação de novos conhecimentos.

\begin{tabular}{|c|c|c|c|}
\hline & \multicolumn{2}{|c|}{ Processo } \\
\hline & & Transferência & Criação \\
\hline \multirow{2}{*}{ 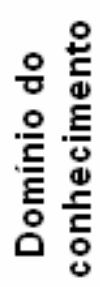 } & Existente & $\begin{array}{l}\text { Estratégia de } \\
\text { Alavancagem }\end{array}$ & $\begin{array}{c}\text { Estratégia de } \\
\text { Expansão }\end{array}$ \\
\hline & Novo & $\begin{array}{l}\text { Estratégia de } \\
\text { Apropriação }\end{array}$ & $\begin{array}{l}\text { Estratégia de } \\
\text { Investigação }\end{array}$ \\
\hline
\end{tabular}

Quadro 3: Quatro estratégias do conhecimento

Fonte: Adaptado de von Krough, Nonaka e Aben (2001:427)

No que concerne as contribuições das metas estratégicas, a estratégia de alavancagem pode, primeiramente, ser direcionada para obtenção de eficiência nas operações e redução de riscos.

Esta estratégia garante que a empresa transfira internamente o conhecimento existente a partir de vários domínios. Sendo, a transferência de conhecimento essencial para a consolidação das atividades e também para a padronização das tarefas.

$\mathrm{Na}$ Tabela 4 é apresentado como a estratégia de alavancagem impacta nas metas estratégicas: eficiência, inovação e gestão de riscos. 
Tabela 4 - Impacto da estratégia de alavancagem sobre as metas estratégicas $\begin{array}{ll}\text { Eficiência } & \begin{array}{l}\text { Compartilhar conhecimento na organização, tais como: na produção, } \\ \text { desenvolvimento de produto, marketing, vendas. }\end{array}\end{array}$

Inovação Compartilhar conhecimento entre os domínios para melhorar o processo de inovação.

Gestão de riscos Compartilhar conhecimento para redução de riscos que sobretaxam recursos. Compartilhar conhecimento com os competidores e ambiente regulador.

Fonte: Adaptado de von Krogh, Nonaka e Aben (2001:430).

A estratégia de expansão, conforme exposto na Tabela 5, inicia no domínio do conhecimento existente da organização, objetivando a criação do conhecimento por meio da extração dos dados existentes, informação e conhecimento já existente. Aumentando o escopo e profundidade do conhecimento.

Tabela 5 - Impacto da estratégia de expansão sobre as metas estratégicas

Eficiência Expandir o conhecimento relacionado aos processos existentes.

Inovação Criar novos processos e inovar em produtos a partir do domínio de conhecimento existente.

Desenvolver domínios de conhecimento para reduzir o risco de sobretaxar recursos.

Gestão de riscos Desenvolver domínios de conhecimento para reduzir a exposição ao risco de deterioração.

Desenvolver domínios de conhecimento para regulamentações e ambiente competitivo.

Fonte: Adaptado de von Krough, Nonaka e Aben (2001:432).

Por outro lado, a estratégia de investigação delega responsabilidade à(s) equipe(s) para construção de um novo conhecimento, observe Tabela 6. A diferença desta estratégia com a anterior é que nesta o conhecimento já foi identificado e está disponível para ser gerenciado. 
Tabela 6 - Impacto da estratégia de investigação sobre as metas estratégicas

Eficiência Criar novo conhecimento que possa melhorar o processo de negócios.

Inovação Criar novo conhecimento por meio de produtos radicais e processos inovadores e melhor adaptação.

Gestão de riscos Reduzir a exposição ao risco de deteriorização do conhecimento existente.

Fonte: Adaptado de von Krough, Nonaka e Aben (2001:435).

E, por fim, a estratégia de apropriação é predominantemente uma estratégia externamente orientada. Nela, o desafio é construir um novo domínio de conhecimento por meio da transferência de conhecimento a partir de fontes externas, conforme mostra a Tabela 7.

\section{Tabela 7 - Impacto da estratégia de apropriação sobre as metas estratégicas}

Eficiência Transferir novo conhecimento a partir de parcerias na: produção, vendas, marketing e desenvolvimento de produtos.

Inovação Transferir novo conhecimento a partir de parcerias para inovação futura.

Transferir novo conhecimento a partir de parcerias, com intuito de reduzir o

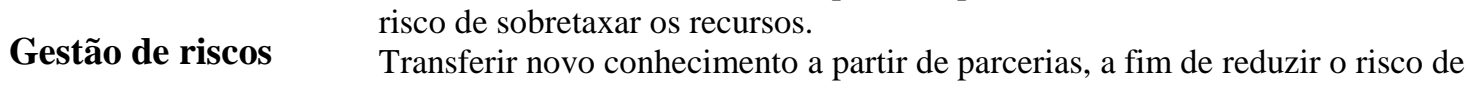
exposição ao risco de deteriorização do conhecimento.

Transferir novo conhecimento no ambiente regulamentador e competidores.

Fonte: Adaptado de von Krough, Nonaka e Aben (2001:433).

Segundo von Krough, Nonaka e Aben (2001), o desenvolvimento de vantagens baseadas no conhecimento requer adequada atenção e ao mesmo tempo uma alocação de recursos que seja paralela ao desenvolvimento de outros tipos de vantagens organizacionais. Tendo em vista que, o custo de criação do conhecimento é alto, em razão da dificuldade de previsão dos resultados, o aumento da pressão por inovação e a alta flexibilidade dos empregados, faz com que o gerenciamento efetivo do processo de gestão do conhecimento seja crucial para o sucesso dos negócios. 


\subsubsection{Abordagem de Terra}

Terra (2001) também desenvolveu uma abordagem em que sob um ponto de vista estratégico, a gestão do conhecimento pode ser entendida, conforme Figura 5, a partir de sete dimensões: o Papel da Alta Administração; Cultura Organizacional; Estrutura Organizacional; Política de Recursos Humanos (R.H); Sistemas de Informação, Mensuração de Resultados e Aprendizado com Ambiente.

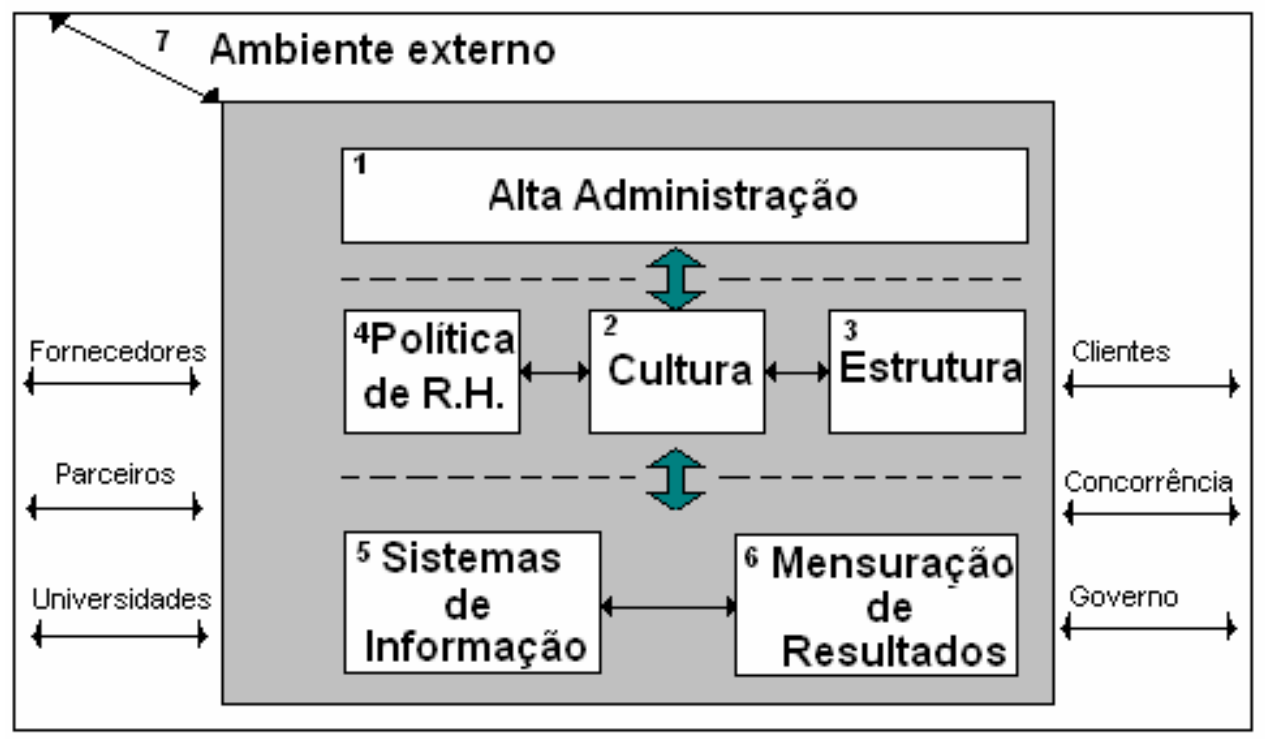

Figura 5: Dimensões da gestão do conhecimento Fonte: Adaptado de Terra (2001:83)

A primeira dimensão, alta administração, refere-se ao papel indispensável desta na definição dos campos do conhecimento que devem ser priorizados, e na clarificação da estratégia empresarial e definição das metas.

A cultura organizacional deve estar condicionada ao desenvolvimento de inovação, experimentação, aprendizado contínuo e compromisso com os resultados e otimização de todas as áreas da empresa.

As novas estruturas organizacionais estão, em grande parte, baseadas no trabalho de equipes multidisciplinares com alto grau de autonomia.

A quarta dimensão, práticas e políticas recursos humanos, está associada com a aquisição de conhecimento externo, por meio de novas contratações, e interno a empresa como 
subsidiar a geração, difusão e armazenamento de conhecimentos na empresa, através de práticas como reconhecimento e recompensas que estimulem o comprometimento dos funcionários.

O impacto que os sistemas de informação exercem sobre os mecanismos de geração, difusão e armazenamento de conhecimento, faz deles uma dimensão fundamental para uma gestão estratégica do conhecimento.

Destaca-se também a necessidade de mensuração dos resultados, principalmente na avaliação do capital intelectual.

E, por fim a necessidade de aprendizado com o ambiente externo, por meio de alianças com outras organizações e relacionamento com os clientes (TERRA, 2001).

\subsubsection{Outras abordagens}

Outros autores desenvolveram estudos em torno da gestão estratégica do conhecimento. Embora, nenhuma abordagem seja tão reconhecida pela literatura como as citadas anteriormente, vale a pena ressaltar algumas dimensões consideradas por estes autores sobre a GEC.

McCann III e Buckner (2004) identificaram como fatores estratégicos a forma como o conhecimento é: avaliado; expressado; construído internamente e/ou adquirido externamente; compartilhado internamente e/ou externamente; armazenado; e, aplicado para criação e sustentação no conhecimento agregado a produtos e serviços.

Embora o conhecimento possa sempre ser compartilhado, a maneira como ele é internalizado e aplicado difere do tipo de pessoa, situação e empreendimento em questão (SNYMAN e KRUGER, 2004).

Taylor et al. (apud SNYMAN e KRUGER, 2004) aborda a gestão estratégica do conhecimento sob duas dimensões. A primeira consiste nas atividades críticas para criação do conhecimento e inovação: compartilhamento, captura, reutilização e internalização do 
conhecimento. A segunda dimensão consiste naqueles elementos que permitem ou influenciam as atividades de criação do conhecimento, tais como: estratégia; medições; política; conteúdo, processo; tecnologia e cultura.

Tendo em vista, os diferentes ângulos possíveis para realização da gestão estratégica do conhecimento, serão apresentados, primeiramente, alguns critérios de classificação para as possíveis formas ostentadas pela gestão estratégica do conhecimento. E, em seguida serão expostos os fatores que serão, especificamente, estudados nesta pesquisa.

\subsubsection{Critérios de classificação das possíveis formas assumidas na GEC}

Em geral, observa-se na literatura a elaboração de poucos modelos estratégicos relacionados com a gestão do conhecimento (em termos de processos orientados ao conhecimento, estruturas organizacionais, atividades relacionadas à cultura e implementação de tecnologias), e estratégia de negócios (MAIER, 2001).

De acordo com o autor, muitos estudos empíricos se restringem a:

i) mapear as fontes de "expertise" interna: tornar o conhecimento um recurso visível;

ii) estabelecer novos papéis do conhecimento: criar posições ou papéis responsáveis pelas tarefas relativas a conhecimento, tais como: engenheiro do conhecimento e corretor do conhecimento.

iii) criar um ambiente de trabalho virtual que permita o compartilhamento de conhecimento tácito: criar redes para os trabalhadores do conhecimento, criar espaços virtuais;

iv) viabilizar o fluxo de conhecimento na organização: provedores de conhecimento e aqueles que procuram por este, devem estar conectados através de sistemas e ferramentas que estabelece um balanço entre puxar e empurrar o conhecimento;

v) gerenciar o conhecimento como estratégia de negócio: a GC deve estar integrada com as estratégias de negócio ou deve ser tratada como uma estratégia de negócio separada paralelamente às outras estratégias; 
vi) focar o conhecimento no cliente: a chave estratégica é capturar o conhecimento sobre as necessidades, preferências e negócios dos consumidores, bem como suas reações perante as ações da organização;

vii) desenvolver estratégias de gestão do capital intelectual: a estratégia neste caso seria a gestão no nível de negócio das patentes, tecnologias, práticas operacionais e de gestão, relações com consumidores, dentre outros;

viii) inovar e criar conhecimento: pesquisa e desenvolvimento focado na inovação e criação do conhecimento.

Evidencia-se uma gama de diversas possibilidades estratégicas correlatas a gestão do conhecimento que possam ser utilizadas para caracterizar uma gestão estratégica do conhecimento particular (MAIER, 2001). Com intuito de classificar estas estratégias que norteiam o conhecimento, Maier (2001) propõe um modelo baseado nas seguintes dimensões estratégicas: tipo de conhecimento; grupo alvo; sistemas de gestão do conhecimento; cultura; tipo de processo do conhecimento e orientação do processo.

- Tipo de conhecimento: este varia de acordo com sete sub-dimensões: competitivo (conhecimento central, avançado ou de inovação); relativo ao conteúdo do conhecimento (concreto vs. abstrato ou universal vs. particular); relativo ao detentor do conhecimento (tácito vs. explícito, personalizado vs. codificado); relativo ao projeto organizacional (secreto vs. público, individual vs. coletivo); relativo aos sistemas (acessível vs. não acessível, codificável vs. não codificável); relativo ao ciclo de vida do conhecimento (existente vs. novo) e, por fim, relativo ao processo de negócios (conhecimento sobre o processo vs. conhecimento dentro do processo vs. conhecimento derivado do processo).

- Grupo alvo: este pode ser subdividido em quatro sub-dimensões: nível do funcionário (empregado vs. gerente vs. diretor); ciclo de vida do funcionário (novato vs. aposentado 
vs. encontra-se em um momento específico da carreira); papel do funcionário (técnico, assume uma função ou várias) e escopo do funcionário (grupo central, vs. organização vs. organização e parcerias).

- Sistemas de gestão do conhecimento (SGC): duas são as sub-dimensões encontradas: integrado (armazena conhecimento vs. descobre vs. mapeia vs. sistemas empurrado), interativo (cooperação vs. transferência de conhecimento).

- Ambiente cultural: o qual aborda mecanismos sociais para compartilhamento de conhecimento (cultura familiar vs. modelo de mercado), e o grau de interesse (alto vs. baixo).

- Tipo de processo do conhecimento (TPC): neste encontra-se a sub-dimensão: processo do conhecimento, que pode ser de: criação, aquisição, organizacional, controle, distribuição, dentre outros.

- Orientação do processo de negócio: esta última dimensão engloba o foco do processo (simples, múltiplo ou ambos) e o tipo do processo (complexo, central, gestão, etc).

A interdependência entre as dimensões estratégicas da gestão do conhecimento, segundo Maier (2001), pode ser observada na Figura 6.

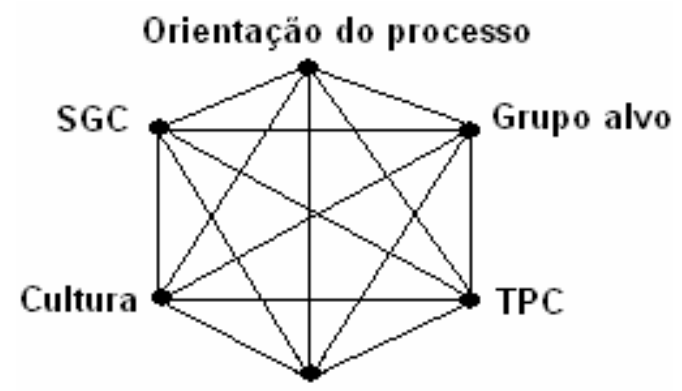

Tipo de conhecimento

Figura 6: Interdependência entre as dimensões estratégicas da gestão do conhecimento Fonte: Adaptado de Maier (2001:9)

A Figura 6 mostra que a dimensão estratégica deve ser analisada mediante as inter-relações com as demais dimensões e não isoladamente, uma vez que elas são interdependentes, a mudança em uma delas implicará na alteração nas demais. 
Com base, nas perspectivas de GEC apresentadas e nos critérios de classificação elaborados por Maier, é possível identificar o foco adotado pelos diferentes autores encontrados na literatura. Por exemplo, a classificação da abordagem de Hansen, Nohria e Tierney (1999) e a de von Krough, Nonaka e Aben (2001).

A abordagem de Hansen, Nohria e Tierney (1999), conforme exposto, considera duas estratégias: a codificação e a personalização. De acordo com o modelo de Maier (2001), elas estão contidas na dimensão: tipo de conhecimento.

Por outro lado, pode inferir-se que a perspectiva de von Krough, Nonaka e Aben (2001) está relacionada com duas dimensões: tipo de conhecimento e tipo de processo, sendo que na primeira dimensão ele insere-se na sub-dimensão: ciclo de vida do conhecimento.

Pode-se averiguar a complexidade dos elementos envolvidos em todo o processo estratégico de gestão do conhecimento e as diversas direções que a GEC pode ter.

De acordo com Vasconcelos (2001), a complexidade não surge do conhecimento preciso para construir um objeto, mas da ignorância em determinar as variáveis fundamentais que governam determinada situação.

Neste âmbito, o presente trabalho identifica: cultura, sistemas de informação e práticas de recursos humanos, como as dimensões estratégicas principais que estão diretamente relacionadas com a gestão do conhecimento, as quais foram selecionadas com base na fundamentação teórica apresentada na próxima seção.

\subsection{Dimensões Estratégicas}

Conforme apresentado não há na literatura especializada um estudo que realize apropriadamente para MPE's residentes em parques tecnológicos o relacionamento: fatores inerentes a gestão do conhecimento com dimensões estratégicas organizacionais.

Neste âmbito, foi realizada uma ampla pesquisa bibliográfica, a fim de determinar quais as 
variáveis que viabilizam este relacionamento. Tendo-se como base todo o estudo apresentado anteriormente, e os possíveis enfoques estratégicos que podem ser pesquisados. Este estudo identificou como as dimensões estratégicas mais relevantes ao contexto abordado: cultura, sistemas de informação e práticas de recursos humanos.

\subsubsection{Cultura}

Um dos grandes entraves ao compartilhamento do conhecimento é a comportamento natural das pessoas em querer guardar os seus conhecimentos, dificultando sobremaneira o ato de compartilhamento. Fato que sem o apropriado gerenciamento estratégico, dificilmente fará do conhecimento um diferencial competitivo.

Nesse sentido, a cultura deve voltar-se para conscientização dos empregados, incentivo e reconhecimento (BENÍTEZ e RODRIGUEZ y RODRIGUEZ, 2004).

A cultura tem como função viabilizar: a clareza das missões e valores organizacionais por meio de atos simbólicos; o compartilhamento de conhecimento e experimentação a partir do comprometimento e reconhecimento dos funcionários. Estabelecendo uma cultura de confiança e liberdade, satisfazendo assim as necessidades e aspirações dos membros da organização, incentivando a exploração de territórios desconhecidos, tais como: novos mercados, novos clientes, produtos e novas tecnologias de manufatura (DAVENPORT, DE LONG e BEERS, 1998; NONAKA, 1994; NONAKA, UMEMOTO e SENOO, 1996; ORSI, 2003; TERRA, 2001; TIPARK, 2005; uit BEIJERSE, 1999; von KROGH, 1998; ZACK, 1999). O que conduz a Figura 7.

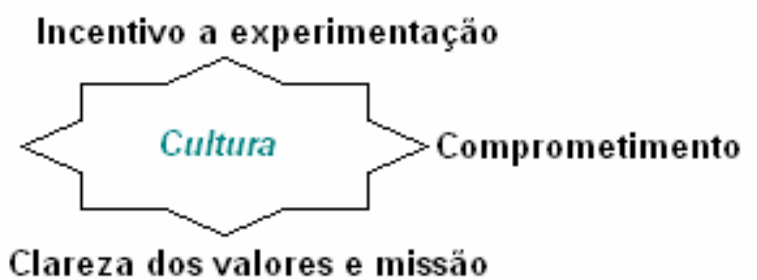

Figura 7: Atributos que compõem o fator cultura 
Desse modo, a Figura 7 apresenta as sub-dimensões que melhor sintetizam a dimensão estratégica cultura. Uma vez que esclarecer os valores e a missão da empresa configura a conscientização dos membros organizacionais sobre o papel da empresa, o comprometimento e incentivo a experimentação estabelece uma cultura de liberdade aos funcionários na tomada de decisão.

De acordo com Schein (2001), a cultura organizacional é um conjunto de valores, e pressupostos básicos que um grupo inventou, descobriu ou desenvolveu ao aprender a lidar com os problemas de integração interna e adaptação externa e que funcionaram bem o suficiente para serem considerados válidos e assim serem ensinados a novos membros como forma correta de perceber, pensar e sentir, em relação a esses problemas.

Schein (2001) afirma que a cultura organizacional possui três níveis: artefatos, que engloba estruturas e processos organizacionais visíveis; valores, que engloba as estratégias, os objetivos e a filosofia da organização; e, por fim as certezas básicas fundamentais, onde se encontra o inconsciente da organização, suas crenças, percepções e pressupostos, os quais não podem ser mensurados em um simples questionário, uma vez que exigem uma análise mais profunda e individualizada dos casos.

Neste contexto, a seleção da variável cultura para posterior análise no presente trabalho remete à sua importância estratégica, e, portanto fundamental no relacionamento com o processo de gestão do conhecimento.

\subsubsection{Sistemas de informação}

Devido ao suporte técnico e toda funcionalidade que os sistemas de informação oferecem ao processo de gestão do conhecimento, considera-se aqui os sistemas de informação como uma dimensão estratégica. 
Os recursos da tecnologia de informação podem otimizar fases do processo SECI, seja por: facilitar que as pessoas sejam encontradas, podendo ocorrer então a socialização e externalização; auxiliar no registro do conhecimento, na combinação; além de agilizar o acesso ao conhecimento, na internalização (SILVA, 2002).

Os sistemas de informação geram, coletam, combinam, armazenam, codificam e disseminam dados, informações e conhecimento, caracterizando uma ferramenta que sistematiza o funcionamento dos processos que são estabelecidos por meio de uma estratégia predefinida (SCHULZ, 2001).

Portanto, a integração dos sistemas de informação e redes de comunicação, principalmente, são elementos indispensáveis para sistematizar todo o processo de coleta, armazenamento e disseminação de informação e conhecimento. Por conseqüência, para viabilizar este processo é requerido investimentos em tecnologia de informação (COWAN, DAVID e FORAY, 2000; COHENDET e STEINMUELLER, 2000).

Desse modo, a Figura 8 sintetiza as principais sub-dimensões que compõem os sistemas de informação.

Investimentos em T.I.

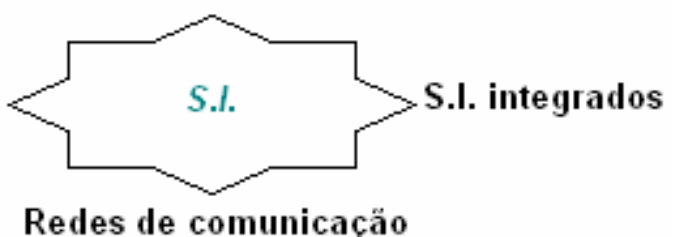

Figura 8: Sub-dimensões que compõem os Sistemas de Informação

Assim, investimentos em tecnologias de informação e integração dos sistemas tornam-se indispensáveis na facilitação de transferência de informações, e, principalmente, conhecimento, sem contar o modo como facilitam o processo de codificação do conhecimento, configurando um importante aspecto estratégico (COWAN, DAVID e FORAY, 2000; COHENDET e STEINMUELLER, 2000; DAVENPORT, DE LONG e BEERS, 1998; HANSEN, NOHRIA, TIERNEY, 1999; HITT, IRELAND e HOSKINSSON, 
2005; NONAKA, 1994; PRAHALAD e HAMEL, 1990; TERRA, 2001; VASCONCELOS, 2001; ZACK, 1999).

\subsubsection{Práticas de Recursos Humanos}

De acordo com Jerez-Gómez, Céspedes-Lorente e Valle Cabrera (2005) e Terra (2001), as práticas de recursos humanos envolvem, principalmente, reconhecimento, recompensa por meio de políticas de compensação, treinamento e admissão de novas competências, como pode ser observado na Figura 9.

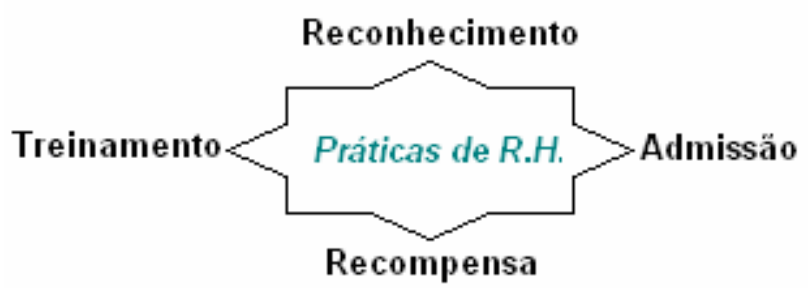

Figura 9: Atributos que compõem as práticas de R.H.

Storey e Quintas (2001) afirmam que para obter-se uma gestão do conhecimento efetiva é necessário um alto comprometimento da empresa com estratégias de inovação, para tanto, as estruturas organizacionais devem ser redesenhadas, e isso perante as práticas de recursos humanos implica: novas prioridades em recrutamento/seleção/equipes; nova ênfase no aprendizado organizacional; revisão completa da gestão de desempenho e sistemas de recompensas. Estas práticas visam atrair, reter, motivar e encorajar os membros da organização (JEREZ-GÓMEZ， CÉSPEDES-LORENTE e VALLE-CABRERA， 2005; TERRA, 2001; uit BEIJERSE, 1999).

Medeiros (2003) corrobora com os atributos supracitados inseridos nas práticas de recursos humanos ao analisar em seu estudo: contratação, carreira, remuneração, treinamento e avaliação de desempenho. As quais estão diretamente relacionadas com as que serão estudadas, com exceção das variáveis: carreira e a avaliação de desempenho. Esta última, 
embora não seja pesquisada diretamente, está relacionada indiretamente com as políticas de compensação que são proporcionais ao desempenho.

Por outro lado, sabe-se que a variável carreira exerce um papel fundamental no desenvolvimento pessoal, entretanto esta não será tratada de forma direta, visto que os casos, de micro e pequenas empresas instaladas em parques tecnológicos, analisados possuem pouco tempo de fundação e muitos não apresentam um planejamento de carreira para seus funcionários.

Neste contexto, observou-se que o atributo, reconhecimento, configura-se mais apropriado ao ambiente organizacional estudado, uma vez que visa atender as necessidades pessoais, além de abranger a variável carreira.

Em sua obra sobre a gestão de recursos humanos, Storey (2001) observa que as práticas de recursos humanos configuram um papel estratégico fundamental, uma vez que auxilia na competitividade, por não meramente conforma-se com as regras organizacionais, mas por desempenhar um papel de comprometimento com o trabalhador. Alguns elementos-chave identificados pelo autor que estão diretamente relacionados com as práticas de recursos humanos são: integração de ação e seleção, comunicação, treinamento, recompensa e desenvolvimento. Corroborando com os atributos selecionados anteriormente.

Segundo Nonaka, Peltokorpi e Tomae (2005), a gestão estratégica pode ser vista como um processo mecanicista ou orgânico que corresponde, respectivamente, a escola do posicionamento que produz serviços e produtos baseado na análise de mercado, portanto ambiente externo (PORTER, 2003); e, a visão baseada em recursos (VBR) que prioriza o acúmulo de recursos internos (WERNERFELT, 1984).

Outra perspectiva é a visão baseada no conhecimento, tratada no presente trabalho, a qual analisa que tanto os fatores exógenos (externos) quanto endógenos (internos) devem ser considerados na estratégia. A cultura, as práticas de recursos humanos e os sistemas de 
informação estão mais relacionados com fatores endógenos a organização. Neste âmbito, observa-se a necessidade de compreensão de algum fator do ambiente externo, constituído por multivariáveis, para caracterizar a visão baseada no conhecimento.

Assim, analisar-se-á o relacionamento dos fatores endógenos (cultura, práticas de recursos humanos e os sistemas de informação) com o processo de gestão de conhecimento, SECI, que considera não apenas os processos inerentes a organização como os mecanismos de transferência externa, a partir de fornecedores, clientes e parceiros; mas também o processo interno de gestão do conhecimento, mediante o desenvolvimento de práticas que promovam um ciclo contínuo de ampliação do conhecimento.

O processo de gestão do conhecimento, por sua vez, inclui os atributos apresentados no Quadro 2 do capítulo anterior, que são necessários à gestão sistemática e deliberada da construção do conhecimento, renovação e aplicação (WIIG, 2003).

Na visão de Nonaka e Toyama (2005), uma empresa pode criar novo conhecimento e habilidades que vão além do ponto de equilíbrio de sua capacidade de síntese, a qual está incorporada na visão de conhecimento da empresa (cultura), no $b a$, nos sistemas de incentivo e distribuição de liderança.

Neste contexto, a fim de adequar a empresa estrategicamente no desenvolvimento de uma gestão do conhecimento mais efetiva, o Quadro 4 apresenta uma síntese dos fatores do processo SECI e as dimensões estratégicas que serão consideradas ao longo do estudo empírico. 


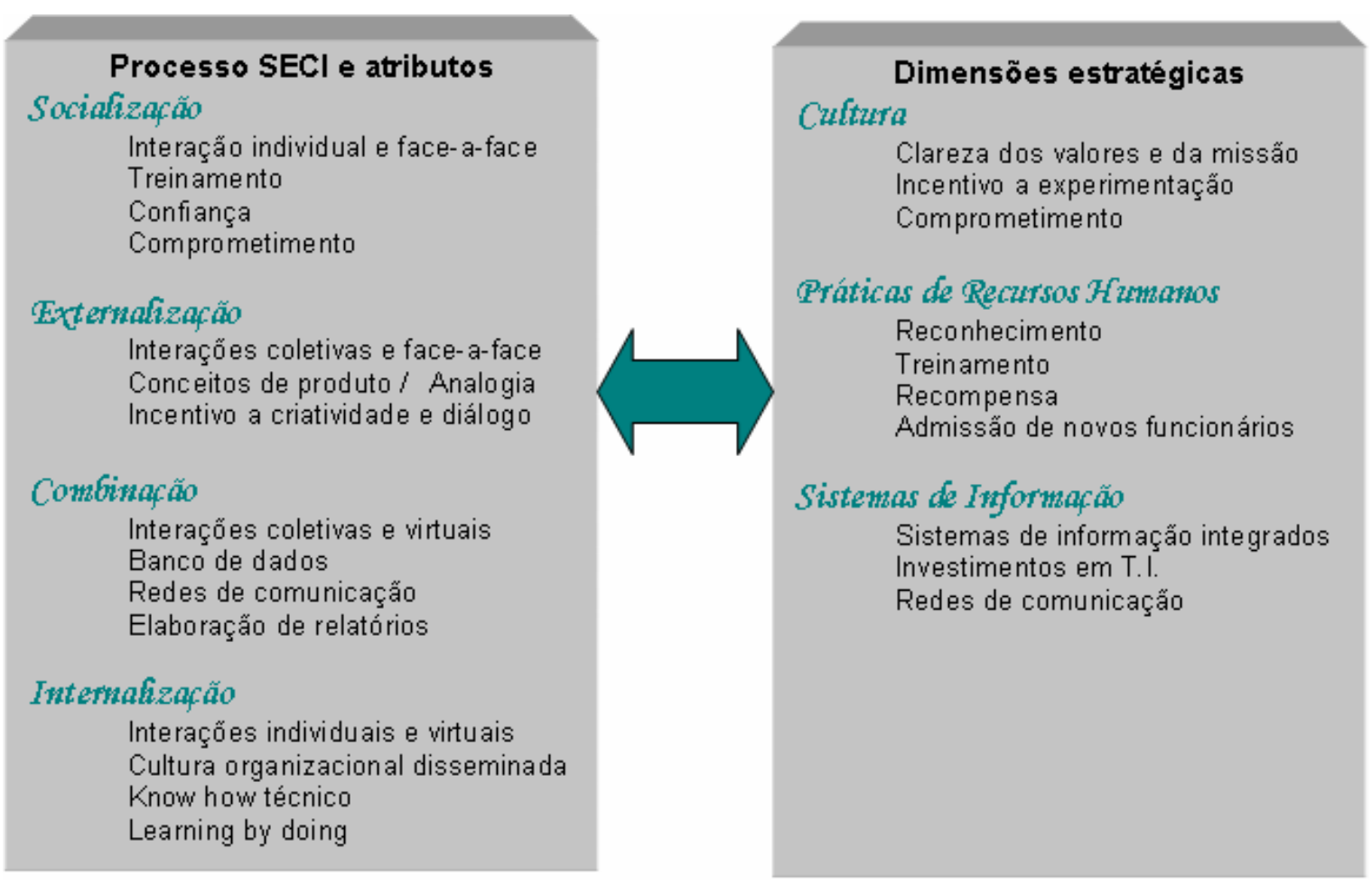

Quadro 4: Relacionamento entre os fatores do processo SECI e as dimensões estratégicas

O Quadro 4 configura o relacionamento que provém de um cruzamento entre os fatores do processo SECI e as dimensões estratégicas, por isso o duplo sentido de relação indicado pela seta que os relacionam.

Uma vez identificado as principais variáveis do processo SECI, bem como as estratégicas, valendo-se da literatura especializada, encerra-se a primeira fase deste trabalho. Neste âmbito, a segunda fase caracteriza-se pela apresentação do capítulo quatro que enfatiza o método de pesquisa, expondo o tipo de pesquisa, análise, escolha da amostra e a técnica de coleta de dados utilizada. Os quais viabilizarão a terceira fase deste trabalho, permitindo a avaliação do grau de relacionamento entre as variáveis apresentadas no Quadro 4, por meio da análise quantitativa denominada análise de correlação. E, por fim, na última fase, capítulo seis, encontra-se os principais resultados obtidos na pesquisa e as suas limitações. 


\section{MÉTODO DE PESQUISA}

Este capítulo apresenta o método de pesquisa; caracteriza o ambiente em que foi realizada a pesquisa de campo, denotando algumas de suas peculiaridades; descreve as questões secundárias de pesquisa necessárias à conclusão do problema central; e indica os principais temas pesquisados. Não obstante, são apresentados: a técnica para coleta de dados e, por fim, a análise empregada e interpretação dos resultados.

\subsection{Caracterização da Pesquisa}

A análise do relacionamento entre os fatores relativos a gestão do conhecimento e as dimensões estratégicas em empresas residentes em parques tecnológicos é uma tema pouco explorado na literatura, caracterizando uma pesquisa exploratória e descritiva, seja por realizar descrições categóricas da situação, visando descobrir as relações existentes entre os elementos componentes da mesma, bem como explorar um assunto pouco abordado, medindo as características descritas nas questões de pesquisa (CERVO E BERVIAN, 1983; DANE, 1990; GIL, 2002; HAIR JR et al., 2005; LAKATOS e MARCONI, 1992).

O delineamento da pesquisa é um estudo de casos múltiplos em virtude dos seguintes aspectos: primeiro, porque o problema de pesquisa remete a forma do tipo "como", considerando um conjunto contemporâneo de acontecimentos sobre o qual a pesquisadora tem pouco controle; segundo, por investigar, a gestão estratégica do conhecimento, uma temática contemporânea, em empresas residentes em parques tecnológicos, dentro do contexto da vida 
real, em que os limites entre o fenômeno e o contexto não estão claramente definidos, tendo em vista a carência de literatura sobre a temática; ademais, almeja-se investigar a fundo o processo de gestão do conhecimento para fins estratégicos, corroborando novamente com a utilização de estudo de casos (YIN, 2004).

A Associação Nacional de Entidades Promotoras de Empreendimentos de Tecnologias Avançadas - ANPROTEC (2003) define parque tecnológico como um organismo gerenciado por profissionais especializados que objetivam fundamentalmente incrementar a riqueza da sua comunidade por meio da promoção da cultura, inovação e competitividade das empresas e instituições geradoras de saber instaladas no Parque ou associadas a ele.

Para isso, um Parque Tecnológico deve: estimular e gerenciar a transferência de conhecimento e tecnologia entre as universidades, instituições de pesquisa, empresas e mercados; incentivar a criação e o crescimento de empresas inovadoras por intermédio de mecanismos de incubação e de spin-off, e oferecer outros serviços de alto valor agregado bem como espaço e instalações de alta qualidade.

Segundo Plonski (1998), “a cooperação é o eixo estruturante para a sustentabilidade da sociedade contemporânea, como contraponto a competição, que por vezes parece ser o valor supremo da sociedade". Afirma ainda que a cooperação é constituída num dos componentes básicos da estratégia das organizações no seu processo de desenvolvimento institucional.

O Estado de São Paulo possui quatro parques tecnológicos, ANPROTEC (2004), dentre aqueles em projeto, implantação e operação: o SPTec Parque Centro Incubador de Empresas Tecnológicas (Cietec), localizado na cidade de São Paulo; o Parque Tecnológico UNIVAP, residente na cidade de São José dos Campos; a Fundação Parque de Alta Tecnologia de São Carlos (ParqTec), localizado na cidade de São Carlos; e, Cia. de Desenvolvimento do Pólo de Alta Tecnologia de Campinas (Ciatec), localizado na cidade de Campinas. 
Em princípio, a presente pesquisa visou abranger uma amostra de três parques tecnológicos: Cietec, Ciatec e o ParqTec por possuírem o maior número de empresas instaladas, possibilitando um maior poder para generalizações dos resultados obtidos no que concerne aos parques tecnológicos; entretanto após contatar empresas instaladas no Cietec, observou-se que a grande maioria das empresas era composta por apenas um pessoa, era o proprietário quem exercia tanto as atividades operacionais quanto administrativas, neste âmbito seria inexequiível falar sobre gestão do conhecimento, em que as interações humanas internas é uma das alicerces da teoria, além do que as empresas que possuíam um número maior de funcionários não se dispuseram a participar da pesquisa. O Parque Tecnológico UNIVAP, por sua vez, encontra-se em implantação, e as poucas empresas instaladas também são compostas por uma pessoa.

Dessa forma, a pesquisa foi realizada junto às empresas residentes em dois dos parques tecnológicos do Estado de São Paulo: Cia. de Desenvolvimento do Pólo de Alta Tecnologia de Campinas - Ciatec; e Parque Tecnológico de São Carlos - ParqTec, o que possibilitou a comparação entre os dois grupos de empresas (Ciatec e ParqTec) no que se refere a gestão do conhecimento. Esses parques são essencialmente de base tecnológica representando, em 2004, 94\% do total de parques brasileiros (em projeto, implantação e operação) (ANPROTEC, 2004).

A escolha de uma amostra de pesquisa constituída por empresas residentes em Parques Tecnológicos remete a magnitude de conhecimento incorporado nestes, tratam-se de empresas que estão constantemente inovando, formada em sua maioria por pessoas altamente especializadas em sua área de atuação, ademais há transferência continua de conhecimento universidades-empresas devido ao contexto em que estão inseridas. Não obstante, sabe-se que diferenças estruturais, pessoal e gestão, entre outras são comuns entre as empresas, e a 
abordagem quantitativa desta pesquisa permitiu visualizar a existência ou não de diferenças significativas entre as empresas pesquisadas.

A amostra absorveu todas as empresas instaladas nos Parques Tecnológicos investigados, nestes existem as denominadas incubadoras de empresas entidades físicas onde são instaladas as empresas nascentes as quais tem por função prover um contexto favorável ao desenvolvimento destas empresas; e, aquelas empresas que quando ingressaram nos parques tecnológicos já existiam em um outro ambiente. Dessa forma, a amostra envolveu tanto as empresas nascentes quanto as existentes instaladas nos Parques Tecnológicos pesquisados.

Tendo em vista, o tamanho da amostra de empresas optou-se por fazer uma análise quantitativa e qualitativa nas empresas residentes nos parques tecnológicos, justificando-se o objeto de estudo da seguinte forma:

i) a taxa de sucesso destas empresas, isto é, de permanência no mercado das empresas que se tornam graduadas corresponde a 93\%, entenda-se graduadas como organizações que passam pelo processo de incubação e alcançam desenvolvimento suficiente para ser habilitada e sair da incubadora. A empresa graduada pode manter o vínculo com a incubadora ou o parque tecnológico na condição de empresa associada (ANPROTEC, 2002);

ii) as empresas residentes em parques tecnológicos, em sua maioria, pertencem ao universo das MPE's, tendo assim exercendo um papel relevante para a sociedade;

iii) e, o total de empregos gerados por elas corresponde a $42,98 \%$ do total de empregos das empresas associadas, graduadas e residentes a Parques Tecnológicos (ANPROTEC, 2004);

iv) estão inseridas em um mesmo local (Parque Tecnológico), compartilhando de recursos similares, possibilitando uma comparação entre elas.

Com base no tipo de pesquisa, análise escolhida e toda a revisão de literatura apresentada nos capítulos anteriores é possível delinear quais questões de pesquisa são necessárias para a realização deste trabalho e sintetizar os temas abordados. 


\subsection{Questões de Pesquisa}

De acordo com Yin (2004), determinar as questões mais significantes sobre um determinado tópico e obter certo grau de precisão na formulação delas, requer uma boa preparação, neste âmbito a revisão de literatura surge como um recurso fundamental.

Com intuito de não incorrer nestes erros, e visando garantir o estado-da-arte do presente trabalho, foi realizada uma ampla revisão bibliográfica em que se evidenciou os seguintes questionamentos:

- Quais são os principais fatores e atributos que caracterizam o processo de gestão do conhecimento?

- Quais são as dimensões e sub-dimensões estratégicas mais relevantes que de alguma forma estão relacionados com a gestão do conhecimento?

E partir da pesquisa empírica buscou-se responder:

- Como procede o relacionamento entre os elementos identificados na questões anteriores no contexto organizacional das empresas residentes em parques tecnológicos, mediante análise quantitativa?

A partir disso, almeja-se propor mecanismos de gestão estratégica do conhecimento podem ser alternativas viáveis às empresas residentes em parques tecnológicos. Por conseguinte, faz-se a identificação dos temas de pesquisa investigados.

\subsection{Temas de Pesquisa}

Os temas de pesquisa encontrados são:

- Processo de Gestão do Conhecimento: neste projeto, deve ser entendido como a capacidade de uma empresa criar novo conhecimento, difundi-lo na organização como um todo e incorporá-lo a produtos, serviços e sistemas. Mais especificamente, dentro 
do enfoque deste trabalho, esta variável é analisada a tomando-se por base os fatores: processo SECI, $b a$ e os recursos do conhecimento.

- Gestão Estratégica do Conhecimento: significa trabalhar o conhecimento estrategicamente relevante para a empresa, seja por meio de processos externos ou internos das empresas, facilitando esta atividade, apoiando e estimulando o aprendizado individual, amplificando-o, cristalizando-o e sintetizando-o ao nível organizacional através de diálogos, debates e troca de experiências. Esta variável será examinada mediante análise do relacionamento do processo de gestão do conhecimento e as dimensões estratégicas escolhidas: cultura, sistemas de informação e práticas de recursos humanos.

- Características das empresas residentes em Parques Tecnológicos: apresenta peculiaridades como: a gestão centralizada, a pessoalidade, possui o conhecimento científico-tecnológico como principal insumo de produção, dentre outras, que exerce grande influência no processo de gestão do conhecimento. Os fatores que caracterizam esta variável não serão analisados quantitativamente, mas considerados na análise dos resultados, sob o aspecto qualitativo.

\subsection{Amostragem, Coleta e Manejo do Dados}

A população alvo é composta por 39 empresas residentes nos dois parques tecnológicos do Estado de São Paulo explicitados anteriormente. A composição das empresas por parque configura-se do seguinte modo:

i) 23 empresas no Cia. de Desenvolvimento do Pólo de Alta Tecnologia de Campinas (Ciatec);

ii) 16 empresas no Parque Tecnológico de São Carlos - ParqTec. 
Estas empresas foram escolhidas por terem parcerias com centros de pesquisa e universidades, os quais detêm um grande leque de conhecimento; e por serem empresas de inovação, favorecendo o processo de criação do conhecimento. Além do que estes são os dois parques tecnológicos mais consolidados do Estado de São Paulo, acarretando em empresas constituídas por um maior número de funcionários, ao contrário de outros parques investigados que em sua maioria eram constituídos por empresas compostas por apenas uma pessoa, inviabilizando o estudo de gestão do conhecimento neste contexto.

Com o objetivo de realizar uma análise quantitativa, foi construído um questionário fechado, Apêndice B, que buscou captar e compreender o processo de gestão do conhecimento, e as dimensões estratégicas, assim empregou-se a escala Likert para mensurar estes elementos. A escala está contida no intervalo de 1 a 7, em que 1 corresponde a discordo totalmente e 7 a concordo plenamente. Com intuito de traçar o diagrama de correlação das variáveis estudadas (G.C. e dimensões estratégicas), estabelecendo o relacionamento entre estas, o questionário foi dividido em três partes: a primeira que caracteriza a empresa e o dirigente; a segunda que evidencia o comportamento das variáveis de gestão do conhecimento, e a última que busca captar o comportamento das dimensões estratégicas.

Cada questão teve por intuito medir um atributo específico, quinze questões medindo o SECI e outras dez questões medindo as dimensões estratégicas. A fim de validar o questionário, denotando até que ponto os constructos estavam medindo o que se esperava, foi realizado um pré-teste do questionário em dez pós-graduandos; mediante estes dados, a confiabilidade do questionário (alpha de Cronbach) para esta amostra foi obtido por meio do software Statistical Package for the Social Sciences (SPSS), resultando num coeficiente alpha de 0,9068 , um resultado excelente perante a literatura, uma vez que quanto mais próximo do valor 1 (máximo) mais confiável a formulação do questionário (HAIR et al., 2005). Vale 
destacar, que todo este processo envolvendo a formulação do questionário, aplicação do préteste e análise da confiabilidade levou aproximadamente um período de mês e meio.

A primeira etapa para coleta de dados consistiu em uma pesquisa realizada junto aos administradores dos parques tecnológicos, busca nos sites dos parques e das empresas residentes, visando obter as informações para estabelecer contato com todas as empresas instaladas no Ciatec e ParqTec.

Identificadas as empresas, foi enviada uma carta de apresentação da pesquisa aos dirigentes das empresas instaladas nos parques tecnológicos, via e-mail, conforme Apêndice A; simultaneamente, foi feito contato com os dirigentes por telefone para frisar o interesse da pesquisa na colaboração deles, e solicitar, em alguns casos, a liberação dos correios eletrônicos das empresas para aceite da carta de apresentação como um documento anexo. $\mathrm{O}$ processo de identificação e contato com as empresas perdurou cerca de dois meses. Além disso, a dinâmica de empresas que se graduaram e ingressaram nos parques foi alta durante este período da pesquisa, o que dificultou o contato com alguns dirigentes.

Após esta etapa, aguardou-se a resposta dos dirigentes sobre a disponibilidade deles em colaborar com a pesquisa, procedeu então a coleta de dados por meio do envio de um questionário fechado, Apêndice B, via e-mail aos dirigentes das empresas. O questionário foi elaborado através da ferramenta formulários do Microsoft Word, a fim de agilizar o processo de preenchimento do questionário, uma vez que muitos dirigentes argumentaram que detinham pouco tempo, foi por esse motivo, inclusive, que a maioria deles não se dispôs ao agendamento de entrevistas que pudesse aprofundar os estudos em gestão do conhecimento. O processo de coleta de todos os questionários enviados teve uma duração de aproximadamente cinco meses.

Com base nas respostas em escala Likert, intervalar, a qual utiliza números para classificar eventos de modo que a distância entre os números esteja eqüiespaçada, foi possível a 
realização de análises, como análise descritiva, análise de correspondência, teste binomial e diagrama de correlação que permitiu avaliar a associação entre as variáveis investigadas (HAIR JR et al., 2005).

Neste âmbito, o tratamento dos dados e análise procede da seguinte forma: na primeira fase, as respostas são sistematizadas permitindo uma análise descritiva, em que é denotado o alfa de Cronbach, que objetiva a validação do questionário; depois os resultados são cruzados, desenvolvendo-se uma análise de correspondência, o teste binomial e análise de correlação. Nesta fase, são expostos: o nível de significância da amostra e a verificação das hipóteses.

Dessa forma, mediante a validação do questionário e posterior tratamento dos dados por meio de análise descritiva, de correspondência, teste binomial e análise de correlação, foi possível analisar todas as variáveis (fatores SECI e dimensões estratégicas) e o seu grau de relacionamento. Desse modo, são apresentados quais elementos estão relacionados ou não com os aspectos estratégicos no ambiente dos parques tecnológicos, permitindo a proposição de mecanismos que contribuam com a gestão estratégica do conhecimento nas MPE's residentes em parques tecnológicos. 


\section{ANÁLISE DA GESTÃo ESTRATÉGICA DO CONHECIMENTO}

Os dados foram analisados, inicialmente, sob a forma quantitativa, com o intuito de demonstrar o grau de relacionamento entre os fatores estratégicos e aqueles relativos à gestão do conhecimento. Foram realizados três tipos de análises: primeiramente uma análise descritiva, visando denotar o comportamento das questões individualmente e validação do questionário através do alpha de Cronbach; posteriormente, foi realizada a análise de correspondência com o objetivo de demonstrar graficamente o comportamento dos atributos investigados perante os dois grandes grupos de empresas pesquisadas do ParqTec e do Ciatec; posteriormente um teste binomial, visando validar ou refutar a hipótese $\mathrm{H}_{0}$ de que as proporções de "discordância", "concordância" e "parcial" são iguais para os Parques de São Carlos e Campinas, ParqTec e Ciatec, respectivamente; e, por fim, foi construído os diagramas de correlação que demonstra a associação entre as variáveis métricas (quantitativas) empregadas.

\subsection{Descrição do comportamento das variáveis}

Após os dados contidos nos questionários serem coletados, foi verificada a integridade e coerência das respostas, uma vez que incoerências como respostas faltantes, mais de uma alternativa assinalada podiam ainda ser corrigidas. Tendo feito esta verificação, o próximo 
passo foi tabular somente as respostas em uma planilha do Statistical Package for the Social Sciences (SPSS).

Dentre as 39 empresas pesquisadas, foi invalidado os questionários em quatro empresas do Ciatec e cinco do ParqTec, pois estas eram compostas por apenas 1 pessoa, impossibilitando as inferências sobre gestão do conhecimento. Em outras cinco empresas do Ciatec não foi possível estabelecer contato, uma vez que os e-mails retornavam e o telefone não foi atendido; e, por fim, quatro empresas do Ciatec optaram por não participar da pesquisa.

Totalizou assim uma amostra restante de 21 empresas, onze empresas instaladas no ParqTec, dez empresas do Ciatec, a taxa de questionários aceitos sobre a amostra inicial de 16 empresas do ParqTec corresponde a 68,75\% e da amostra de 23 empresas do Ciatec é 43,48\%.

Perante as respostas coletadas, obteve-se primeiramente o coeficiente alpha de Cronbach, uma etapa fundamental na primeira fase de análise dos dados, pois se refere a consistência das respostas dos indivíduos em relação a todos os itens investigados, além de não requerer separação de itens nem repetição da aplicação (BLAND e ATLMAN, 1997; SCHMITT, 1996). Foi obtido um alpha equivalente a 0,8426, para um questionário composto por 25 questões e uma amostra de 21 empresas instaladas nos dois parques. $\mathrm{O}$ alpha, que varia de $0 \mathrm{a}$ 1, indica a confiabilidade do questionário, em que um nível aceitável indica que os respondentes se posicionaram de forma coerente mediante as questões, de acordo com Hair et al. (2005) e outros autores, um alpha entre 0,8 e 0,9 possui uma confiabilidade muito boa, o que vêm validar o questionário elaborado nesta pesquisa.

Com isso, construiu-se o histograma para cada variável (questão), obtendo o desvio padrão, média e a frequiência das respostas, neste âmbito foi possível observar uma boa distribuição na freqüência das respostas, não denotando tendências acentuadas. 


\subsection{Mapeamento das percepções dos dirigentes}

A análise de correspondência é uma técnica de análise multivariada, isto é, que analisa múltiplas variáveis em um único relacionamento ou conjunto de relações. A correspondência apresenta-se como uma técnica de interdependência desenvolvida tanto para facilitar a redução dimensional (SECI e Estratégia) da classificação de objetos (os Parques tecnológicos: Ciatec e Parqtec) em um conjunto de atributos (socialização, externalização, combinação, internalização, práticas de recursos humanos, cultura e sistemas de informação) quanto o mapeamento perceptual de objetos relativo a esses atributos (HAIR et al., 2005).

Desse modo, as questões estudadas foram agrupadas em conjuntos de atributos, conforme Tabela 8:

Tabela 8 - Atributos relacionados aos grupos de questões
\begin{tabular}{|l|l|}
\hline \multicolumn{1}{|c|}{ ATRIBUTOS } & NÚMERO DA QUESTÃO \\
\hline Socialização & $1,2,3$ e 4 \\
Externalização & 5,6 e 7 \\
Combinação & $8,9,10$ e 11 \\
Internalização & $12,13,14$ e 15 \\
Cultura & 16,17 e 18 \\
Práticas de R.H. & $19,20,21$ e 22 \\
Sistemas de Informação & 23,24 e 25 \\
\hline
\end{tabular}

A partir deste agrupamento de questões denotados na tabela anterior, foi aplicada a técnica de correspondência, por meio do software The SAS System, que exibe de forma gráfica as respostas dadas grupos de empresas entrevistadas, ParqTec e Ciatec.

Os gráficos demonstram a proximidade ou afastamento dos grupos ( $\mathrm{S}$ - ParqTec e $\mathrm{C}$ Ciatec) sobre determinado atributo, o qual é composto por conjuntos de questões. Por exemplo, R24, $R$ indica resposta de cada empresa tanto do Ciatec como ParqTec, 2 questão número dois e 4 corresponde a escolha do número quatro na escala Likert utilizada no questionário. Vale ressaltar que o estudo sobre a proximidade ou afastamento dos grupos de empresas é realizado visualmente, portanto as análises variam de acordo com a percepção do pesquisador. 
Analisando o atributo Socialização pelo Gráfico 3.

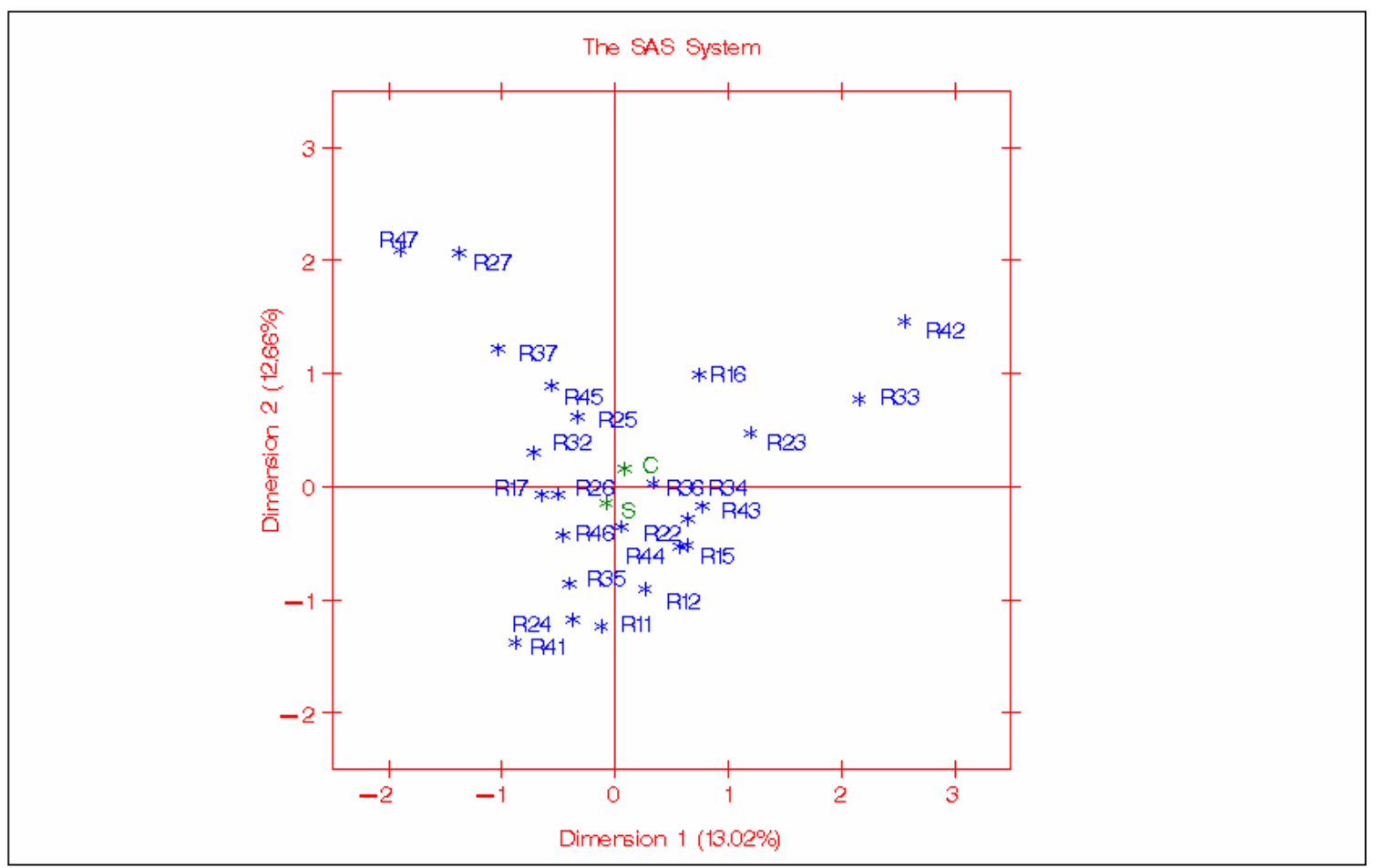

Gráfico 3: Análise de correspondência para a Socialização

A socialização foi caracterizada com base na quantidade de interações individuais e face-aface, no treinamento dados aos funcionários pela empresa, na confiança e no comprometimento dos funcionários em socializar seu conhecimento com a empresa. Pode-se observar que, embora algumas questões apresentem um distanciamento como: a quarta questão, com a R47 e R42, que demonstra um pouco de divergência de opiniões quanto ao comprometimento dos funcionários com as empresas; a terceira questão, R33, por exemplo, quanto à confiança dos funcionários em compartilhar seu conhecimento e a questão 2, por exemplo, R27, no que concerne ao investimento das empresas no treinamento de funcionários. Os parques tecnológicos, Parqtec e Ciatec compartilham, de forma geral, opiniões similares no que concerne ao atributo Socialização, composto pelas questões 1, 2, 3 e 4, uma vez que os resultados obtidos denotam uma proximidade gráfica central entre eles (S e C). 
A externalização, por sua vez, foi analisado a partir das interações coletivas e face-a-face que ocorrem nas empresas, da utilização de conceitos/analogia para o desenvolvimento de produtos, e do incentivo a criatividade e diálogo. Conforme mostra o Gráfico 4, há uma dispersão das questões investigadas e, portanto um afastamento entre os centros dos grupos (ParqTec e Ciatec).

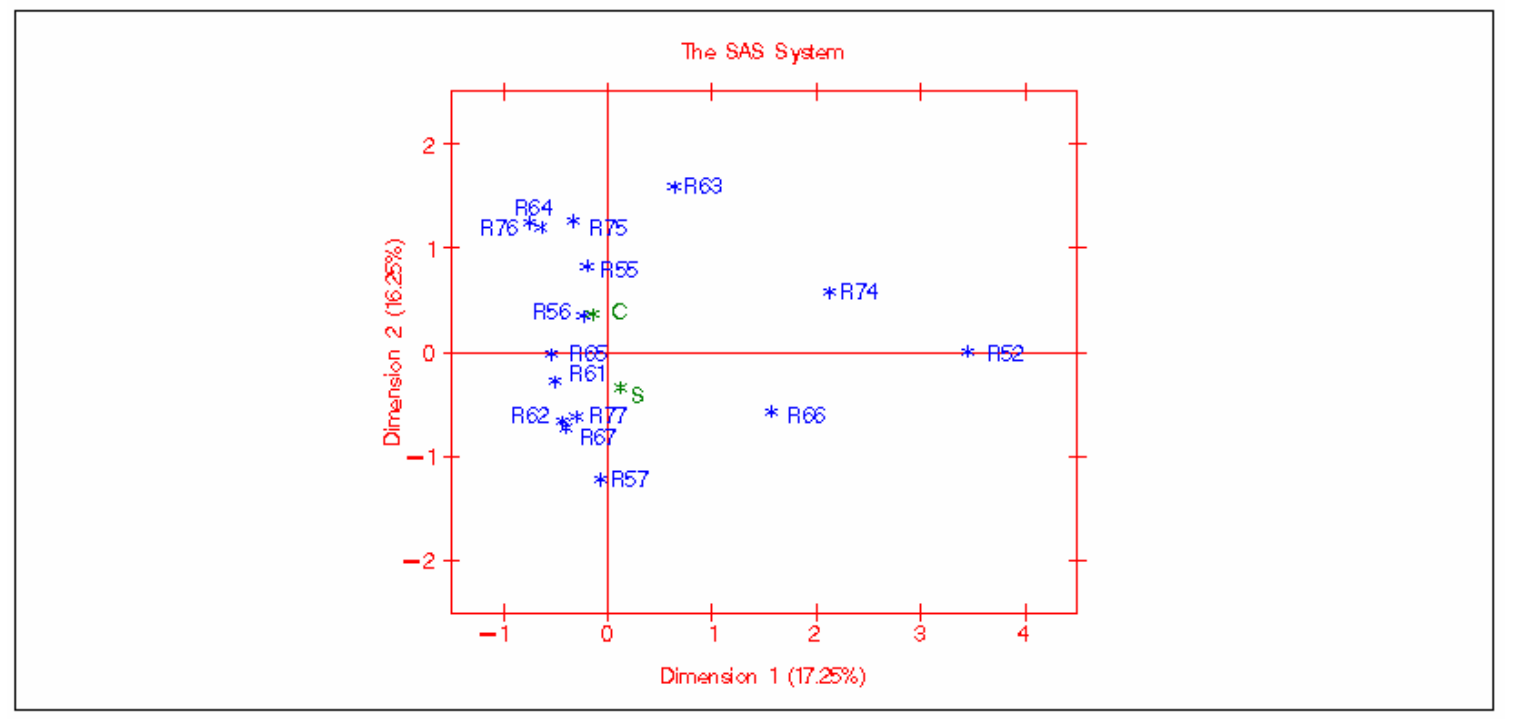

Gráfico 4: Análise de correspondência para a Externalização

Dessa forma, os dois grupos pesquisados compartilham de opiniões um pouco mais diferenciadas quanto ao nível de interações face-a-face, do uso de conceitos e analogias, do incentivo a criatividade e diálogo, representados pelas questões 5, 6 e 7. Provavelmente, isso decorre do fato de que o Ciatec é composto por equipes maiores de funcionários, enquanto o ParqTec é menor, então as interações individualizadas são mais acentuadas, não obstante as empresas do Ciatec, em sua maioria, trabalham com conceitos de produtos tangíveis por serem do ramo eletrônico e biotecnologia, enquanto muitas empresas do ParqTec desenvolvem softwares, dificultando a emprego de analogias.

A combinação apresenta uma dispersão das questões similar a externalização, Gráfico 5, acarretando em centros um pouco afastados entre os grupos pesquisados, as questões que provocaram algumas divergências tinham o objetivo de investigar os atributos: interações coletivas e virtuais, banco de dados, redes de comunicação e elaboração de relatórios. 


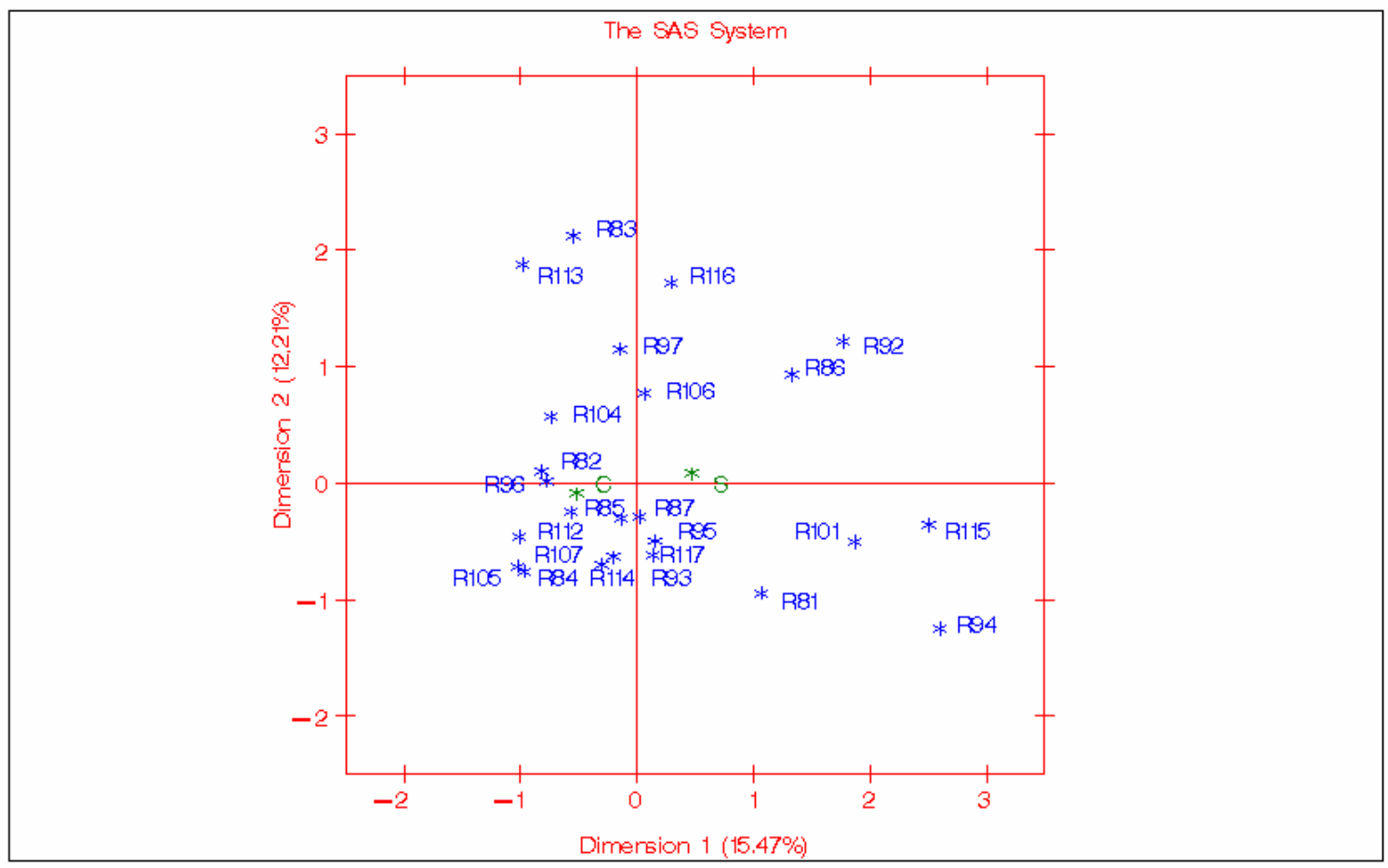

Gráfico 5: Análise de correspondência para a Combinação

As divergências mais acentuadas foram observadas nos atributos: interações coletivas e virtuais, questão 8; a utilização de banco de dados, questão 9; e, a elaboração de relatórios, questão 11. A diferença encontrada nos dois primeiros atributos, provavelmente, ocorreu em virtude do tamanho maior das equipes de trabalho do Ciatec, que viabiliza as interações coletivas e o uso freqüente em ambientes virtuais, entretanto no ParqTec as empresas, em geral, são compostos por poucas pessoas, então o acesso face-a-face entre indivíduos apresenta-se como um mecanismo mais rápido para troca de informações e conhecimento. Já a elaboração de relatórios é uma prática mais estabelecida nas empresas do ParqTec, provavelmente por serem mais antigas e mais estruturadas na gestão de projetos.

Assim como a externalização e a combinação, a internalização apresentou também pouca dispersão nas questões analisadas: 12, 13, 14 e 15, Gráfico 6, demonstrando centros pouco afastados. Os atributos, analisados nas questões de internalização, foram: interações individuais e virtuais, cultura organizacional e disseminada, know how técnico e learning by 
doing, tratam-se de características que almejam investigar a incorporação do conhecimento nas rotinas organizacionais, e nas empresas instaladas no ParqTec isto se verifica de modo mais enfático, provavelmente devido a estrutura mais consolidada das empresas do parque.

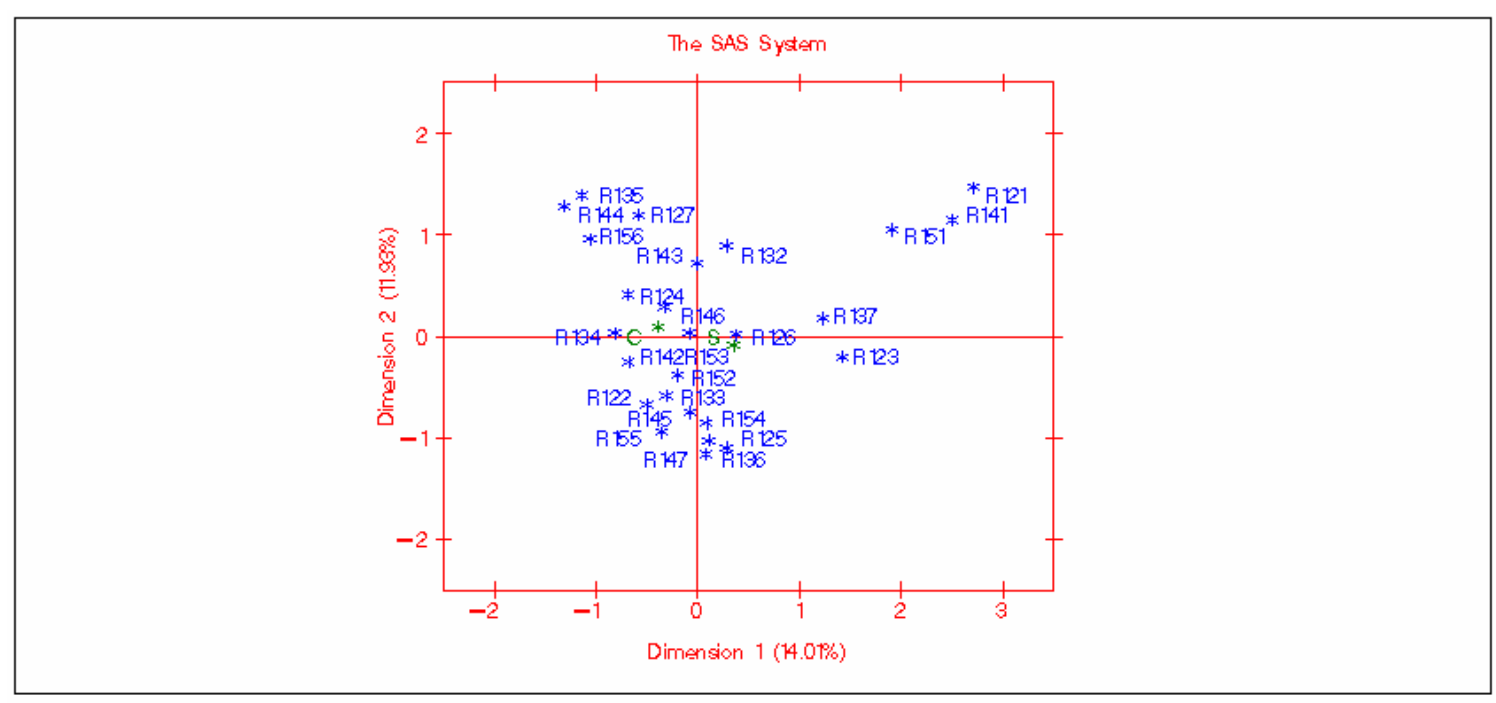

Gráfico 6: Análise de correspondência para a Internalização

No que concerne à análise de correspondência para as dimensões estratégicas: cultura, práticas de recursos humanos e sistemas de informação, o comportamento dos grupos se verifica conforme os Gráficos 7, 8 e 9, a seguir.

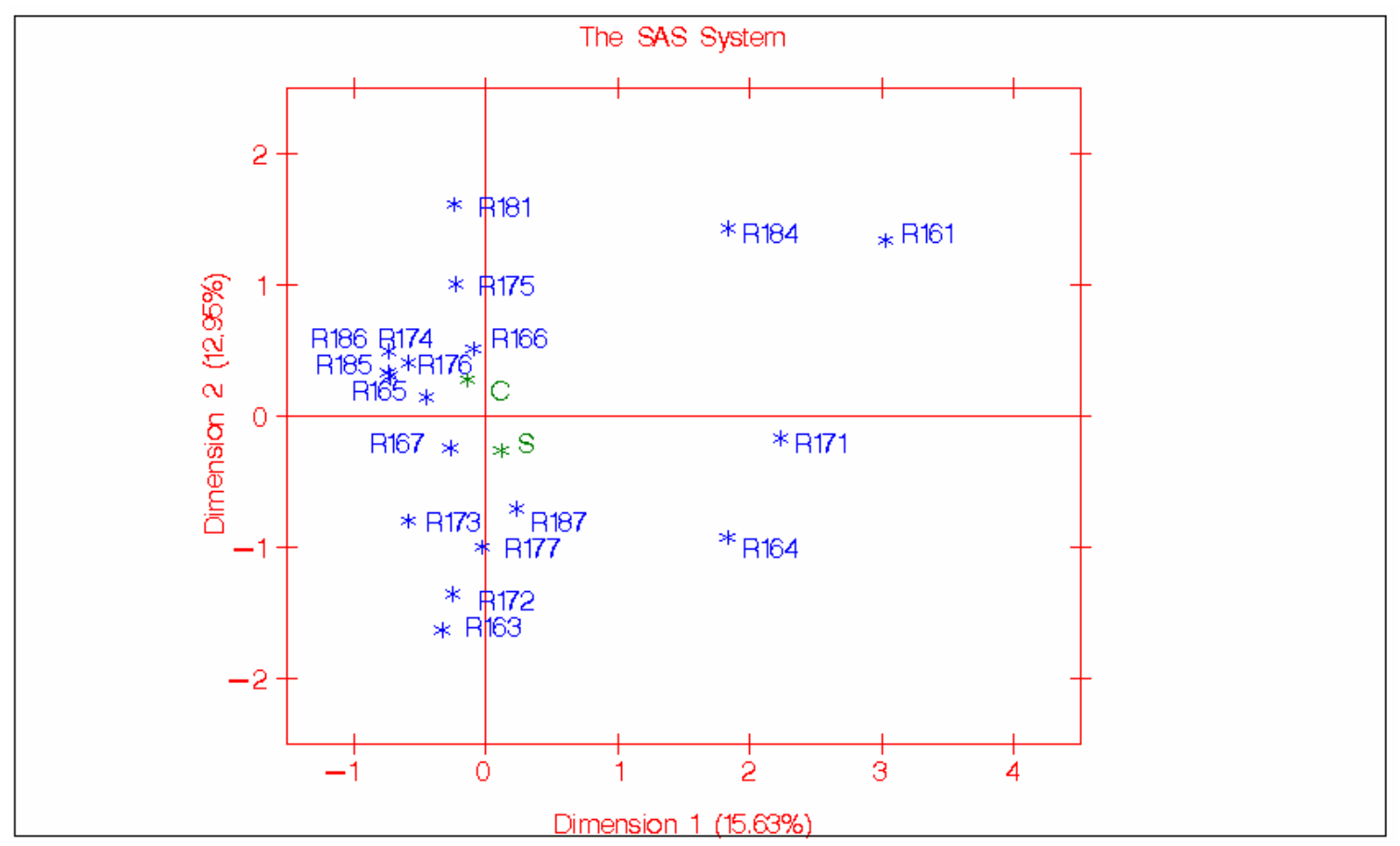

Gráfico 7: Análise de correspondência para a Cultura 
As questões relativas à cultura, apresentam pouquíssima dispersão, Gráfico 7, e portanto uma grande proximidade entre os centros dos grupos investigados, dessa forma é praticamente mínima a diferença entre as opiniões das empresas residentes nos parques tecnológicos. A cultura foi analisada a partir dos atributos: clareza dos valores e da missão, incentivo a experimentação e comprometimento com a organização, aspectos intangíveis que independente da possível dificuldade em diagnosticá-los, apresentaram comportamento similar nos parques, possivelmente decorre do fato de serem ambos os parques de atuação tecnológica, com cultura e valores parecidos.

Denota-se o mesmo para as práticas de recursos humanos, Gráfico 8, em que a dispersão das questões 19, 20, 21 e 22, relativas ao reconhecimento, treinamento, recompensa e admissão de novos funcionários é mínima e os centros pesquisados próximos. Desse modo, as estratégias para gerenciar pessoas são similares nos dois ambientes, provavelmente por terem necessidades de mão-de-obra parecidas.

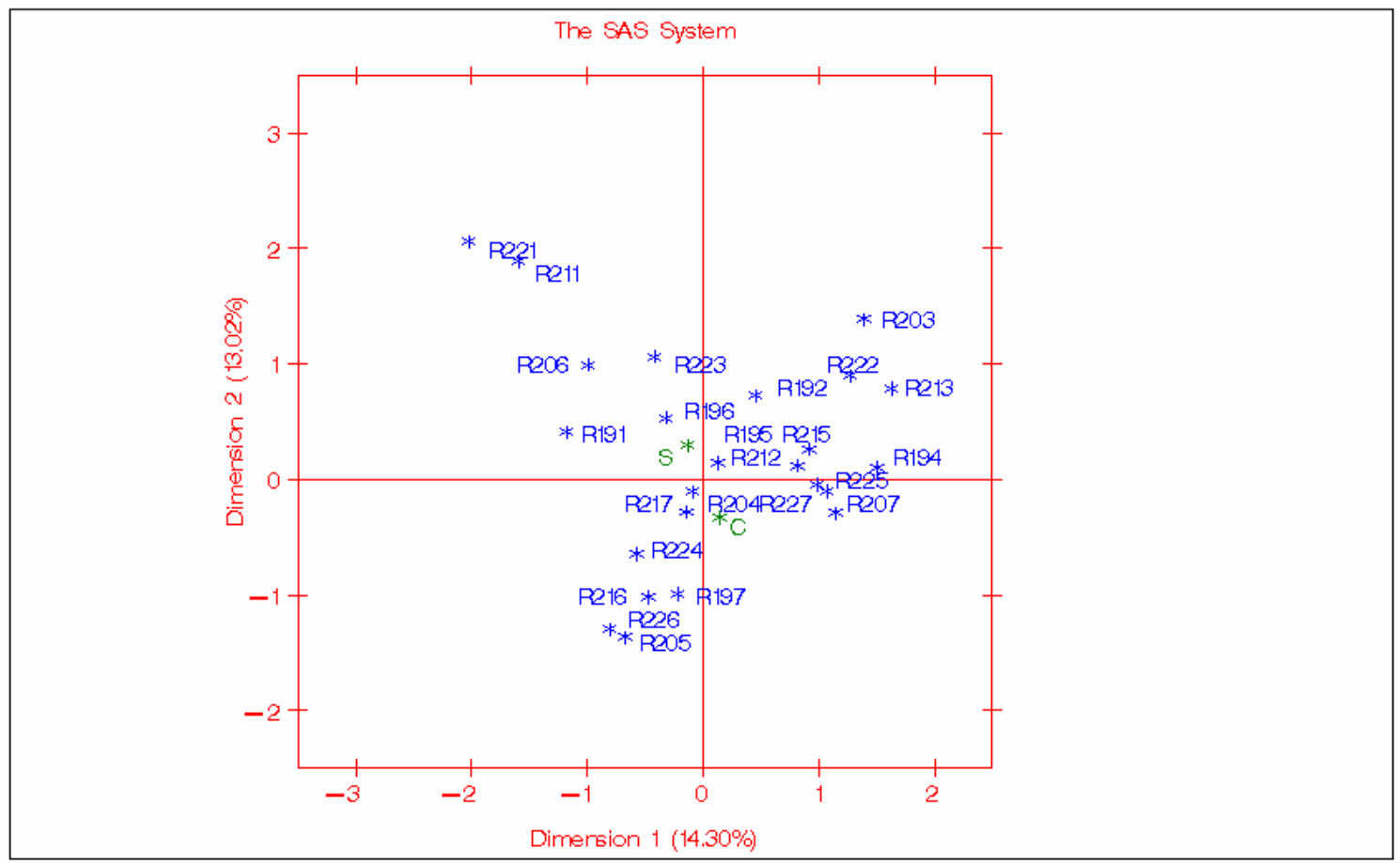

Gráfico 8: Análise de correspondência para a Práticas de Recursos Humanos 
O sistema de informação, por sua vez, foi a dimensão que apresentou maior proximidade entre os grupos investigados, denotando que de modo geral, os parques compartilham a mesma opinião. Foram explorados nesta dimensão, os investimentos destinados as tecnologias de informação e a integração dos sistemas de informação, o que expressou um comportamento similar entre Ciatec e ParqTec devido, provavelmente, a atuação tecnológica de ambas.

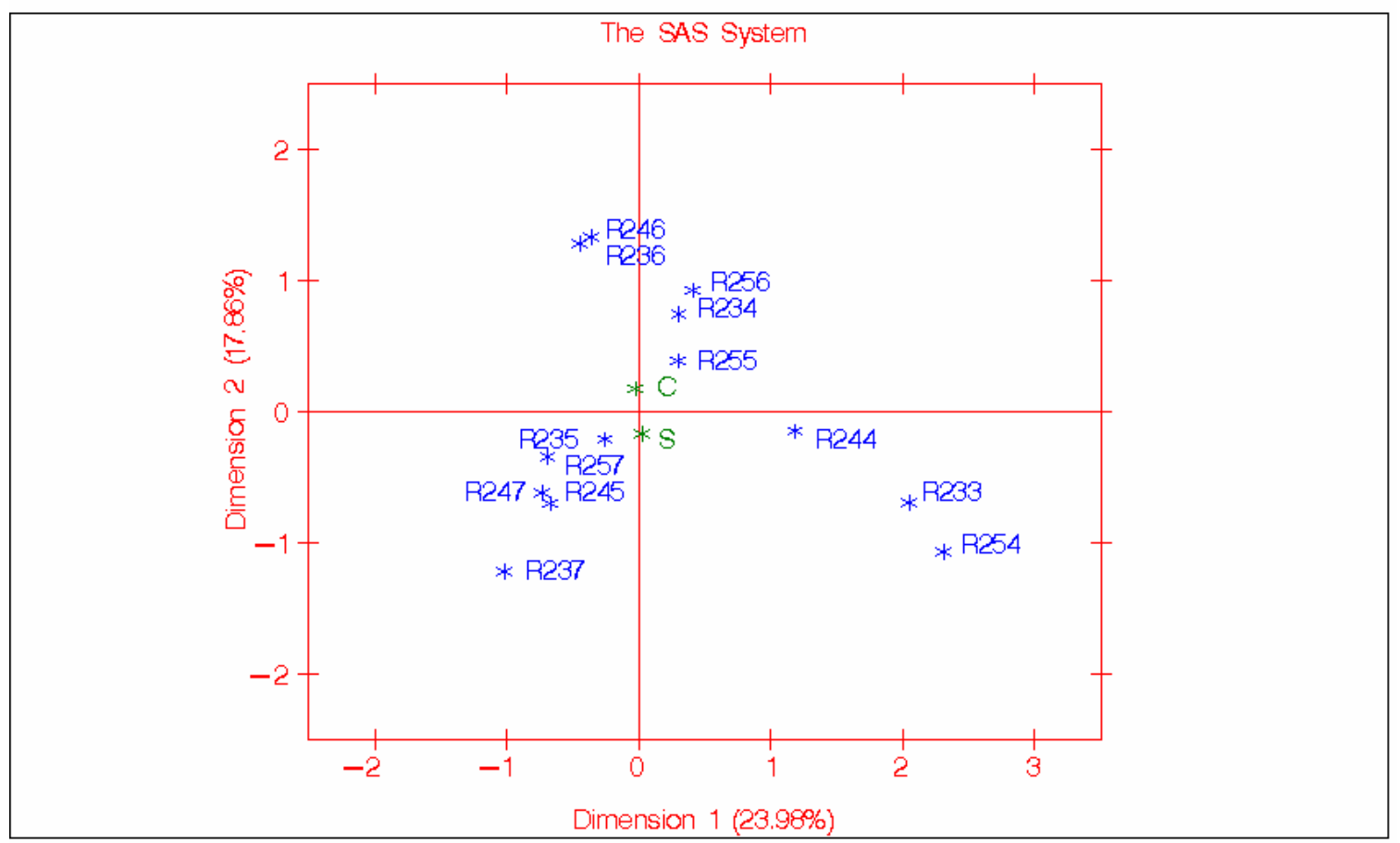

Gráfico 9: Análise de correspondência para os Sistemas de Informação

Denota-se que os atributos que apresentaram maior similaridade de opiniões entre os parques pesquisados foram: socialização e os sistemas de informação, é provável que essa semelhança ocorreu em virtude destes parques serem compostos por empresas de base tecnológica, que requerem uma infra-estrutura parecida, estão inseridas em ambientes similares de mão-de-obra especializada formada em sua maioria por técnicos e engenheiros que possuem um conhecimento tácito acumulado importante, mas que em geral, têm dificuldades em externalizarem o conhecimento individual com os demais. 
No entanto, deve-se ressaltar que o distanciamento entre os grupos para os fatores externalização, combinação, internalização, cultura e práticas de recursos humanos é pouco significativo, uma vez que é a dispersão das respostas não é tão acentuada.

Com intuito de visualizar de forma geral o comportamento de todos os atributos que compõem o SECI e a Estratégia foi realizada uma análise de correspondência total para eles, conforme Gráfico 10 e 11 respectivamente.

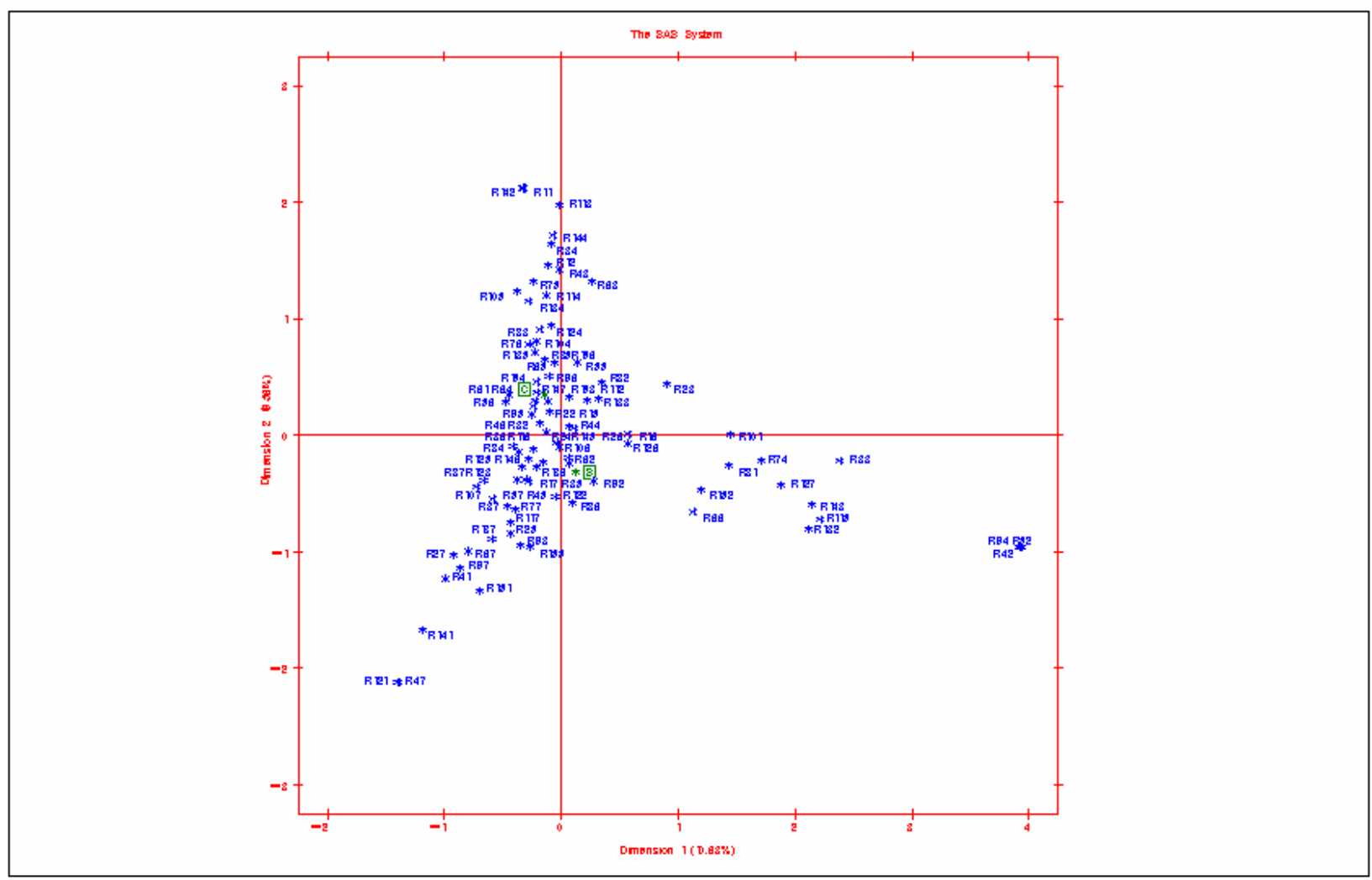

Gráfico 10: Análise de correspondência para SECI

A análise do SECI permite denotar que os parques estão um pouco afastados do centro, mas nada acentuado. Já a análise de correspondência para as dimensões estratégicas apresenta uma proximidade maior do que o SECI, conforme Gráfico 11. 


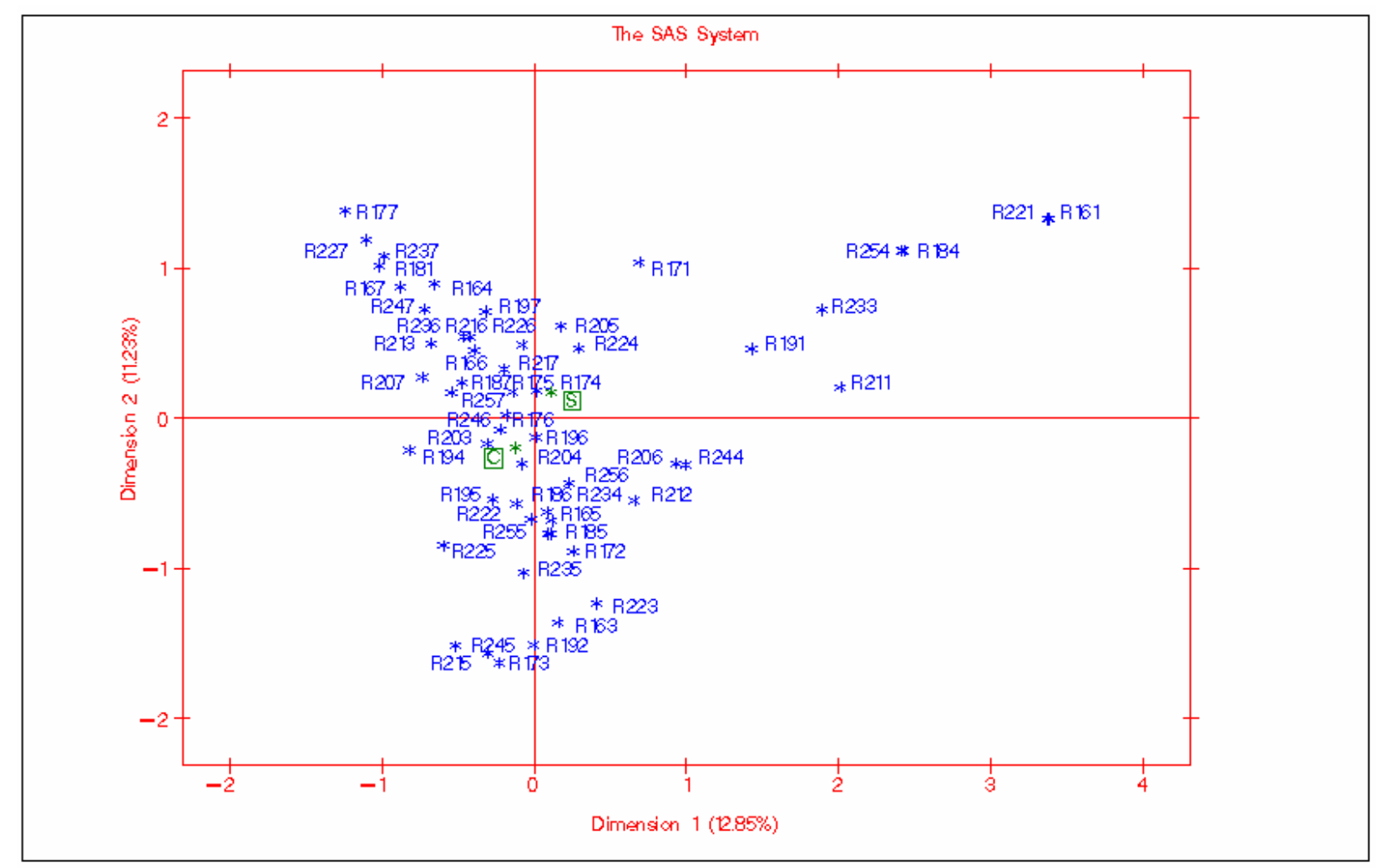

Gráfico 11: Análise de correspondência para Estratégia

Sendo assim, observa-se que os resultados do grupo de empresas investigadas no ParqTec estão muito próximos do outro grupo de empresas pesquisadas no Ciatec, uma vez que a dispersão das respostas dadas as questões não é muito acentuada e os centros destes grupos na representação gráfica estão próximos.

Portanto, a gestão do conhecimento configura-se de modo diferenciado nos dois parques tecnológicos, alguns motivos que explanam este fato são: infra-estrutura diferenciada, diferentes tamanhos de equipes de trabalho e tempo de existência da empresa: empresas nascentes vs. maduras. Por outro lado, as estratégias adotadas referentes a cultura, práticas de recursos humanos e sistemas de informação são semelhantes, possivelmente, em virtude: da área de atuação das empresas, das necessidades similares de mão-de-obra e da infra-estrutura tecnológica análoga.

A análise de correspondência demonstra-se assim como uma forma de visualização geral do comportamento dos objetos investigados, a fim de aprofundar os estudos nas empresas 
investigadas, foi realizado um teste binomial para verificar as diferenças entre os grupos pesquisados.

\subsection{Comparação dos Parques Tecnológicos perante os elementos da gestão estratégica do conhecimento}

O teste binomial é usado para fazer inferências de diferenças entre duas populações baseadas em dados de duas amostras aleatórias. Assim, os dados experimentais utilizados pelo teste são as frequiências relativas p e q referentes às duas alternativas possíveis naquele determinado experimento. A freqüência esperada para $\mathrm{p}$ e q, em caso de igualdade perfeita, seria $1 / 2$ para ambos. Como, num experimento, dificilmente $\mathrm{p}$ é igual a $\mathrm{q}$, o teste avalia, em última análise, até que ponto os valores de $\mathrm{p}$ e $\mathrm{q}$ podem diferir, sem deixarem de ser estatisticamente iguais, dessa forma o teste fornece o $p$-value que informa se a proporção amostral de diferenças é significativa, isto é, se $\mathrm{H}_{0}$ for a hipótese verdadeira (CAMPOS, 2001).

Neste contexto, o teste binomial, através do software Minitab 2000, foi utilizado como método de análise de proporção que compara as visões e opiniões entre os parques diferentes a respeito das mesmas questões, para tanto foi construído as Tabelas 18 e 19 conforme destaca o Apêndice C.

\section{Hipótese Científica:}

$\mathrm{H}_{0}$ : Proporções de "discordância", "parcial" e "concordância" são iguais para os parques de São Carlos e Campinas.

$\mathrm{H}_{1}$ : Proporções de "discordância", "parcial" e "concordância" são diferentes para os parques de São Carlos e Campinas.

Hipótese Estatística: 


$$
H_{0}:\left(\begin{array}{l}
P 1_{p 1} \\
P 2_{p 1} \\
P 3_{p 1}
\end{array}\right)=\left(\begin{array}{l}
P 1_{p 2} \\
P 2_{p 2} \\
P 3_{p 2}
\end{array}\right) \quad H_{1}:\left(\begin{array}{l}
P 1_{p 1} \\
P 2_{p 1} \\
P 3_{p 1}
\end{array}\right) \neq\left(\begin{array}{l}
P 1_{p 2} \\
P 2_{p 2} \\
P 3_{p 2}
\end{array}\right)
$$

Tal que P1 é a proporção de empresas do parque que discordam, P2 é a proporção de empresas do parque com opinião parcial e P3 é a proporção de empresas do parque que concordam.

A Tabela 9 mostra o comportamento de cada questão perante a comparação entre os dois Parques: ParqTec ( $p 1)$ e Ciatec ( $p 2)$.

Tabela 9 - Comparação: Parque de São Carlos e Campinas

\begin{tabular}{lllll}
\hline Questões & p-value P1 & p-value P2 & p-value P3 & Resultado \\
\hline 1 & 0,943 & $*$ & 0,943 & Aceito \\
2 & 0,279 & 0,015 & 0,269 & Rejeito \\
3 & 0,476 & 0,593 & 0,890 & Aceito \\
4 & 0,696 & 0,696 & 0,505 & Aceito \\
5 & 0,329 & $*$ & 0,329 & Aceito \\
6 & 0,407 & 0,476 & 0,801 & Aceito \\
7 & $*$ & 0,476 & 0,476 & Aceito \\
8 & 0,217 & 0,050 & 0,835 & Rejeito \\
9 & 0,034 & 0,329 & 0,015 & Rejeito \\
10 & 0,593 & 0,476 & 0,890 & Aceito \\
11 & 0,020 & 0,314 & 0,284 & Rejeito \\
12 & 0,217 & 0,269 & 0,864 & Aceito \\
13 & 0,072 & 0,476 & 0,256 & Aceito \\
14 & 0,157 & 0,119 & 0,757 & Aceito \\
15 & 0,104 & 0,537 & 0,269 & Aceito \\
16 & 0,314 & 0,943 & 0,407 & Aceito \\
17 & 0,466 & 0,916 & 0,528 & Aceito \\
18 & 0,283 & 0,943 & 0,476 & Aceito \\
19 & 0,696 & 0,943 & 0,757 & Aceito \\
20 & 0,329 & 0,269 & 0,537 & Aceito \\
21 & 0,217 & $*$ & 0,217 & Aceito \\
22 & 0,217 & 0,525 & 0,528 & Aceito \\
23 & 0,593 & 0,916 & 0,757 & Aceito \\
24 & $*$ & 0,757 & 0,757 & Aceito \\
25 & $*$ & 0,943 & 0,943 & Aceito \\
p-value $\leq 0,05$ & & & & \\
O asterisco $(*)$ & representa que as respostas das empresas foram exatamente as & mesmas
\end{tabular}

Observa-se que apenas quatro questões rejeitaram $\mathrm{H}_{0}$, mostrando que as proporções de "discordância", "concordância" e "parcial” são diferentes para os parques de São Carlos e Campinas no que concerne às estas quatro questões. 
As questões rejeitadas foram: 2, 8, 9 e 11 as quais correspondem às variáveis: treinamento, interações coletivas e virtuais, banco de dados e elaboração de relatórios, respectivamente. Pode-se observar que uma delas está inserida na fase de socialização e as demais na combinação.

As empresas residentes no Parque Científico Tecnológico de Campinas - Ciatec demonstraram que a prática de treinamento, por meio de cursos extras são pouco empregadas, provavelmente decorre do fato de serem empresas que tiveram sua fundação recente em relação aquelas do ParqTec, e por isso anseiam que os seus funcionários já tenham uma qualificação alinhada à sua função, sem necessitar de investimentos extras da empresa no treinamento de funcionários. Ademais, o Ciatec é uma fundação recente, denotando uma estrutura que está em crescimento quanto à organização de treinamentos e cursos para as empresas residentes.

As interações coletivas e virtuais, por sua vez são mais empregadas pelo Ciatec, o que pode ser explicado pelo maior número de funcionários das empresas, pois no Ciatec das dez empresas pesquisadas $50 \%$ das empresas possuem mais de cinco funcionários, então as interações coletivas e virtuais tornam-se indispensáveis para a execução dos projetos, dentre as onze empresas entrevistadas do ParqTec, por outro lado, apenas $20 \%$ das empresas possuem mais de cinco funcionários, acarretando interações muito mais individualizadas.

Embora mais de 50\% das empresas instaladas no ParqTec concordem com o acesso ao banco de dados da empresa, as empresas investigadas do Ciatec apresentaram $100 \%$ de utilização dos bancos de dados, o que denotou na rejeição da hipótese $\mathrm{H}_{0}$; o tamanho das empresas segundo o critério por número de funcionário pode explanar este fato, mas é provável que a cultura de incentivo ao acesso aos bancos de dados seja muito mais intensa nas empresas do Ciatec. 
Por outro lado, a elaboração de relatórios é uma prática mais ativa no ParqTec, tornando assim o conhecimento sistematizado disponível para necessidades futuras, evitando a perda de tempo em tarefas que já foram executadas em projetos passados.

O teste binomial permitiu indicar as principais divergências entre as empresas pesquisadas no ParqTec e do Ciatec, observou-se que, assim como na análise de correspondência, as diferenças são poucas entre os dois grupos investigados. Como foi verificado pela indicação do asterisco na Tabela 9 houve seis casos dentre os 75 , correspondendo a $8 \%$ de respostas exatamente iguais entre os Parques, e apenas 5,33\% de questões que demonstraram diferenças entre os grupos. Ademais as variáveis que compõem a fase combinação foram aquelas que geraram o maior distanciamento entre o ParqTec e o Ciatec.

\subsection{Mapeamento da gestão estratégica do conhecimento}

Em administração muitas vezes há o desejo de saber se duas ou mais variáveis estão associadas, o coeficiente de correlação (R) é usado para avaliar esta associação, grande coeficientes indicam uma forte relação, sendo a existência dessa verificada quando uma variável coerente e sistematicamente muda em relação a outra variável, pequenos coeficientes indicam uma fraca relação. A importância desta técnica é que a partir do entendimento da relação entre as variáveis é possível inferir mecanismos administrativos que podem direcionar as práticas mais adequadas ao contexto analisado (HAIR Jr, et al., 2005b).

No presente trabalho foi empregado a análise de correlação de Pearson, por meio do software Statistical Package for the Social Sciences (SPSS), que mensura a associação linear entre duas variáveis métricas (quantitativas), o número que representa esta correlação é denominado coeficiente de correlação $(\mathrm{R})$ e varia de $-1,00$ a $+1,00$, com o zero representando absolutamente nenhuma associação entre as duas variáveis métricas. Embora $-1,00$ ou +1,00 seja possível e represente uma associação perfeita entre duas variáveis, essa forma raramente 
acontece. Os coeficientes podem ser positivos ou negativos, dependendo da relação entre as variáveis, se for positivo mostra que as variáveis apresentam uma relação direta, e se for negativo caracteriza uma relação inversa entre as variáveis (HAIR Jr, et al., 2005b).

Os atributos no presente trabalho são indicados por meio das questões investigadas, portanto os números indicados dentro das circunferências desenhadas nos diagramas correspondem à numeração da questão.

Analisando as correlações entre as variáveis do Parque Tecnológico e Científico de Campinas - Ciatec, que podem ser visualizadas no Apêndice C, Tabela 20, foi considerado que valores maiores ou iguais a $0,8(0,8 \leq \mathrm{R})$ proporcionam uma alta correlação e que valores menores ou iguais a $-0,60(-0,60 \geq R)$ proporcionam uma correlação inversa.

Dessa forma, as Figuras 10 e 11 apresentam o diagrama de alta correlação correspondente para as empresas instaladas no Ciatec.

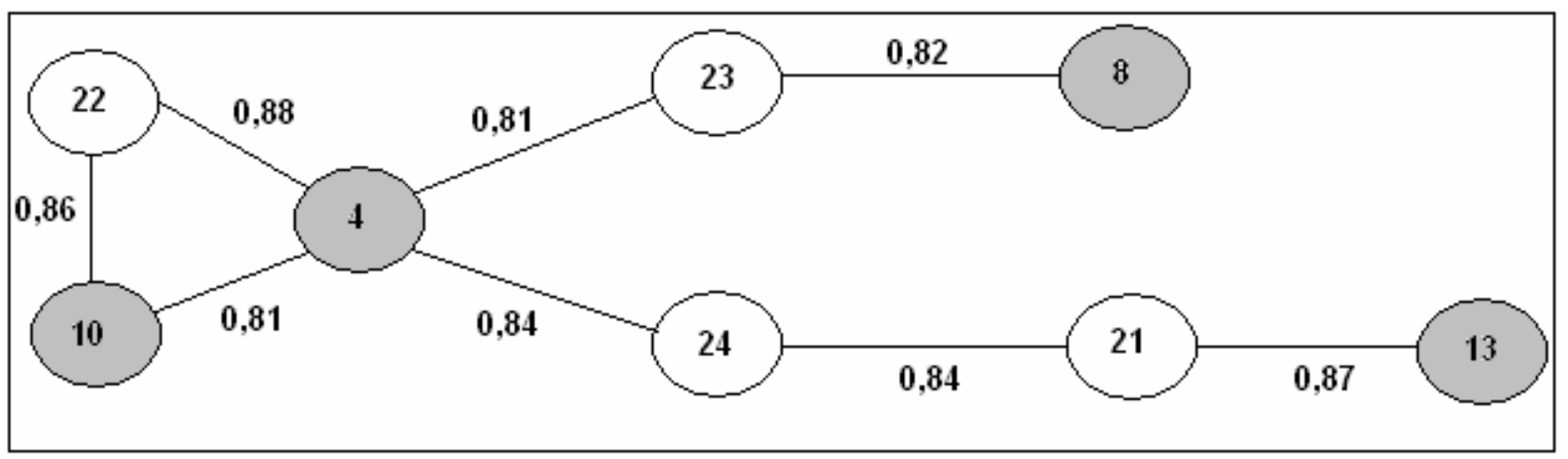

Figura 10: Diagrama de alta correlação entre as variáveis - Ciatec

Com o intuito de discutir os relacionamentos entre os fatores de gestão do conhecimento e as dimensões estratégicas apresentados nos diagramas foram destacadas (em fundo cinza) algumas questões, aqui denominadas questões de correlação que são aquelas inerentes ao processo SECI e é analisado apenas as relações com as dimensões estratégicas, excluindo-se da análise os casos em que há relações entre duas questões referente ao SECI ou duas que constituem as dimensões estratégicas, uma vez que este não é objetivo deste trabalho. 
Por exemplo, na Figura 10, as questões de correlação são: 4, 8, 10 e 13. A variável (ou questão) 4 possui um coeficiente de correlação alto com as dimensões estratégicas: 22,23 e 24. A análise pode ser vista na Tabela 10.

Tabela 10 - Análise das variáveis de alta correlação do Ciatec - Correlação 1

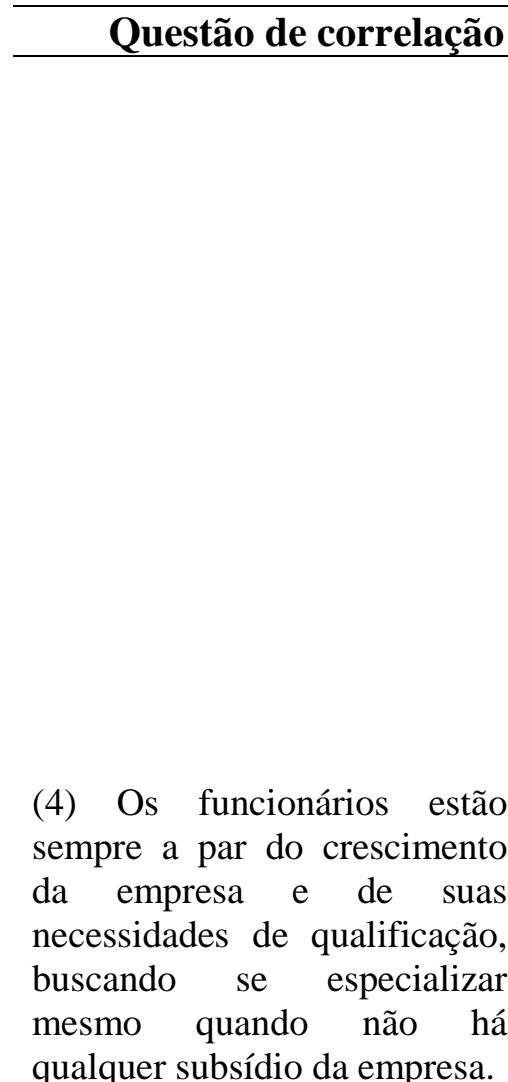

Atributo: Comprometimento Elemento: SOCIALIZAÇÃO

(22) Na contratação busca-se a diversidade (personalidades, experiências, cultura, etc), em detrimento do know how técnico.

Atributo: Admissão de novos funcionários

Elemento: PRÁTICAS DE RECURSOS HUMANOS $\mathrm{R}=0,88$

(23) Todos os sistemas de informação estão integrados, assim é possível que qualquer área da empresa tenha acesso ao conteúdo das demais via intranet.

Atributo: Sistemas de informação integrados

Elemento: SISTEMAS DE INFORMAÇÃO

$\mathrm{R}=0,81$

(24) Um dos maiores investimentos realizados pela empresa anualmente, dedicase aos sistemas de informação.

Atributo: Investimentos em tecnologia de informação

Elemento: SISTEMAS DE INFORMAÇÃO

$\mathrm{R}=0,84$ Análise

Observa-se neste caso uma forte correlação entre o comprometimento e a admissão de novos funcionários, conforme denota Storey (2001) as práticas de recursos humanos configuram um papel estratégico fundamental por exercer o comprometimento com o trabalhador. $\mathrm{O}$ comprometimento dos funcionários na busca de novos conhecimentos pode resultar de uma prática relevante de R.H., ou ainda, ser uma forma de manter-se qualificados.

Neste caso, os sistemas de informação novamente apresentam uma forte correlação com o comprometimento dos funcionários, só que nesta correlação a integração dos sistemas está em pauta, então há necessidade dos funcionários acompanharem $\mathrm{o}$ avanço tecnológico por meio de qualificações.

Os investimentos em tecnologias de informação são indispensáveis no contexto atual, (COWAN, DAVID e FORAY, 2000), empregar estes recursos da forma mais adequada é quesito para os funcionários, é provável que esse seja o motivo pelo comprometimento na busca de novos conhecimentos quando há investimentos em T.I.. 
Embora nesta primeira análise de correlação foram encontradas duas interseções mediante o uso do software, deve-se ter cautela que assim como os outros métodos, o quantitativo também apresenta suas limitações, e as vezes configura correlações que não procedem mediante a literatura, tais como as correlações entre: comprometimento e admissão de novos funcionários; comprometimento e investimentos em T.I., ou ainda comprometimento com sistemas integrados.

Por outro lado, prover uma infra-estrutura apropriada de integração dos sistemas de informação aparece indiretamente na literatura com a necessidade de comprometimento dos funcionários para atentar-se em especializações (DAVENPORT, DE LONG e BEERS, 1998; NONAKA e TAKEUCHI, 1997).

A Tabela 11 mostra a questão de correlação 10 com um grande coeficiente de correlação com a variável 22 .

Tabela 11 - Análise das variáveis de alta correlação do Ciatec - Correlação 2

Questão de correlação Questão de análise Análise

(10) A empresa provê sistemas integrados que incentivam diálogos por meio de intranet $\mathrm{e}$ internet, tais como: e-mails, MSN, CRM.

Atributo: Redes de comunicação

Elemento: COMBINAÇÃO
(22) Na contratação busca-se a diversidade (personalidades, experiências, cultura, etc), em detrimento do know how técnico.

Atributo: Admissão de novos funcionários

Elemento: PRÁTICAS DE RECURSOS HUMANOS $\mathbf{R}=0,86$.
Esta correlação também não está estabelecida na teoria, ela pode ter sido verificada, uma vez que a admissão de novos funcionários com diferentes perfis permite uma renovação e interações mais abrangentes

e por meio das redes de comunicação.

Por outro lado, a Tabela 12, denota forte correlação da questão 21 com a 13 e 24, observe a análise. 
Tabela 12 - Análise das variáveis de alta correlação do Ciatec- Correlação 3

\begin{tabular}{|c|c|c|}
\hline Questão de correlação & Questão de análise & Análise \\
\hline $\begin{array}{l}\text { (13) Todos os funcionários } \\
\text { estão aptos a dizerem se } \\
\text { questionados qual a meta e a } \\
\text { missão da empresa }\end{array}$ & $\begin{array}{l}\text { (21) Existem esquemas de } \\
\text { participação nos lucros, } \\
\text { premiação e recompensas por } \\
\text { resultados e contribuições. }\end{array}$ & $\begin{array}{l}\text { Quando reconhecidos por } \\
\text { meio de recompensas, vigora- } \\
\text { se uma cultura de } \\
\text { comprometimento muito mais }\end{array}$ \\
\hline Atributo: Cultura & Atributo: Recompensa & $\begin{array}{l}\text { KA, } 1994 ; \\
\text { uit }\end{array}$ \\
\hline $\begin{array}{l}\text { organizacional disseminada } \\
\text { Elemento: }\end{array}$ & $\begin{array}{l}\text { Elemento: PRATICAS DE } \\
\text { RECURSOS HUMANOS }\end{array}$ & $\begin{array}{l}\text { SCHEIN, } \\
\text { BEIJERSE, }\end{array}$ \\
\hline INTERNALIZAÇÃO & $\mathbf{R}=0,87$ & KROGH, 1998). \\
\hline
\end{tabular}

A Tabela 13 expõe a alta correlação entre as variáveis 8 e 23, as quais explicadas pela literatura, conforme se segue.

Tabela 13 - Análise das variáveis de alta correlação do Ciatec - Correlação 4 Questão de correlação Questão de análise Análise

(23) Todos os sistemas de Estas questões são fortemente

(8) Na empresa há grupos de discussão os quais se relacionam por meio de ambientes virtuais, tais como: fóruns virtuais e grupos de emails.

Atributo: Interações coletivas e virtuais

Elemento: COMBINAÇÃO informação estão integrados, assim é possível que qualquer área da empresa tenha acesso ao conteúdo das demais via intranet. dependentes, uma vez que para que haja interações coletivas e virtuais é necessário sistemas de informação integrados para Atributo: Sistemas de dar suporte a este processo informação integrados (COWAN, DAVID e FORAY, Elemento: SISTEMAS DE 2000; COHENDET e INFORMAÇÃO STEINMUELLER, 2000; $\mathbf{R}=0,82$ DAVENPORT, DE LONG e BEERS, 1998; NONAKA, UMEMOTO, SENOO, 1996).

A Figura 11 mostra um alto coeficiente de correlação de 0,83 entre as questões 25 e 7, sua análise pode ser vista na Tabela 14 .

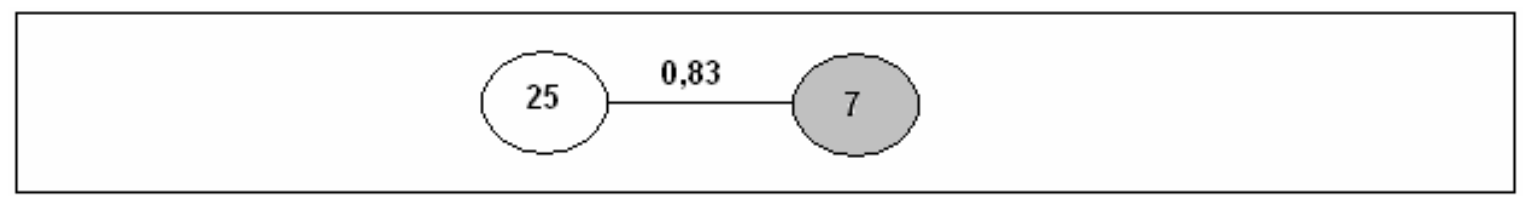

Figura 11: Diagrama de alta correlação entre as variáveis - Ciatec 
Tabela 14 - Análise das variáveis de alta correlação do Ciatec - Correlação 5

Questão de correlação Questão de análise Análise

(7) Novas idéias são (25) A comunicação, por meio Essa correlação se estabelece valorizadas. Há permissão das redes de comunicação, é uma vez que cultura para discussão de novas idéias eficiente em todos os sentidos organizacional viabiliza que a princípio pareçam (de cima para baixo, de baixo valores organizacionais como irrelevantes.

Atributo: Incentivo criatividade e diálogo

Elemento:

EXTERNALIZAÇÃO para cima e entre as diferentes o compartilhamento de conhecimento em todos os áreas) Atributo: Redes de níveis organizacionais e comunicação direções por meio de redes de Elemento: SISTEMAS DE comunicação, que permitem a INFORMAÇÃO experimentação e criatividade, $\mathbf{R}=0,83 \quad$ estabelecendo uma cultura de confiança e liberdade (NONAKA, 1994; SCHEIN, 2001; uit BEIJERSE, 1999; von KROGH, 1998).

É importante salientar que, no caso do Ciatec não houve correlações inversas entre o SECI e as estratégias: cultura, práticas de recursos humanos e sistemas de informação empregadas.

As correlações entre as variáveis do Parque Tecnológico de São Carlos - ParqTec, podem ser visualizadas no Apêndice C, Tabela 21, a fim de comparar a similaridade no relacionamento das variáveis do Ciatec, foi considerado o mesmo intervalo de valores, em que aqueles maiores ou iguais a $0,8(0,8 \leq \mathrm{R})$ proporcionam uma alta correlação e que valores menores ou iguais a $-0,60(-0,60 \geq \mathrm{R})$ proporcionam uma correlação inversa.

Dessa forma, as Figuras 12 e 13 apresentam o diagrama de alta correlação correspondente para as empresas instaladas no ParqTec e as Tabelas 15 e 16 analisam estas relações.

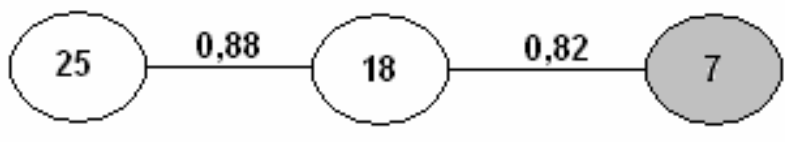

Figura 12: Diagrama de alta correlação entre as variáveis - ParqTec 
Tabela 15 - Análise das variáveis de alta correlação do ParqTec - Correlação 1

\begin{tabular}{|c|c|c|}
\hline lação & lise & An \\
\hline Novas & pessoas & e haver \\
\hline valorizadas. Há permissã & preocupadas & e o \\
\hline $\begin{array}{l}\text { para discuss } \\
\text { que a p }\end{array}$ & suc & diálogo \\
\hline $\begin{array}{l}\text { Atributo: Incentivo } \\
\text { criatividade e diálogo }\end{array}$ & timento & $\begin{array}{l}\text { como uma cultura mais } \\
\text { flexível exerce sobre a }\end{array}$ \\
\hline $\begin{array}{l}\text { Elemento: } \\
\text { EXTERNALIZAÇÃO }\end{array}$ & & $\begin{array}{l}\text { liberdade de expressão } \\
\text { comunicação. }\end{array}$ \\
\hline
\end{tabular}

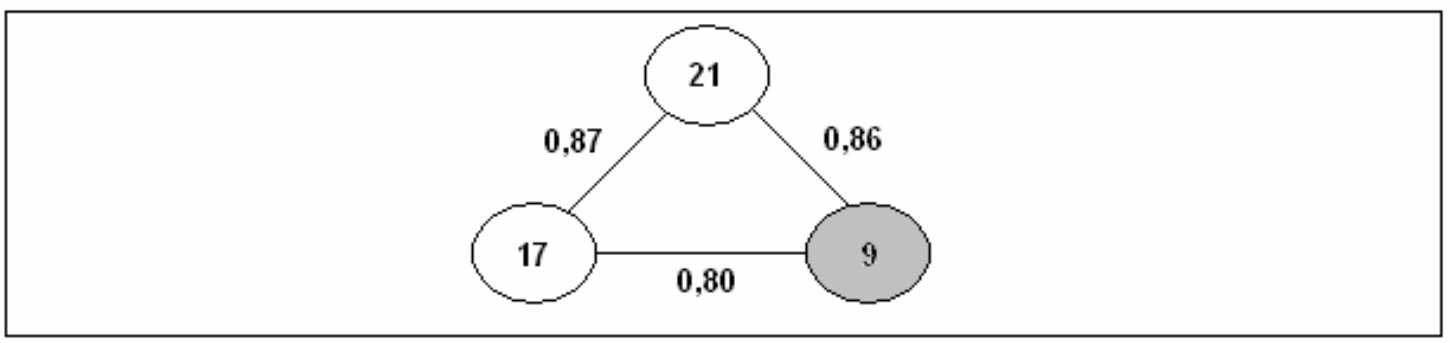

Figura 13: Diagrama de alta correlação entre as variáveis - ParqTec

Tabela 16 - Análise das variáveis de alta correlação do ParqTec - Correlação 2

Questão de correlação

(21) Existem esquemas de $\mathrm{O}$ reconhecimento por meio de participação nos lucros, recompensas acarreta em uma premiação e recompensas por cultura de confiança e resultados e contribuições. liberdade na empresa Atributo: Recompensa (SCHEIN, 2001), Elemento: PRÁTICAS DE configurando um maior

(9) O banco de dados da empresa é intensamente acessado, tanto para armazenar como fornecer dados/informações a todos na empresa.

Atributo: Banco de dados Elemento: COMBINAÇÃO

\section{RECURSOS HUMANOS}

$\mathbf{R}=0,86$

(17) A experimentação é estimulada. Há liberdade para tentar e falhar.

Atributo: Incentivo experimentação

Elemento: CULTURA

$\mathbf{R}=0,80$ compartilhamento de informações e conhecimento via banco de dados.

Esta alta correlação ocorreu, provavelmente, em virtude, da confiabilidade que $o$ funcionário deve ter na empresa para explicitar e deixar registrado seus conhecimentos, permitindo aos demais acessar o seu conhecimento (CARDOSO, 2003).

Ao contrário do Ciatec que não apresentou correlações inversas entre os grandes grupos de variáveis, o ParqTec, Figura 14, apresentou quatro questões (18, 19, 22 e 25) sobre estratégia 
correlacionadas com a variável 12 inerente ao SECI, mais especificamente a internalização (Tabela 17).

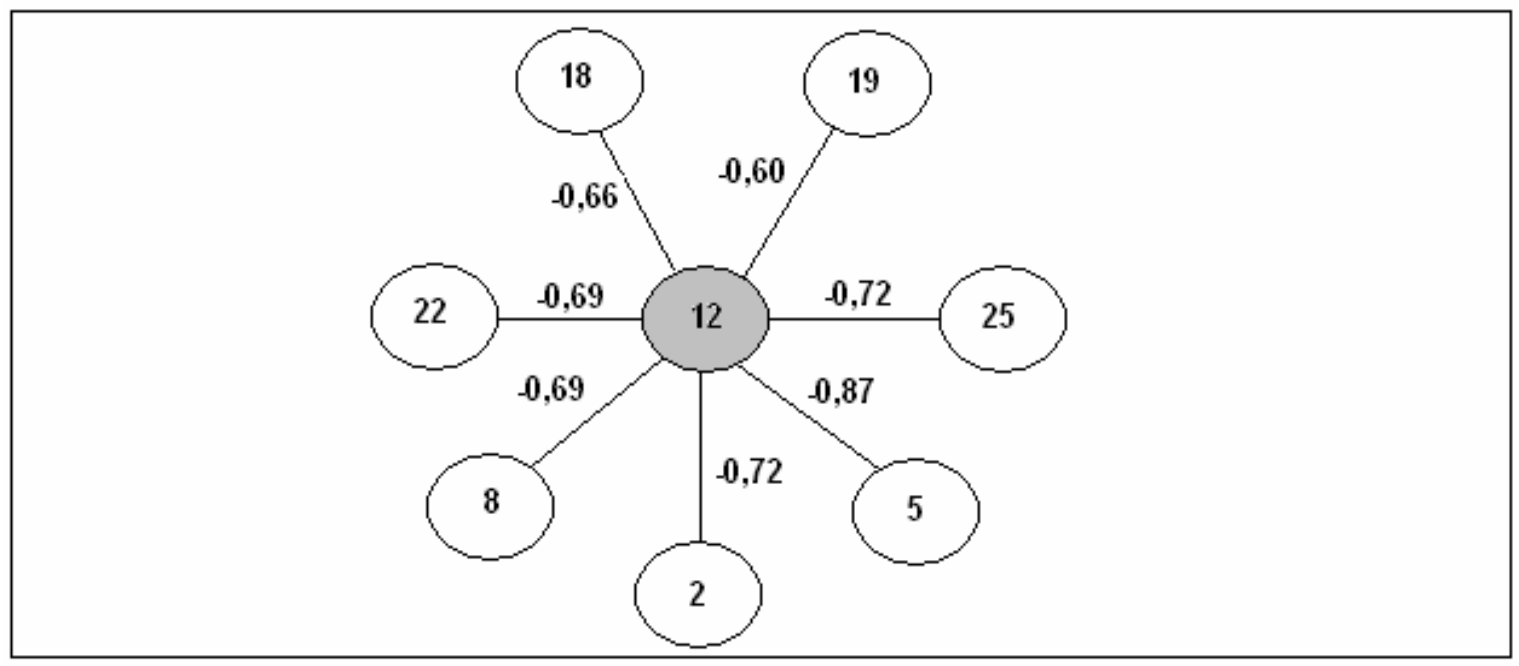

Figura 14: Diagrama de correlação inversa entre as variáveis - ParqTec 
Tabela 17 - Análise das variáveis de correlação inversa do ParqTec

\begin{tabular}{|c|c|c|}
\hline Questão de correlação & Questão de análise & Análise \\
\hline \multirow{3}{*}{$\begin{array}{l}\text { (12) Os ambientes virtuais de } \\
\text { comunicação (intranet, } \\
\text { internet) são utilizados mais } \\
\text { como veículos de } \\
\text { comunicação entre dois } \\
\text { indivíduos ao invés de ser } \\
\text { entre grupos. } \\
\text { Atributo: Interações } \\
\text { individuais e virtuais } \\
\text { Elemento: } \\
\text { INTERNALIZAÇÃo }\end{array}$} & $\begin{array}{l}\text { (18) As pessoas estão } \\
\text { preocupadas com toda a } \\
\text { organização e não apenas com } \\
\text { sua área de trabalho, buscando } \\
\text { soluções conjuntas. } \\
\text { Atributo: Comprometimento } \\
\text { Elemento: CULTURA } \\
\mathbf{R}=-0,66\end{array}$ & $\begin{array}{l}\text { O grande número de } \\
\text { interações individuais } \\
\text { virtuais, ao contrário do que a } \\
\text { teoria de criação do } \\
\text { conhecimento explana está } \\
\text { vinculada neste caso com uma } \\
\text { falta de comprometimento por } \\
\text { parte dos funcionários. }\end{array}$ \\
\hline & $\begin{array}{l}\text { (22) Na contratação busca-se a } \\
\text { diversidade (personalidades, } \\
\text { experiências, cultura, etc), em } \\
\text { detrimento do know how } \\
\text { técnico. } \\
\text { Atributo: Admissão de novos } \\
\text { funcionários } \\
\text { Elemento: PRÁTICAS DE } \\
\text { RECURSOS HUMANOS } \\
\mathbf{R}=-0,69\end{array}$ & $\begin{array}{l}\text { Um menor número de } \\
\text { interações individuais es e } \\
\text { virtuais denota uma maior } \\
\text { prática de admissão de novos } \\
\text { funcionários, é provável que } \\
\text { isto seja realizado no sentido } \\
\text { de renovar as habilidades que } \\
\text { não estão interagindo. }\end{array}$ \\
\hline & $\begin{array}{l}\text { (25) A comunicação, por meio } \\
\text { das redes de comunicação, é } \\
\text { eficiente em todos os sentidos } \\
\text { (de cima para baixo, de baixo } \\
\text { para cima e entre as diferentes } \\
\text { áreas). } \\
\text { Atributo: Redes de } \\
\text { comunicação } \\
\text { Elemento: SISTEMAS DE } \\
\text { INFORMAÇÃO } \\
\mathbf{R}=-0,72\end{array}$ & $\begin{array}{l}\text { A correlação inversa destas } \\
\text { variáveis é peculiar, uma vez } \\
\text { que teoricamente as redes de } \\
\text { comunicação } \\
\text { apresentam uma coveriam } \\
\text { direta com as interação } \\
\text { virtuais, entretanto o inverso } \\
\text { foi verificado. }\end{array}$ \\
\hline
\end{tabular}

Neste âmbito, denota-se que a hipótese 1 dessa pesquisa, descrita no capítulo 1: "uma cultura organizacional comprometida com o crescimento profissional e pessoal do funcionário promove um aumento na confiança dos funcionários para o compartilhamento do 
conhecimento por meio de interações individuais e coletivas, tanto face-a-face, quanto virtual"; é refutada pelo Ciatec, uma vez que das variáveis que apresentaram fortes correlações nenhuma está associada com a cultura, portanto neste parque a cultura não se destaca como elemento essencial para a gestão do conhecimento nas empresas. Entretanto, no ParqTec a variável cultura apresentou-se fortemente correlacionada com a utilização de banco de dados; os dirigentes de forma geral, percebem a necessidade de uma cultura direcionada ao compartilhamento de informações por meio de ambientes virtuais; por outro lado as empresas do ParqTec também apresentaram uma correlação inversa com interações individuais e virtuais em que quanto mais estabelecida uma cultura de G.C. menor o número destas interações, provavelmente isto ocorre devido as interações individuais, que são mais acentuadas quando não há incentivo da cultura organizacional, privilegiando as interações coletivas. Por ser um elemento de natureza intangível a dificuldade em explicitar o valor da cultura organizacional pode acarretar nesta divergência entre os Parques Tecnológicos quanto a esta primeira hipótese.

A hipótese 2, por sua vez, pressupôs que "práticas de reconhecimento, recompensas e de desenvolvimento das habilidades dos membros da empresa por meio de treinamentos promove uma maior socialização, anseio por inovação, aumento da utilização das redes de comunicação e do know how técnico". No Ciatec, as práticas de recursos humanos estão fortemente correlacionadas com as dimensões estratégicas: cultura, sistemas de informação, o que procede segundo Schein (2001) e Storey (2001), a necessidade deste alinhamento entre estas variáveis, a fim de que os indivíduos sintam-se comprometidos com a utilização de seus recursos. Já com as fases SECI, no Ciatec, a correlação se dá apenas com a internalização, percebe-se então a necessidade de práticas que desenvolvam a habilidade de incorporar o conhecimento adquirido em sua rotina (TEECE, 2000; NONAKA e TAKEUCHI, 1997; SCHEIN, 2001). 
As empresas instaladas no ParqTec também relacionam as práticas de recursos humanos com a cultura, remetendo a relevância destacada anteriormente por Schein (2001) e Storey (2001), enquanto a correlação com os fatores de G.C. ocorre apenas com a combinação, observa-se que as práticas de R.H. neste caso, incentivam o uso a base de dados.

A terceira e última hipótese, propôs que "uma infra-estrutura adequada em sistemas de informação com sistemas integrados promove a confiança entre os membros organizacionais para interações virtuais, acesso a banco de dados e armazenamento de informações e conhecimento". Esta hipótese foi refutada apenas pelo ParqTec, no Ciatec os sistemas de informação apresentam forte correlação com a socialização, externalização e combinação, o que era esperado perante a literatura, pois facilitam e agilizam o processo de comunicação por meio dos sistemas integrados e são indispensáveis no armazenamento de conhecimento (COWAN, DAVID e FORAY, 2000; COHENDET e STEINMULLER, 2000; NONAKA, 1994). Os sistemas também aparecem fortemente correlacionados com a cultura, e recursos humanos, o que demonstra a importância dos recursos tecnológicos, o que era esperado, uma vez que o objeto de pesquisa tem atuação tecnológica.

No ParqTec, os sistemas de informação, para o coeficiente de correlação selecionado, não apresentou qualquer correlação, o que refuta a literatura, pois a teoria denota a necessidade dos sistemas de informação subsidiarem as interações virtuais características da combinação e internalização, e com a externalização como ferramentas na criação de conceitos de produtos (COWAN, DAVID e FORAY, 2000; COHENDET e STEINMULLER, 2000; NONAKA e TAKEUCHI, 1997; TERRA, 2001 e TIRPAK, 2005).

Neste contexto, foram analisadas neste capítulo as correlações dos fatores do processo de gestão do conhecimento com as dimensões estratégicas em empresas residentes aos Parques Tecnológicos: Ciatec e ParqTec. Por conseguinte, o capítulo 6 fará as considerações finais sobre a gestão do conhecimento nas empresas estudadas e as características que influenciam a 
gestão estratégica do conhecimento. Serão discorridas as limitações do trabalho e apresentados alguns mecanismos que possam auxiliar na estruturação da gestão do conhecimento a situação peculiar destas empresas pesquisadas, bem como algumas sugestões para futuras pesquisas. 


\section{CONSIDERAÇÕES FINAIS}

Esta pesquisa foi desenvolvida com o objetivo de evidenciar a gestão do conhecimento em empresas instaladas em parques tecnológicos a partir de aspectos estratégicos, almejava-se com isso diferenciar as características inerentes a dois parques distintos: Ciatec e ParqTec, no que concerne à gestão estratégica do conhecimento. Desse modo, foi necessária a identificação perante a literatura dos elementos indispensáveis a esta gestão. Mediante a revisão bibliográfica foi delimitado os seguintes temas de pesquisa: processo de gestão do conhecimento (SECI), gestão estratégica do conhecimento e as características das empresas residentes em parques tecnológicos.

Com intuito de compreender a gestão do conhecimento neste contexto e aprofundar o método de pesquisa em análises quantitativas, os temas de pesquisa: processo de gestão do conhecimento e gestão estratégica do conhecimento; foram caracterizados por atributos. O processo de gestão do conhecimento, por exemplo, foi subdividido em quatro variáveis macros: Socialização, Externalização, Combinação e Internalização, (SECI), caracterizadas pelos atributos: (S) interação face-a-face e individual, treinamento, confiança e comprometimento; (E) interações coletivas e face-a-face, conceitos de produtos/analogia, incentivo a criatividade e diálogo; (C) interações coletivas e virtuais, banco de dados, redes de comunicação, elaboração de relatórios; (I) interações individuais e virtuais, cultura organizacional disseminada, know how técnico e learning by doing. Enquanto, a gestão estratégica do conhecimento foi interpretada perante três dimensões estratégicas: cultura, 
práticas de recursos humanos e sistemas de informação, (Cultura, P.R.H., S.I.), as quais são constituídas por: (Cultura) clareza dos valores e missão, incentivo a experimentação, comprometimento; (P.R.H.) reconhecimento, treinamento, recompensa, admissão de novos funcionários; (S.I.) sistemas de informação integrados, investimentos em T.I., redes de comunicação. E, por outro lado, as características das empresas instaladas nos parques tecnológicos possibilitaram o entendimento de alguns aspectos específicos de gestão divergentes entre as empresas.

Foram estudadas vinte e uma empresas, das quais dez estão instaladas no Ciatec e onze no ParqTec, constatou-se, conforme a análise de correspondência, que de maneira geral não houve grandes disparidades na avaliação dos elementos integrantes do processo SECI e das dimensões estratégicas. O que permite afirmar, no que se refere à gestão estratégica do conhecimento, que o comportamento dos parques é similar, de forma geral.

Entretanto, o teste binomial demonstrou que a intensidade dos atributos: treinamento, interações coletivas e virtuais, banco de dados e elaboração de relatórios, é divergente entre os parques. No atributo treinamento, característico da fase de socialização, foi observado que as empresas residentes no Ciatec demonstraram que a prática de treinamento, por meio de cursos extras são pouco empregadas, provavelmente decorre do fato de serem empresas que tiveram sua fundação recente em relação aquelas do ParqTec, e por isso anseiam que os seus funcionários já tenham uma qualificação alinhada com a sua função, não necessitando de investimentos extras da empresa em treinamento de funcionários. Sem contar de que a maioria das empresas é constituída por pequenas empresas nascentes que buscam em princípio a sobrevivência, portanto os recursos são escassos para investimentos em treinamento (GREINER, 1998; LEONE, 1999). Ademais, o Ciatec é uma fundação recente, denotando uma estrutura de parque que está em crescimento quanto à organização de 
treinamentos e cursos para as empresas residentes ao contrário do ParqTec que está mais consolidado.

As interações coletivas e virtuais, acesso ao banco de dados e elaboração de relatórios constituem a fase de combinação. Foi observado que as interações coletivas e virtuais são mais empregadas pelo Ciatec, o que pode ser explicado pelo número de funcionários das empresas, pois no Ciatec das dez empresas pesquisadas $50 \%$ possui mais de cinco funcionários, então as interações coletivas e virtuais tornam-se indispensáveis para a execução dos projetos, dentre as onze empresas entrevistadas do ParqTec, por outro lado, apenas duas possuem mais de 10 funcionários, acarretando interações muito mais individualizadas.

Embora mais de 50\% das empresas instaladas no ParqTec concordem na importância do acesso ao banco de dados da empresa, as empresas investigadas do Ciatec apresentaram 100\% de utilização dos bancos de dados, o tamanho das empresas segundo o critério por número de funcionário pode explanar este fato, mas é provável que a cultura incentivo ao acesso aos bancos de dados seja muito mais intensa nas empresas do Ciatec.

Por outro lado, a elaboração de relatórios é uma prática mais ativa no ParqTec, tornando assim o conhecimento sistematizado disponível para necessidades futuras, evitando a perda de tempo em tarefas que já foram executadas em projetos passados, atribui-se a isto o fato das empresas do Ciatec, em geral, serem nascentes possuindo uma estrutura pouca formalizada (LEONE, 1999). Desse modo, quanto aos atributos mencionados, a hipótese $\mathrm{H}_{0}$ foi rejeitada, evidenciando proporções diferentes de "discordância", "concordância" e "parcial" entre os parques Ciatec e ParqTec.

A fim de aprofundar os estudos nas correlações existentes entre a gestão do conhecimento e as dimensões estratégicas, foram construídos os diagramas de correlação os dois grupos de empresas, Ciatec e ParqTec, individualmente, apresentados no capítulo 5. Foi considerado que valores maiores ou iguais a 0,8 proporcionavam uma alta correlação e que valores 
menores ou iguais a $-0,60$ proporcionam uma correlação inversa. O que permitiu caracterizar as relações mais destacadas no Ciatec e no ParqTec, conforme Figura 15 e 16.

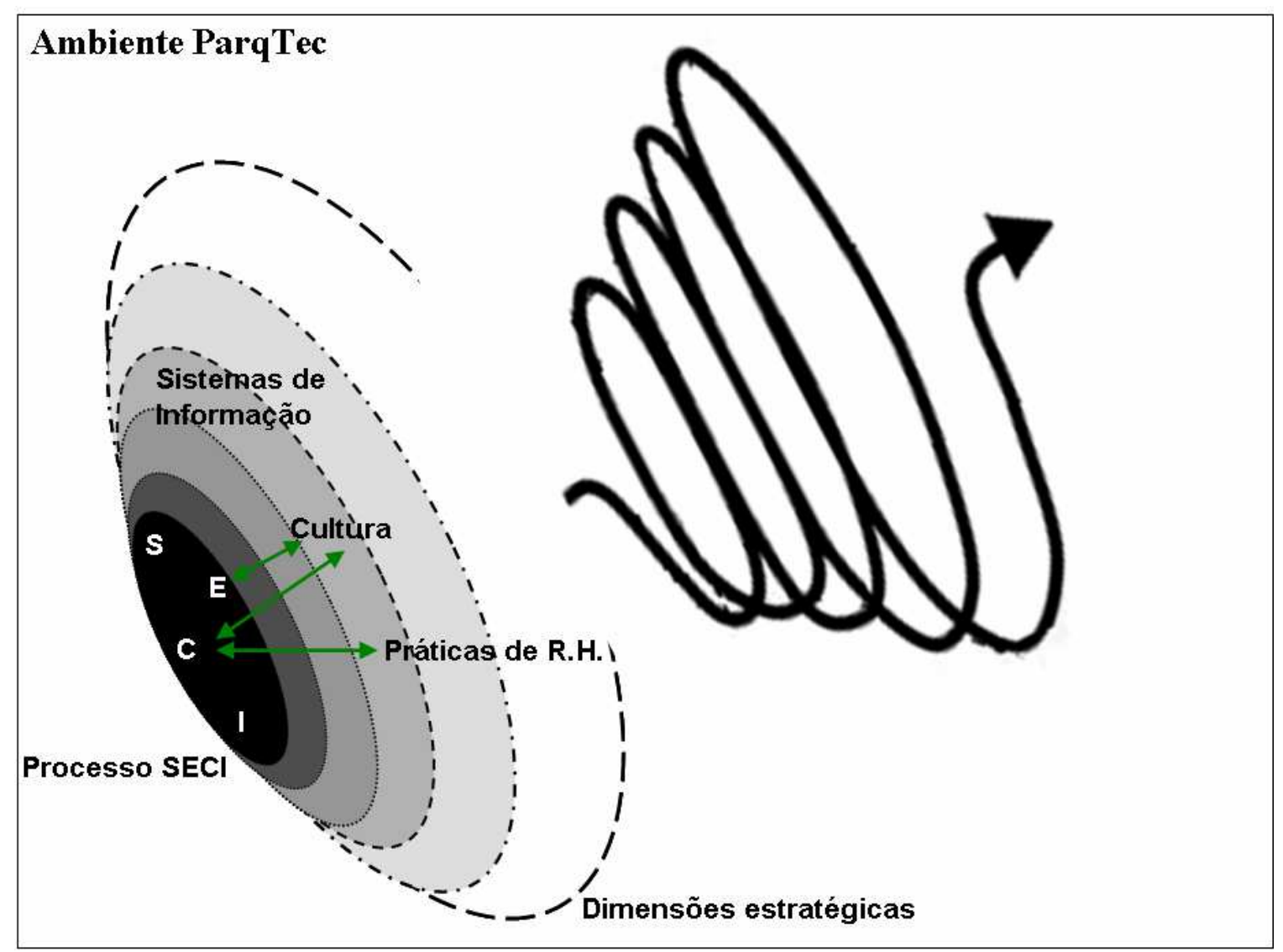

Figura 15: Esquema representativo da gestão estratégica do conhecimento no ParqTec

No ParqTec observa-se que a externalização estabelece uma forte correlação com a cultura por meio dos atributos: incentivo a criatividade e diálogo, e comprometimento, ressaltando assim a importância de uma cultura voltada ao incentivo da transferência de conhecimento.

Por outro lado, a combinação apresentou uma forte correlação com as dimensões estratégicas: recursos humanos e cultura, isso foi verificado a partir da relação do atributo banco de dados com os atributos: recompensa e incentivo a experimentação, respectivos as dimensões mencionadas. Mostrando que para ocorrência efetiva do processo de conversão de conhecimento explícito em explícito por meio de interações coletivas, neste contexto, são essenciais mecanismos de recompensa e liberdade para experimentação. 
Fica claro que, o processo de gestão estratégica do conhecimento, que configura a relação da gestão do conhecimento com as dimensões estratégicas ocorre, com menor ênfase nas empresas do ParqTec se comparado com o Ciatec, tanto por priorizarem apenas alguns fatores do SECI, externalização e combinação, como também por focarem em relações específicas do SECI com as dimensões estratégicas de apoio, em detrimento de mecanismos que incentivem o compartilhamento do conhecimento por meio de interações individuais e face-a-face e que viabilizem a incorporação efetiva do conhecimento adquirido nas rotinas organizacionais. A cultura é a dimensão que exerce um dos papéis mais indispensáveis para o crescimento do ciclo de criação do conhecimento e sua utilização é restrita neste caso, não obstante os sistemas de informação devem fornecer subsídios que viabilizem uma gestão efetiva de conhecimento e estes mecanismos de apoio aparecem pouco empregados.

O Ciatec, por sua vez, Figura 16, apresentou correlações de todas as fases SECI com duas das dimensões estratégicas, distinguindo-o do ParqTec, que apresentou duas fases do SECI correlacionados com apenas duas dimensões estratégicas. 


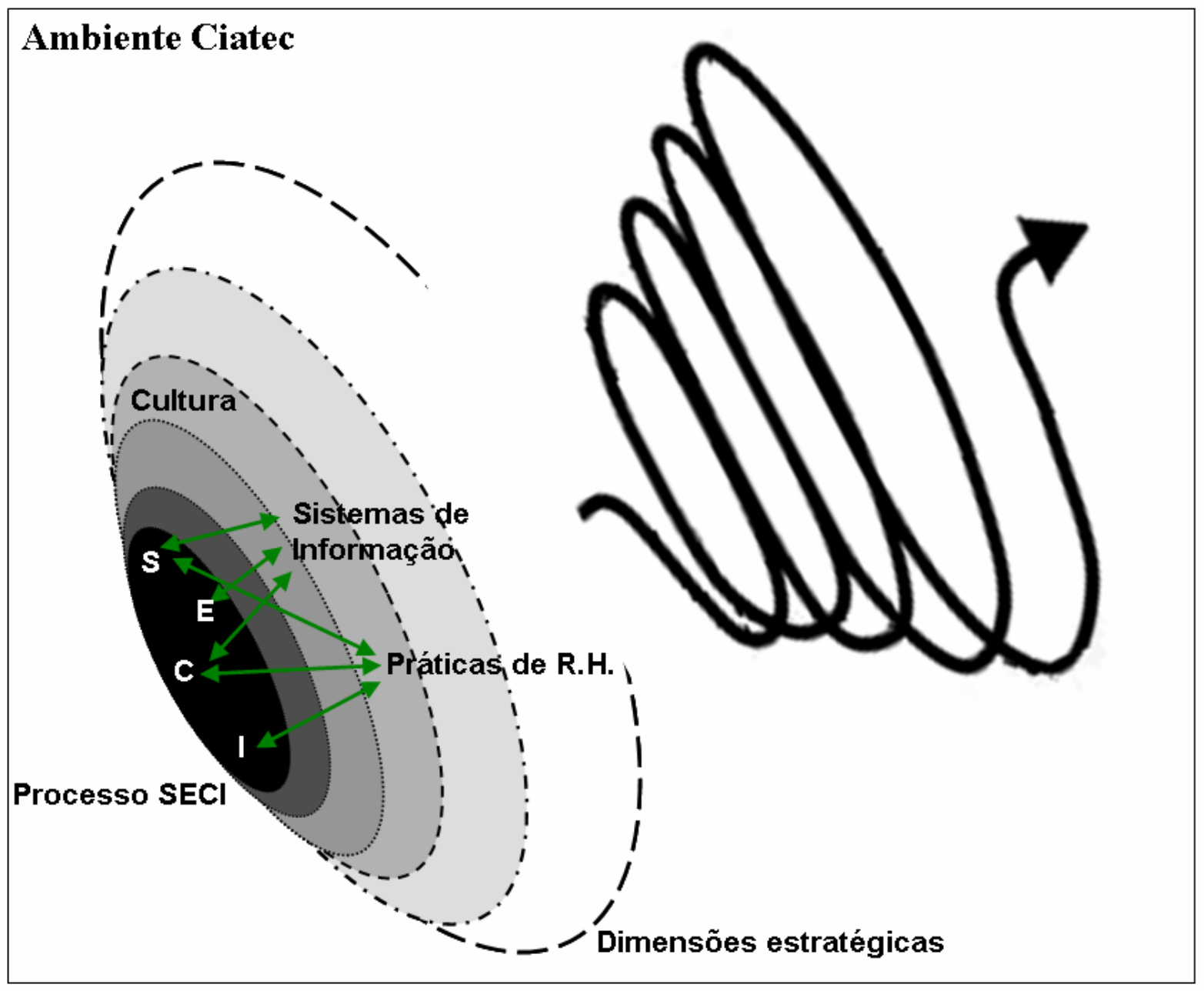

Figura 16: Esquema representativo da gestão estratégica do conhecimento no Ciatec

No Ciatec, a socialização por meio do comprometimento estabeleceu uma forte correlação com os sistemas de informação tanto por meio das redes de comunicação quanto dos sistemas integrados, nota-se a importância do comprometimento nestes ambientes para configuração de comunicação. A socialização também se correlacionou com as práticas de recursos humanos, através dos atributos: comprometimento e admissão de novos funcionários, provavelmente esta correlação é verificada pelo fato de relacionarem admissão de novos funcionários como uma etapa de crescimento da empresa o que torna o comprometimento em disseminar o conhecimento mais acentuado. 
A externalização, por sua vez, correlaciona-se com os sistemas de informação, por meio dos atributos: incentivo a diálogo e redes de comunicação, respectivamente. Interações indispensáveis para compartilhar o conhecimento.

Outro destaque foi o relacionamento da internalização com as práticas de recursos humanos, por meio dos atributos: cultura disseminada e recompensa, denotando que recompensas monetárias vigoram uma cultura de comprometimento muito mais acentuada.

E por fim, a combinação apresentou correlação com as duas dimensões estratégicas: práticas de recursos humanos e sistemas de informação, por meio dos respectivos atributos redes de comunicação - admissão de novos funcionários e interações coletivas e virtuais sistemas integrados.

Desse modo, diferentemente do ParqTec em que há um número menor de relações na gestão estratégica do conhecimento, todos os fatores do processo SECI configuram algum tipo de relação com as dimensões estratégicas: sistemas de informação e práticas de recursos humanos, o interessante é que a dimensão estratégica cultura primária em incentivar o ciclo do conhecimento, foi a única que não estabeleceu ligação com o SECI.

Em ambientes formados em sua maioria por pessoas com estilos muito técnicos, em geral, não priorizam mecanismos intangíveis, como expressão de valores e reconhecimentos; muitas vezes por serem fatores que costumam ter efeito a longo prazo; dessa forma priorizam-se os elementos de suporte a gestão como investimentos nos sistemas de informação que proporciona resultados em um período menor, por exemplo.

Com base, nas diferenças dos esquemas representativos da gestão estratégica do conhecimento em distintos ambientes, é possível denotar alguns argumentos que explicam este comportamento: primeiramente, a heterogeneidade das empresas, uma vez que além de estarem em ambientes distintos que embora possuam recursos similares, apresentam, muitas vezes, diferenças consideráveis em: estilo de gestão, recursos financeiros, tipo de produto ou 
serviço, tipo de processo de desenvolvimento, entre outros aspectos, característicos das empresas. Além do que, a estratégia de muitas das empresas é a sobrevivência do negócio, foi possível observar casos de empresas recém-formadas em que as despesas ainda eram maiores que as receitas, portanto a lucratividade ainda não era uma realidade, dificultando sobremaneira a inferência de práticas como a gestão estratégica do conhecimento que exige um ambiente mais estruturado e consolidado; e, surpreendentemente, apesar destas restrições, inserções informais de mecanismos de gestão estratégica do conhecimento, como a elaboração de relatórios e manuais que contribuem para o armazenamento do conhecimento nestas empresas, e investimento em sistemas integrados de comunicação ocorrem no contexto destas empresas.

Neste âmbito, observa-se que as relações estabelecidas entre o processo de gestão do conhecimento SECI e as dimensões estratégicas são distintas nos parques tecnológicos, embora sejam ambientes (parques) que teoricamente possui algumas características similares, as peculiaridades individuais prevalecem quando se analisa a gestão do conhecimento.

Alguns mecanismos que poderiam ser empregados pelas empresas do ParqTec:

i) conceder maior liberdade aos funcionários, principalmente, no que concerne ao processo criativo, permitir o "tentar e falhar", uma vez que o aprendizado por gerar um crescimento futuro importante. É claro que numa pequena empresa recém-formada, o controle do dirigente ainda é muito forte, mas é interessante delegar as tarefas possibilitando dentro de um leque de opções a autonomia de criação para alguns funcionários;

ii) coletar e armazenar o maior número de informações e conhecimentos de projetos, produtos, serviços prestados anteriormente, a fim de que na replicação de algum projeto um tempo que já foi dispendido para elaborá-lo em uma situação anterior não seja desperdiçado e tornar o acesso a esta base de dados uma rotina;

iii) incentivar interações intra e inter equipes, coletivizando-nas; 
iv) incentivar a utilização do conhecimento nas rotinas organizacionais, através de permitindo que seja agregado valor aos novos conhecimentos;

v) criar mecanismos que viabilizem a inserção do conhecimento adquirido nas práticas organizacionais;

vi) disseminar uma cultura de comprometimento e harmonia com os funcionários, despertando a confiança deles na empresa, como intuito de que possam compartilhar conhecimento com os demais sem temer a substituição.

O Ciatec apresentou, em geral, um relacionamento mais completo entre os elementos estudados, provavelmente por serem compostas, em sua maioria, por equipes maiores de trabalho, mas aspectos como cultura deve ser empregada, algumas sugestões para melhoria do processo destas empresas:

i) subsidiar treinamentos aos funcionários;

ii) coletar e armazenar o maior número de informações e conhecimentos de projetos, produtos, serviços prestados anteriormente e tornar a elaboração de relatórios uma prática rotineira;

iii) ter uma cultura com valores e metas claras que incentivem a experimentação;

iv) incentivar a utilização do conhecimento nas rotinas organizacionais, permitindo que seja agregado valor aos novos conhecimentos.

É possível denotar que algumas das dimensões estratégicas: cultura, práticas de recursos humanos e sistemas de informação são funções de apoio a criação, compartilhamento, armazenamento e incorporação do conhecimento, e que devem ser exploradas ao máximo para configurar uma gestão mais efetiva. Contudo, é importante destacar algumas limitações encontradas nesta pesquisa e sugestões para trabalhos futuros, aspectos que são discutidos a seguir. 


\subsection{Limitações do Estudo}

Embora tenha abrangido vinte e uma empresas instaladas em dois parques tecnológicos, amostra significativa perante a população-alvo, este foi um fator limitador, pois o objetivo da pesquisa era trabalhar com um número maior de participantes, o que não foi possível devido a não colaboração de alguns dirigentes, acarretando assim em resultados da pesquisa que não podem ser generalizados.

Outra limitação foi o contato restrito da pesquisadora com os dirigentes das empresas, o que não permitiu explorar determinados aspectos, a partir de um contato presencial. As respostas dos questionários advindas de questionário eletrônico também são fatores limitantes, por dependerem da honestidade dos entrevistados em compartilhar a situação real vivenciada nas empresas.

A análise quantitativa, por sua vez, também se evidencia como um limitante, uma vez que as organizações e seus contextos não se apresentam como uma ciência exata, é claro que quantificar auxilia nas conclusões, mas não pode ser utilizada como única avaliação. E, por fim, apesar dos cuidados metodológicos descritos, visando a imparcialidade na coleta dos dados e análise, a pesquisa está sujeita a vieses pessoais do entrevistado ou do entrevistador, além disso, a pesquisa empírica baseia-se apenas na percepção dos dirigentes, outro fator limitante.

\subsection{Trabalhos Futuros}

O presente estudo permitiu que diversas vertentes fossem exploradas como pesquisa, tanto no que concerne à gestão estratégica do conhecimento quanto ao ambiente dos parques tecnológicos. Dessa forma, poderão ser realizados trabalhos que auxiliem a sistematizar os pontos principais da gestão do conhecimento e das estratégias organizacionais, permitindo o auxílio destas ao processo de G.C., esta recomendação surge a partir de uma das limitações 
deste trabalho, o qual sintetizou os principais elementos com base em uma pesquisa bibliográfica que, embora ampla, seja ainda restrita.

As relações entre os elementos do próprio processo SECI também podem ser exploradas, conforme se demonstrou neste trabalho há evidências de correlações muito fortes entre eles, assim como entre as dimensões estratégicas.

Ademais, estudos que contemplem a realidade das empresas instaladas nos parques tecnológicos, permitindo que práticas e ferramentas organizacionais, em sua maioria, derivadas das grandes empresas sirvam de base para o aprimoramento e adequação de técnicas compatíveis com a realidade de pequenas empresas.

Vale ressaltar, que o estudo priorizou a análise dos dois grupos de empresas instaladas nos parques tecnológicos, assim pode ser realizado um estudo pontual e em profundidade em cada empresa, explorando os mecanismos qualitativos de gestão estratégica do conhecimento.

Além disso, evidenciar a aplicação das mesmas variáveis encontradas neste trabalho para uma amostra maior de empresas, explorando os pontos que a análise quantitativa permite, recomenda-se o mesmo estudo só que em outros setores de empresas. Não obstante explorar o comportamento das mesmas variáveis sintetizadas nesta pesquisa, em empresas que atuem em parques tecnológicos com atuações distintas. 


\section{REFERÊNCIAS}

ANCORI, B.; BURETH, A.; COHENDET, P. (2000). The economics of knowledge: the debate about codification and tacit knowledge. Industrial and Corporate Change, v. 9, n.2, p. 255-287.

ANPROTEC (2002). Glossário dinâmico de termos na área de tecnópolis, parques tecnológicos e incubadoras de empresa. Brasília, ANPROTEC.

. (2003). Panorama 2003. Brasília, ANPROTEC.

(2004). Panorama 2004. Brasília, ANPROTEC.

(2005). Panorama 2005. Brasília, ANPROTEC. Disponível em: <http://www.anprotec.org.br/pesquisas/panorama2005.pdf>. Acesso em: 10 fev.2006.

BENÍTEZ, Z.R.; RODRIGUEZ y RODRIGUEZ, M.V. (2004). A gestão estratégica do conhecimento e a relutância dos profissionais em compartilhar o conhecimento organizacional. Sustainable Business Internatinal Journal, n.1, p.1-26.

BLAND, J. M.; ALTMAN, D. G. (1997). Statistics notes. BMJ, v.3, n.14, p.571-572. Disponível em: <http://bmj.bmjjournals.com/cgi/reprint/314/7080/572>. Acesso em: 03 jan.2006.

BROWN, J.S.; DUGUID, P. (1998). Organizing knowledge. California Management Review, v.40, n.3, p. 90-111.

CAMPOS,G.M.(2001).Estatística prática para docentes e pós graduandos. Disponível em: <http://www.forp.usp.br/restauradora/gmc/gmc_livro/gmc_livro_cap19.html>. Acesso em:05 nov.2006.

CARDOSO, L.M.G.P.P.A. (2003). Gerir conhecimento e gerar competitividade: estudo empírico sobre a gestão do conhecimento e seu impacto no desempenho organizacional. Tese de Doutorado. Coimbra, Faculdade de Psicologia e Ciências da Educação - Universidade de Coimbra. 
CERVO, A.L.; BERVIAN, P.A. (1983). Metodologia científica: para uso dos estudantes universitários. 3. ed. São Paulo: McGraw-Hill do Brasil.

COHENDET, P.; STEINMUELLER, W. E. (2000). The codification of knowledge: a conceptual and empirical exploration. Industrial and Corporate Change, v.9, n.2, p.195-209.

COWAN, R.; DAVID, P.A.; FORAY, D. (2000). The explicit economics of knowledge codification and tacitness. Industrial and Corporate Change, v.9, n.2, p.211-253.

DANE, F.C. (1990). Research methods. Belmont - CA: Brooks/Cole.

DAVENPORT, T.H.; DE LONG, D.W.; BEERS, M.C. (1998). Successful knowledge management projects. Sloan Management Review, v.39, p.43-57.

.; PRUSAK, P. (2003). Conhecimento empresarial: como as organizações gerenciam o seu capital intelectual. Título original: Working Knowledge, tradução de Lenke Peres, Rio de Janeiro: Elsevier.

DILLON, M. (2002). Knowledge management: chimera or solution? Libraries and the Academy, v.12, n.2, p.321-336.

DRUCKER, P. (1994). Sociedade pós-capitalista. São Paulo: Pioneira.

EDWARDS, J.S. et al. (2003). Knowledge management research \& practice: visions and directions. Knowledge Management Research \& Practice, n. 1, p. 49-60.

FLEURY, A.C.C.; FLEURY, M.T.L. (2003). Estratégias competitivas e competências essenciais: perspectivas para a internacionalização da indústria no Brasil. Gestão \& Produção. São Paulo: v.10, n.2, p.129-144, ago.

FLEURY, M.T.L.; OLIVEIRA Jr, M.M. (2001). Gestão Estratégica do Conhecimento. São Paulo: Atlas.

GIL, A.C. (2002) Como elaborar projetos de pesquisa. 4.ed. São Paulo: Atlas.

GRANT, R.M.(1991) The resource-based theory of competitive advantage: implications for strategy formulation. California Management Review, v.33, n.3, p.114-135.

(1996). Toward a knowledge-based theory of the firm. Strategic Management Journal, v.17 (special issue), p.109-122.

GREINER, L.E. (1998) Evolution and revolution as organizations grow. Harvard Business Review, p.55-67. 
HAIR JR., J.F.; ANDERSON, R.E.; TATHAM, R.L.; BLACK, W.C. (2005a). Análise multivariada de dados. Porto Alegre: Bookman.

HAIR JR., J.F.; BABIN, B.; MONEY, A.H.; SAMOUEL, P.(2005b). Fundamentos de métodos de pesquisa em administração. Porto Alegre: Bookman.

HANDY, C. (1994) A Era do Paradoxo: dando um sentido para o futuro. São Paulo: Makron Books, p.3-32.

HANSEN, M.T.; NOHRIA, N.; TIERNEY, T. (1999). What's your strategy for managing knowledge? Harvard Business Review. v.77, p.106-116. Mar./Apr.

HAYASHI, C. H.; NAKAMURA, M. M.; ESCRIVÃO FILHO, E. (1995). Estratégia empresarial e a pequena empresa. In: VIII Congresso Latino-Americano de Estratégia. Anais, São Leopoldo, Rio Grande do Sul/RS.

HITT, M.A.; IRELAND, R.D.; HOSKINSSON, R.E. (2001). Direct and moderating effects of human capital on strategy and performance in professional service firms: a resource-based perspective. Academy of Management Journal. v.44, n.1. p.13-28.

; _ _ (2002). Administração Estratégica:competitividade e globalização. 4 ed. São Paulo: Pioneira Thomson Learning.

IBGE (2005). Pesquisa - <www.ibge.gov.br>, acesso 1 de ago.2005.

INKPEN, A. (1996). Creating knowledge through collaboration. California Management Review, v.39, n.1, p.123-140.

JERES-GÓMEZ， P.; CÉSPEDES-LORENTE， J.; VALLE-CABRERA， R. (2005). Organization learning and compensation strategies: evidence from the Spanish Chemical Industry. Human Resource Management, v.44, n.3, p.279-299.

KRUGLIANKAS, I.; TERRA, J.C. (2003). Gestão do conhecimento em pequenas e médias empresas. Rio de Janeiro: Campus.

LACOMBE, F; HEILBORN, G. (2003). Administração: princípios e tendências. São Paulo: Saraiva. p.494-500.

LAKATOS, E. M.; MARCONI, M. A.(1992). Metodologia do trabalho científico.4.ed. São Paulo: Atlas.

LEONARD-BARTON, D. (1998). Wellspring of Knowledge. Harvard Business School Press, Boston, MA.

LEONE, N. M. C. P. G. (1999). As especificidades das pequenas e médias empresas. Revista de administração, São Paulo, v.34, n.2, p.91-94. 
LIEBESKIND, J.P. (1996). Knowledge, strategy, and the theory of the firm. Strategic Management Journal, v. 17, winter special issue, p. 93-107.

MAIER, R. (2001). Towards a framework for knowledge management strategies: process orientation as strategic starting point. In: PROCEEDINGS OF THE 34th HAWAII INTERNATIONAL CONFERENCE ON SYSTEM SCIENCES. Disponível em: <http://ieeexplore.iee.org/iel5/7255/20032/00926488.pdf>. Acesso em: 16 nov.2005

MATIAS-PEREIRA, J.; KRUGLIANSKAS, I. (2005). Gestão da Inovação: a lei de inovação tecnológica como ferramenta de apoio às políticas industrial e tecnológica do Brasil. $R A E$ eletrônica. v.4, n.2, art.18. Jul./Dez.

McCAMPBELL, A.S.; CLARE, L.M.; GITTERS, S.H. (1999). Knowledge management: the new challenge for the $21^{\text {st }}$ century. Journal of Knowledge Management, v.3, n.3, p.172-179.

McCANN, J.E.; BUCKNER, M. (2004). Strategically integrating knowledge management initiatives. Journal of Knowledge Management, v.8, n.1, p.47-63.

MEDEIROS, C.A.F. (2003). Comprometimento organizacional: um estudo de suas relações com as características organizacionais e desempenho nas empresas hoteleiras. Tese (Doutorado) - Faculdade de Economia, Administração e Contabilidade, Universidade de São Paulo. São Paulo.

MEDEIROS, J.A.; MEDEIROS, L.A.; MARTINS, T.; PERILO, S. (1992). Pólos, parques e incubadoras: a busca da modernização e competitividade. CNPq, SCT//PR, IBICT, SENAI. Brasília.

MILES, G.; MILES, R.; PERRONE, V.; EDVINSSON, L. (1998). Some conceptual and research barriers to the utilization of knowledge. California Mangament Review, v.40, n.3, p.281-289.

MINTZBERG, H.; AHLSTRAND, B. e LAMPEL, J. (2000). Safári de Estratégia: um roteiro pela selva do planejamento estratégico. Porto Alegre: Bookman.

MORGAN, G. (1996). Imagens da organização. São Paulo: Atlas.

MÜLLER-MERBACH, H. (2004). Knowledge is more than information. Knowledge Management Research \& Pratice, n. 2, p.61-62.

NADLER, D.A.; TUSHMAN, M.L. (2000). A organização do futuro: as lições mais importantes do século XX e os próximos desafios que levarão ao novo desenho da empresa. HSM Management, n.18, jan-fev, p.58-66.

NONAKA, I. (1991). The knowledge-creating Company. Harvard Business Review, p.2-9. Nov./ Dec. 
(1994). A dynamic theory of organizational knowledge creation. Organization Science, v.5, n.1, p.14-37.

.; KONNO, N. (1998). The concept of ba: building a foundation for knowledge creation . California Management Review, v.40, n.3, p.40-55.

.; PELTOKORPI, V.; TOMAE, H. (2005). Strategic knowledge creation: the case of Hamamatsu Photonics. International Journal Techonology Management, v.30,n.3/4, p.248264.

.; TAKEUCHI, H. (1997). Criação de Conhecimento na Empresa: como as empresas japonesas geram a dinâmica da inovação. 13 ed., Rio de Janeiro: Elsevier.

.; TOYAMA, R. (2003). The knowledge-creating theory revisited: knowledge creation as a synthesizing process. Knowledge Management Research \& Practice, p.2-10.

.; (2005). The theory of the knowledge-creating firm: subjectivity, objectivity and synthesys. Industrial and Corporate Change, v.14, n.3, p.419-436.

.; __ KONNO, N. (2000). SECI, Ba and Leadership: a unified model of dynamic knowledge creation. Long Range Planning, v.33, p.5-34.

.; __ . NAGATA, A. (2000). A Firm as a Knowledge-creating Entity: a new perspective on the Theory of the firm. Industrial and Corporate Change, v.9, n.1, p.1-20.

.; UMEMOTO, K.; SENOO, D. (1996). From information processing to knowledge creation: a paradigm shift in business management. Technology in Society, v. 18, n.2, p.203218.

OLIVEIRA Jr,. M. M. (2001). Competências Essenciais e Conhecimento na Empresa. In: FLEURY, M. T. L.; OLIVEIRA Jr, M. M. (Org). Gestão Estratégica do Conhecimento. São Paulo: Editora Atlas S.A. p.121- 156.

ORSI, A. (2003). Incorporação de bases externas do conhecimento: a gestão do conhecimento nas fusões e aquisições de empresas. Dissertação (Mestrado) - Faculdade de Economia, Administração e Contabilidade, Universidade de São Paulo. São Paulo.

PERUSSI FILHO, S. (2001). Uma avaliação da contribuição das cooperações universidadeempresa e inter-empresas para a competitividade das empresas industriais do pólo tecnológicos de São Carlos. Dissertação (Mestrado) - Escola de Engenharia de São Carlos, Universidade de São Paulo. São Paulo.

PLONSKI, G. A. (1998). Cooperação universidade-empresa no Brasil: um novo balanço prospectivo. In: Interação universidade-empresa. Brasília. Instituto Brasileiro de Informação em Ciência e Tecnologia (IBICT). p.9-23. 
PORTER, M.E. (2003). Competitive Strategy: New York: Simon \& Schuster.

PRAHALAD, C. K.; HAMEL, G. (1990). The core competence of the corporation. Harvard Business Review, v.68, n.3, p.79-91.

PREVIDELLI, J. J.; MEURER, V. (2005). Gestão da micro, pequena e média empresa no Brasil: uma abordagem multidimensional. Maringá: UNICORPORE.

RODRIGUEZ y RODRIGUEZ, M. V. (2001). Gestão do Conhecimento: reinventando a empresa para uma sociedade baseada em valores intangíveis. Rio de Janeiro: IBPI Press.

SANTIAGO JR, J. R. S. (2002). O Desenvolvimento de uma Metodologia para a Gestão do Conhecimento em uma Empresa de Construção Civil. Dissertação (Mestrado) - Escola Politécnica, Universidade de São Paulo. São Paulo.

SCHEIN, E. H. (2001). Guia de sobrevivência da cultura corporativa. Rio de Janeiro: José Olympio Editora.

SCHMITT, N. (1996). Uses and abuses of coefficient alpha. Psychological Assessment, v.8, n.4, p.350-353. Disponível em: <http://www.psych.upenn.edu/courses/psych600_303_Spring2003/600lec10a.pdf> Acesso em: 03 jan.2006.

SCHULZ, M. (2001). The uncertain relevance of newness: organizational learning and knowledge flows. Academy of Management Journal, v.44, n.4, p.661-681.

SEBRAE (2005). Pesquisa - <www.sebrae.com.br>, acesso 1 de ago.2005.

SENGE, P. (2004). A Quinta Disciplina: arte e prática da organização que aprende. 16ed. Rio de Janeiro: Best Seller.

SHIH, H.; CHIANG, Y. (2005). Strategy alignment between HRM, KM and corporate development. International Journal of Manpower, v.26, n.6, p.582-603.

SILVA, S. L. (2002). Proposição de um modelo para caracterização das conversões do conhecimento no processo de desenvolvimento de produtos. Tese de Doutorado. São Carlos, EESC-USP.

. (2004). Gestão do conhecimento: uma revisão crítica orientada pela abordagem da criação do conhecimento. Ciência da Informação, v.33, n.2, p.143-151.

SILVA, A. B.; ALBERTON, A.; CANCELLIER, E. L. P. L.; MARCON, R. (2005). Fatores determinantes para a criação e gestão de pequenas empresas. In: PREVIDELLI, J. J.; MEURER, V. (Org.). Gestão da micro, pequena e média empresa no Brasil: uma abordagem multidimensional. Maringá: UNICORPORE. p.27-52. 
SNYMAN, R.; KRUGER, C.J. (2004). The interdependency between strategic management and strategic knowledge management. Journal of Knowledge Management, v.8, n.1, p.5-19.

SOO, C. et al. (2002). Knowledge Management: philosofy, processes and pitfalls. California Management Review, v.44, n.4, p.129-151.

SPENDER, J.C. (2001). Gerenciando Sistemas de Conhecimento. In: FLEURY, M. T. L.; OLIVEIRA Jr, M. M. (Org). Gestão Estratégica do Conhecimento. São Paulo: Editora Atlas S.A. p.27- 49.

STOREY, J. (2001). Human Resource Management Today: An Assessment. In: STOREY, J. (Org). Human Resource Managemen: A Critical Text. Great Britain: Thomson Learning. p.320.

.; QUINTAS, P. (2001). Knowledge Management and HRM. In: STOREY, J. (Org). Human Resource Managemen: A Critical Text. Great Britain: Thomson Learning. p.339-363.

SVEIBY, K. E. (1997). The New Organizational Wealth: Managing and Measuring Knowledge-based Assets. San Francisco: Berret-Koehler Publishers Inc.

TEECE, D. J. (1998). Capturing value from knowledge assets: the new economy, markets for know-how, an intangible assets. California Management Review. Reprint Series, v.40, n.3, p.52-79.

. (2000). Strategies for managing knowledge assets: the role of firm structure and industrial context. Long Range Planning, v.33, p.35-54.

; PISANO, G.; SHUEN, A. (1997). Dynamic capabilities and strategic management. Strategic Management Journal, v.18, n.7, p.509-533.

TERENCE, A. C. F. (2002). Planejamento estratégico como ferramenta de competitividade na pequena empresa. Dissertação de Mestrado. São Carlos, EESC-USP.

TERRA, J. C. C. (2001). Gestão do Conhecimento: o grande desafio empresarial: uma abordagem baseada no aprendizado e na criatividade. São Paulo: Negócio Editora.

TIRPAK, T.M. (2005). Five steps to effective knowledge management. Research Technology Management, v.48, n.3, p.15-16.

THOMPSON JR, A.A.; STRICKLAND III, A.J. (2000). Planejamento estratégico: elaboração, implementação e execução. São Paulo: Pioneira.

TORKOMIAN, A. L. V. (1992). Estrutura de pólos tecnológicos: um estudo de caso. Dissertação de Mestrado. São Paulo, FEA-USP. 
uit Beijerse, R.P. (1999). Questions in knowledge management: defining and conceptualising a phenomenon. Journal of Knowledge Management, v.3, n.2, p.94-109.

VASCONCELOS, F.C. (2001). Da gestão do conhecimento à gestão da ignorância: uma visão co-evolucionária. Revista de Administração de Empresas, v.41, n.4, p.98-102.

von KROGH, G. (1998). Care in knowledge creation. California Management Review, v. 40, n.3, p.133-153.

. ; NONAKA, I.; ABEN, M. (2001). Making the most of your company's knowlegde: a strategic framework. Long Range Planning, n.34, p. 421-439.

YIN, R. (2004) Estudo de casos: planejamento e métodos. São Paulo: Bookman.

ZACK, M. H. (1999). Developing a knowledge Strategy. California Management Review, v.41, n.3, p.125-145.

WERNERFELT, B. (1984). A resource-based view of the firm. Strategic Management Journal, v.5, p.171-180.

WIIG, K. M. (2003). Knowledge management: an emerging discipline rooted in a long history. Disponível em: 〈http://www.krii.com>

WREN, D. A. (1994). The evolution of management thought. 4.ed. New York: John Wiley \& Sons, Inc. 
APÊNDICE 
APÊNDICE A - CARTA DE APRESENTAÇÃO 


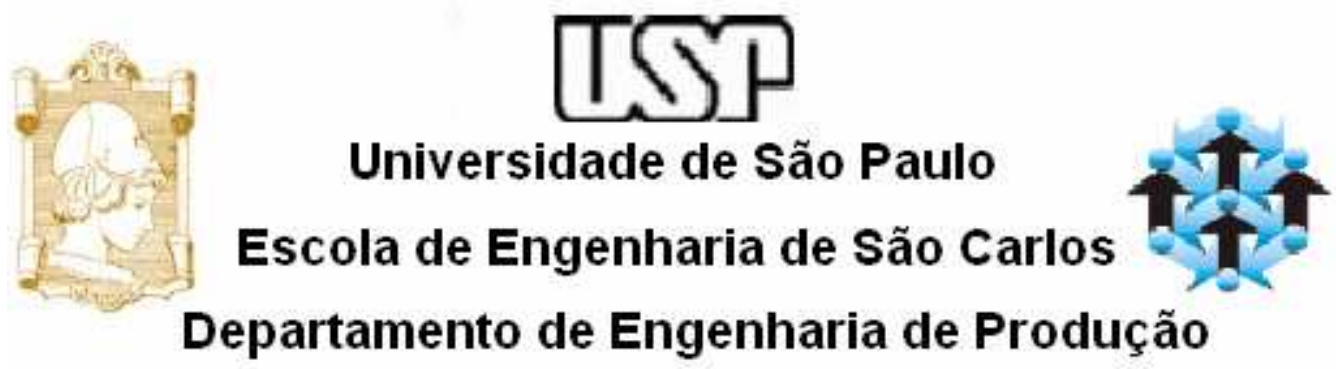

Prezado (a) Senhor (a).

Estou realizando um trabalho de campo para minha pesquisa de mestrado juntamente com o Departamento de Engenharia de Produção - Escola de Engenharia de São Carlos (EESC) -Universidade de São Paulo (USP), conjuntamente e sob orientação do Professor Doutor Marcelo Seido Nagano.

Esta pesquisa busca investigar o processo de gestão do conhecimento e seu relacionamento com dimensões estratégicas organizacionais e envolve o estudo de casos nas empresas residentes em Parques Tecnológicos.

Não obstante, gostaria de frisar que as informações colocadas no questionário serão mantidas em sigilo, uma vez que os dados não serão tratados de forma isolada e individualizados por empresa.

Assim sendo, venho por meio desta solicitar vossa contribuição para o desenvolvimento desta pesquisa. Em breve, entrarei em contato para saber do vosso interesse e disponibilidade para realização da pesquisa.

Antecipadamente agradeço a colaboração, e coloco-me desde já a disposição para maiores esclarecimentos.

Cordialmente,

Eng. Claudia Andressa Cruz

Prof. Dr. Marcelo Seido Nagano

\section{Contato:}

EESC-USP São Carlos - (16)3373-8286 ou cel.(16)9711-6742

E-mail: claudia.andressa@gmail.com

EESC-USP São Carlos - (16)3373-8607

E-mail: drnagano@usp.br 
APÊNDICE B - MODELO DO QUESTIONÁRIO UTILIZADO NO TRABALHO DE CAMPO 


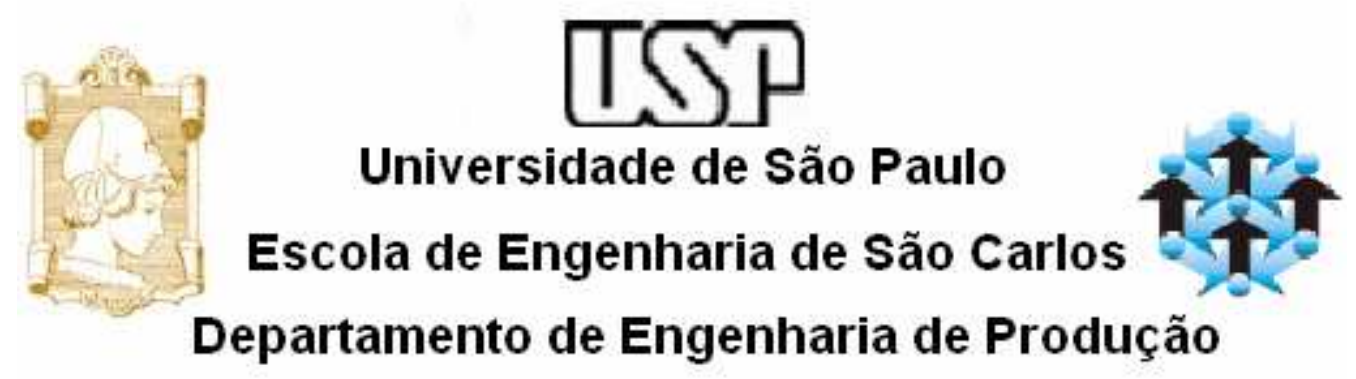

INSTRUÇÕES: Ao abrir o questionário deve-se gravá-lo em uma das pastas de seu computador. Após responder todas as questões grave-o novamente e, por fim anexe-o e envie para o e-mail claudia.andressa@gmail.com

Etapa 1: Caracterização da Empresa

Nome da Empresa:

Ano de Fundação da Empresa:

Localização:

Número total de empregados:

Quando ingressou no parque a empresa era:

$\square$ Existente $\square$ Nova $\square$ Proveniente de incubadora

Etapa 2: Identificação do Dirigente da Empresa

Nome do entrevistado:

É o proprietário da empresa? $\square$ Sim $\square$ Não

Cargo na empresa:

Qual seu nível de escolaridade?

Observações:

- $\quad$ Esta pesquisa tem como finalidade a investigação de temas importantes dentro do contexto da gestão empresarial nos dias atuais, para seu estudo e desenvolvimento no meio acadêmico.

- Todas as informações fornecidas são estritamente confidenciais e as respostas serão tratadas de forma agregada e não isoladas.

- $\quad$ Por favor, responda de forma que as respostas representem de fato a realidade da empresa e tenha em mente que responderá pela empresa como um todo.

- $\quad$ Os resultados desta pesquisa serão disponibilizados para você e sua empresa.

Muito obrigada.

Claudia Andressa Cruz.

E-mail: claudia.andressa@ gmail.com comercial(16)3373-8286 ou cel.(16)9711-6742

Marcelo Seido Nagano

E-mail: drnagano@usp.br

comercial(16)3373-8607 
INSTRUÇÕES: Para responder a questão, deve-se assinalar (com o mouse) o número mais adequado dentro da escala, segundo a visão da organização, com relação à afirmação colocada, como o exemplo abaixo.

Ex. Seus clientes estão satisfeitos com o serviço prestado

\begin{tabular}{|c|c|c|c|c|c|c|}
\hline $\begin{array}{l}\text { Discordo } \\
\text { Totalmente }\end{array}$ & $\begin{array}{c}\text { Discordo de } \\
\text { praticamente } \\
\text { tudo }\end{array}$ & $\begin{array}{l}\text { Discordo } \\
\text { ligeiramente }\end{array}$ & $\begin{array}{l}\text { Concordo } \\
\text { parcialmente }\end{array}$ & $\begin{aligned} & \text { Concordo } \\
& \text { e ligeiramente }\end{aligned}$ & $\begin{array}{l}\text { Concordo com } \\
\text { praticamente } \\
\text { tudo }\end{array}$ & $\begin{array}{l}\text { Concordo } \\
\text { totalment }\end{array}$ \\
\hline 1 & 2 & 3 & & 5 & 6 & 7 \\
\hline
\end{tabular}

\section{Questionário I}

1. Quando um funcionário está em dúvida sobre determinada atividade de trabalho, uma de suas primeiras ações é recorrer a um colega de trabalho.

2. A empresa contrata cursos e treinamentos para seus funcionários, sempre que surge um novo projeto no qual o funcionário deverá desempenhar uma atividade diferente daquela até então exercida.

3. Após aprimorarem seus conhecimentos em cursos e treinamentos, os funcionários interagem sobre os conceitos aprendidos.

4. Os funcionários estão sempre a par do crescimento da empresa e de suas necessidades de qualificação, buscando se especializar mesmo quando não há qualquer subsídio da empresa.

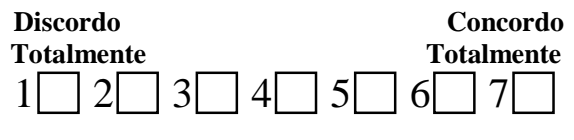

$1 \square 2 \square 3 \square 4 \square 5 \square 6 \square 7 \square$ 
5. Os projetos de trabalho são realizados em sua maioria por equipes que executam suas atividades e análises, através de interações conjuntas.

6. É comum entre os funcionários o uso de metáforas e analogias para explicar idéias e atividades.

7. Novas idéias são valorizadas. Há permissão para discussão de idéias que a princípio pareçam irrelevantes.

8. Na empresa há grupos de discussão os quais se relacionam por meio de ambientes virtuais, tais como: fóruns virtuais e grupos de e-mails.

9. $\mathrm{O}(\mathrm{s})$ banco (s) de dados da empresa é (são) intensamente acessado(s), tanto para armazenar como fornecer dados/informações a todos na empresa.

10. A empresa provê sistemas integrados que incentivam diálogos por meio de intranet e internet, tais como: emails, MSN, CRM.

11. A empresa exige que, após a conclusão de projetos e atividades, os funcionários redijam relatórios sobre os mesmos.

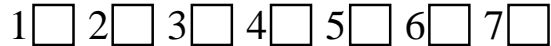

$1 \square 2 \square 3 \square 4 \square 5 \square 6 \square 7 \square$

$1 \square 2 \square 3 \square 4 \square 5 \square 6 \square 7 \square$

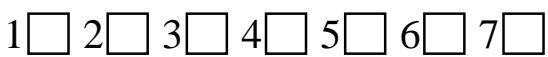


12. Os ambientes virtuais de comunicação (intranet, internet) são utilizados mais como veículos de comunicação entre dois indivíduos ao invés de ser entre grupos.

13. Todos os funcionários estão aptos a dizerem se questionados qual a meta e a missão da empresa.

14. Os funcionários, em sua maioria, apresentam mais know how técnico, isto é, são mais especialistas, do que generalistas.

15. Quando um funcionário começa a realizar uma nova atividade que ele nunca exerceu, ele tenta desempenhá-la, primeiramente, por meio da prática, isto é, aprender-fazendo.
$1 \square 2 \square 3 \square 4 \square 5 \square 6 \square 7 \square$

$1 \square 2 \square 3 \square 4 \square 5 \square 6 \square 7 \square$

$1 \square 2 \square 3 \square 4 \square 5 \square 6 \square 7 \square$

$1 \square 2 \square 3 \square 4 \square 5 \square 6 \square 7 \square$ 


\section{Questionário II}

1. Os funcionários têm consciência de que se contribuírem com o alcance da meta da empresa, por exemplo, criando um produto/serviço inovador, eles serão reconhecidos (valorizados).

2. A experimentação é estimulada. Há liberdade para tentar e falhar.

3. As pessoas estão preocupadas com toda a organização e não apenas com sua área de trabalho, buscando soluções conjuntas.

4. Os cursos, especializações e títulos obtidos pelos funcionários são valorizados.

5. Os recém-contratados, antes de iniciarem suas atividades, são treinados pelos funcionários mais antigos à empresa.

6. Existem esquemas de participação nos lucros, premiação e recompensas por resultados e contribuições

7. $\mathrm{Na}$ contratação busca-se a diversidade (personalidades, experiências, cultura, etc), em detrimento do know how técnico.

8. Todos os sistemas de informação estão integrados, assim é possível que qualquer área da empresa tenha acesso ao conteúdo das demais via intranet.

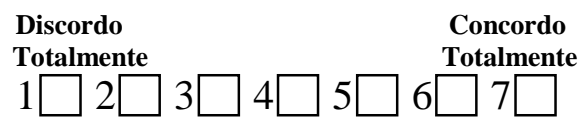

$1 \square 2 \square 3 \square 4 \square 5 \square 6 \square 7 \square$

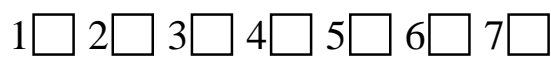

$1 \square 2 \square 3 \square 4 \square 5 \square 6 \square 7 \square$

$1 \square 2 \square 3 \square 4 \square 5 \square 6 \square 7 \square$

$1 \square 2 \square 3 \square 4 \square 5 \square 6 \square 7 \square$

$1 \square 2 \square 3 \square 4 \square 5 \square 6 \square 7 \square$

$1 \square 2 \square 3 \square 4 \square 5 \square 6 \square 7 \square$ 
9. Um dos maiores investimentos realizados pela empresa anualmente, dedica-se aos sistemas de informação.

10. A comunicação, por meio das redes de comunicação, é eficiente em todos os sentidos (de cima para baixo, de baixo para cima e entre as diferentes áreas).
$1 \square 2 \square 3 \square 4 \square 5 \square 6 \square 7 \square$

$1 \square 2 \square 3 \square 4 \square 5 \square 6 \square 7 \square$ 
APÊNDICE C - TABELAS DE ANÁLISE 
Tabela 18 - Porcentagem de cada questão para o Parque de São Carlos

\begin{tabular}{|c|c|c|c|}
\hline Questões & \% Discordância & \% Parcial & \% Concordância \\
\hline 1 & 9 & 0 & 91 \\
\hline 2 & 36 & 45 & 18 \\
\hline 3 & 9 & 18 & 73 \\
\hline 4 & 27 & 27 & 45 \\
\hline 5 & 9 & 0 & 91 \\
\hline 6 & 36 & 9 & 55 \\
\hline 7 & 0 & 9 & 91 \\
\hline 8 & 45 & 0 & 55 \\
\hline 9 & 36 & 9 & 55 \\
\hline 10 & 18 & 9 & 73 \\
\hline 11 & 0 & 27 & 73 \\
\hline 12 & 45 & 18 & 36 \\
\hline 13 & 45 & 9 & 45 \\
\hline 14 & 36 & 0 & 64 \\
\hline 15 & 55 & 27 & 18 \\
\hline 16 & 27 & 9 & 64 \\
\hline 17 & 45 & 18 & 36 \\
\hline 18 & 0 & 9 & 91 \\
\hline 19 & 27 & 9 & 64 \\
\hline 20 & 9 & 18 & 73 \\
\hline 21 & 45 & 0 & 55 \\
\hline 22 & 45 & 18 & 36 \\
\hline 23 & 18 & 18 & 64 \\
\hline 24 & 0 & 36 & 64 \\
\hline 25 & 0 & 9 & 91 \\
\hline
\end{tabular}


Tabela 19 - Porcentagem de cada questão para o Parque de Campinas

\begin{tabular}{|c|c|c|c|}
\hline Questões & \% Discordância & $\%$ Parcial & \% Concordância \\
\hline 1 & 10 & 0 & 90 \\
\hline 2 & 60 & 0 & 40 \\
\hline 3 & 20 & 10 & 70 \\
\hline 4 & 20 & 20 & 60 \\
\hline 5 & 0 & 0 & 10 \\
\hline 6 & 20 & 20 & 60 \\
\hline 7 & 0 & 20 & 80 \\
\hline 8 & 20 & 30 & 50 \\
\hline 9 & 0 & 0 & 100 \\
\hline 10 & 10 & 20 & 70 \\
\hline 11 & 40 & 10 & 50 \\
\hline 12 & 20 & 40 & 40 \\
\hline 13 & 10 & 20 & 70 \\
\hline 14 & 10 & 20 & 70 \\
\hline 15 & 20 & 40 & 40 \\
\hline 16 & 10 & 10 & 80 \\
\hline 17 & 30 & 20 & 50 \\
\hline 18 & 10 & 10 & 80 \\
\hline 19 & 20 & 10 & 70 \\
\hline 20 & 0 & 40 & 60 \\
\hline 21 & 20 & 0 & 80 \\
\hline 22 & 20 & 30 & 50 \\
\hline 23 & 10 & 20 & 70 \\
\hline 24 & 0 & 30 & 70 \\
\hline 25 & 0 & 10 & 90 \\
\hline
\end{tabular}


Tabela 20: Matriz de correlação referente as respostas dadas pelas empresas instaladas no Ciatec

\begin{tabular}{|c|c|c|c|c|c|c|c|c|c|c|c|c|c|c|c|c|c|c|c|c|c|c|c|c|c|}
\hline & V1 & V2 & $\mathrm{V3}$ & V4 & V5 & V6 & V7 & V8 & V9 & V10 & V11 & V12 & V13 & V14 & V15 & V16 & V17 & V18 & V19 & V20 & V21 & V22 & $\mathrm{V} 23$ & V24 & $\mathrm{V} 25$ \\
\hline V1 & 1,000 & 217 & 0,056 & 50 & 0,162 & 0,364 & 133 & $-0,248$ & 120 & 0,588 & 283 & 0,069 & 0,205 &, 020 & $-0,355$ &, 162 & $-0,491$ & 171 & $-0,132$ & $-0,192$ & 0,504 & 0,431 & 0,249 & 0,474 & 0,294 \\
\hline V2 & 0,217 & 000 & 0,672 & 75 & 0,409 & 220 & 0.078 & 0,166 & 25 & 160 & 675 & $-0,003$ & 491 & $-0,011$ & 0,028 &, 215 & $-0,307$ & 653 & 0,437 & $-0,487$ & 0,389 & 0,288 & 312 & 301 &, 103 \\
\hline V3 & $-0,056$ & 672 & 1,000 & 192 & 0,582 & 060 & 258 & 0,538 & 132 & 0,10 & 663 & $-0,652$ & 0,667 & 0,132 & $-0,065$ & 104 & $-0,137$ & 423 & 0,305 & $-0,486$ & 0,603 & 0,337 & 539 & 606 &, 368 \\
\hline \begin{tabular}{|l|}
$\mathrm{V} 4$ \\
\end{tabular} & 0,450 & 0,475 & 0,492 & 1,000 & 0,762 & 0,243 & 0,217 & 0,606 & 0,454 & 0,808 & 0,511 & $-0,335$ & 0,623 & 0,363 & $-0,158$ & 0,452 & 0,227 & 164 & 0,454 & 0,010 & 0,792 & 0,881 & 0,812 & 837 & 0,579 \\
\hline V5 & 0,162 & 0,409 & 0,582 & 0,762 & 1,000 & 0,004 & 0,635 & 0,553 & 0,609 & 0,679 & 0,288 & $-0,458$ & 0,766 & 0,593 & 0,346 & 0,597 & 0,355 & 0,386 & 0,373 & $-0,238$ & 0,769 & 0,789 & 0,649 & 0,575 & 0,765 \\
\hline V6 & 0,364 & 0,220 & $\begin{array}{l}0,060 \\
\end{array}$ & 0,243 & 0,004 & 1,000 & $-0,163$ & 0,192 & $-0,401$ & 0,072 & 0,729 & 0,046 & $-0,006$ & $-0,527$ & $-0,306$ & $-0,294$ & $-0,230$ & $-0,069$ & 0,201 & 0,381 & 0,063 & 0,205 & 0,554 & 0,262 & 0,074 \\
\hline V7 & $-0,133$ & 0,078 & 0,258 & 0,217 & 0,635 & $-0,163$ & 1,000 & 0,340 & 0,247 & 0,198 & $-0,039$ & $-0,122$ & 0,475 & 0,755 & 0,554 & 0,305 & 0,426 & 0,437 & $-0,253$ & 0,027 & 0,369 & 0,394 & 0,277 & 0,136 & 0,825 \\
\hline V8 & $-0,248$ & 0,166 & 0,538 & 0,606 & 0,553 & 0,192 & 0,340 & 1,000 & 0,092 & 0,189 & 0,437 & $-0,607$ & 0,391 & 0,246 & 0,116 & 0,430 & \begin{tabular}{l|l}
0,548 \\
\end{tabular} &, 111 & 0,375 & 0,354 & 0,463 & 0,515 & 0,818 & 0,526 & 0,472 \\
\hline \begin{tabular}{|l|} 
V9 \\
\end{tabular} & 0,120 & 0,125 & 0,132 & 0,454 & 0,609 & $-0,401$ & 0,24 & 0,092 & 000 & 0,694 & 289 & $-0,076$ & 0,695 & 397 & 0,315 & 735 & 0,293 & 377 & \begin{tabular}{|l|}
413 \\
\end{tabular} & $-0,360$ & 0,591 & 0,435 & 173 & 39 & 0,243 \\
\hline V10 & 0,588 & 0,160 & 0,104 & 0,808 & 0,679 & 0,072 & 0,19 & 0,189 & 0,694 & 1,000 & 118 & $-0,126$ & 0,542 & 0,449 & $-0,137$ & 0,644 & 0,255 & 015 &, 358 & $-0,058$ & 7710 & 864 & 18 & 66 &, 536 \\
\hline V11 & 0,283 & 0,675 & 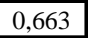 & 0,511 & 0,288 & \begin{tabular}{ll|l}
0,729 \\
\end{tabular} & $-0,039$ & 0,437 & $-0,289$ & 0,118 & 1,000 & $-0,323$ & 0,310 & $-0,255$ & $-0,386$ & $-0,215$ & $-0,266$ & 0,149 & 0,358 & $-0,032$ & 0,383 & 0,402 & 0,691 & 0,567 & 0,235 \\
\hline V12 & 0,069 & $-0,003$ & $-0,652$ & $-0,335$ & $-0,458$ & 0,046 & $-0,122$ & $-0,607$ & $-0,076$ & $-0,126$ & $-0,323$ & 1,000 & $-0,338$ & $-0,165$ & 0,086 & $-0,388$ & $-0,122$ & 0,256 & $-0,179$ & 0,221 & $-0,522$ & $-0,353$ & $-0,509$ & $-0,531$ & $-0,394$ \\
\hline V13 & 0,205 & 0,491 & 0,667 & 0,623 & 0,766 & $-0,006$ & 0,475 & 0,391 & 0,695 & 0,542 & 0,310 & $-0,338$ & 1,000 & 0,288 & 0,174 & 0,428 & $-0,003$ & 0,626 & 0,271 & $-0,425$ & 0,870 & 0,504 & 0,580 & 653 & 0,548 \\
\hline V14 & $-0,020$ & $-0,011$ & 0,132 & 0,363 & 0,593 & $-0,527$ & 0,755 & 0,246 & 0,397 & 0,449 & $-0,255$ & $-0,165$ & 0,288 & 1,000 & 0,310 & 0,520 & 0,565 & 0,098 & $-0,158$ & $-0,038$ & 0,368 & 0,569 & 0,113 & 0,211 & 0,727 \\
\hline V15 & $-0,355$ & 0,028 & $-0,065$ &, 158 & 0,346 & $-0,306$ & 0,554 & 0,11 & 315 & $-0,137$ & $-0,386$ & 0,086 & 0,174 & 0,310 & 1,000 & 0,142 & 0,339 & 0,516 & 0,019 & $-0,105$ & $-0,029$ & $-0,101$ & $-0,135$ & $-0,476$ & 0,182 \\
\hline V16 & $-0,162$ & $-0,215$ & 0,104 & 0,452 & 0,597 & $-0,294$ & 0,305 & 0,430 & 0,735 & 0,644 & $-0,215$ & $-0,388$ & 0,428 & 0,520 & 0,142 & 1,000 & \begin{tabular}{ll|}
0,740 \\
\end{tabular} & $-0,076$ & 0,478 & 0,084 & 0,443 & \begin{tabular}{ll|}
0,611 \\
\end{tabular} & 0,376 & 0,343 & 0,381 \\
\hline \begin{tabular}{|l|} 
V17 \\
\end{tabular} & $-0,491$ & $-0,307$ & $-0,137$ & 0,227 & 0,355 & $-0,230$ & 0,426 & 0,548 & 0,293 & 0,255 & $-0,266$ & $-0,122$ & $-0,003$ & 0,565 & 0,339 & 0,740 & 1,000 & $-0,081$ & 0,321 & 0,547 & $-0,010$ & 0,421 & 0,258 & $-0,035$ & 0,310 \\
\hline V18 & $-0,171$ & 0,653 & 0,423 & 0,164 & 0,386 & $-0,069$ & 0,437 & 0,111 & 0,377 & $-0,015$ & 0,149 & 0,256 & 0,626 & 0,098 & 0,516 & $-0,076$ & $-0,081$ & 1,000 & 0,175 & $-0,354$ & 0,253 & $-0,033$ & 0,098 & $-0,004$ & 0,117 \\
\hline V19 & $-0,132$ & 0,437 & 0,305 & 0,454 & 0,373 & 0,201 & $-0,253$ & 0,375 & 0,413 & 0,358 & 0,358 & $-0,179$ & 0,271 & $-0,158$ & 0,019 & 0,478 & 0,321 & 0,175 & 1,000 & $-0,064$ & 0,198 & 0,395 & 0,399 & 0,176 & $-0,184$ \\
\hline V20 & $-0,192$ & $-0,487$ & $-0,486$ & 0,010 & $-0,238$ & 0,381 & 0,027 & 0,354 & $-0,360$ & $-0,058$ & $-0,032$ & 0,221 & $-0,425$ & $-0,038$ & $-0,105$ & 0,084 & 0,547 & $-0,354$ & $-0,064$ & 1,000 & $-0,330$ & 0,083 & 0,261 & $-0,071$ & 0,045 \\
\hline V21 & 0,504 & 0,389 & 0,603 & 0,792 & 0,769 & 0,063 & 0,369 & 0,463 & 0,591 & 0,710 & 0,383 & $-0,522$ & 0,870 & 0,368 & $-0,029$ & 0,443 & $-0,010$ & 0,253 & 0,198 & $-0,330$ & 1,000 & 0,722 & 0,712 & 0,838 & 0,686 \\
\hline $\mathrm{V} 22$ & 0,431 & 0,288 & 0,337 & 881 & 0,789 & 0,205 & 0,394 & 0,515 & 0,435 & 0,864 & 0,402 & $-0,353$ & 0,504 & 0,569 & $-0,101$ & 0,611 & 0,421 & $-0,033$ & 0,395 & 0,083 & 0,722 & 1,000 & 0,740 & 0,711 & 0,738 \\
\hline $\mathrm{V} 23$ & 0,249 & 0,312 & 0,539 & 812 & 0,649 & 0,554 & 0,277 & 0,818 & 2 & 0,518 & 0,691 & $-0,509$ & 0,580 & 0,113 & $-0,135$ & 0,376 & 0,258 & 0,098 & 0,399 & 0,261 & 0,712 & 0,740 & 1,000 & 0,793 &, 604 \\
\hline \begin{tabular}{|l|}
$\mathrm{V} 24$ \\
\end{tabular} & 0,474 & 0,301 & 0,606 & 0,837 & 0,575 & 0,262 & 0,136 & 0,526 & 0,289 & 0,656 & 0,567 & $-0,531$ & 0,653 & 0,211 & $-0,476$ & 0,343 & $-0,035$ & $-0,004$ & 0,176 & $-0,071$ & 0,838 & 0,711 & 0,793 & 1,000 & 0,574 \\
\hline V25 & 0,294 & 0,103 & 0,368 & 0,579 & 0,765 & 0,074 & 0,825 & 0,472 & 0,243 & 0,536 & 0,235 & $-0,394$ & 0,548 & 0,727 & 0,182 & 0,381 & \begin{tabular}{|c|}
0,310 \\
\end{tabular} & 0,117 & $-0,184$ & 0,045 & 0,686 & \begin{tabular}{|c|}
0,738 \\
\end{tabular} & 0,604 & 0,574 & 1,000 \\
\hline
\end{tabular}


Tabela 21: Matriz de correlação referente as respostas dadas pelas empresas instaladas no ParqTec

\begin{tabular}{|c|c|c|c|c|c|c|c|c|c|c|c|c|c|c|c|c|c|c|c|c|c|c|c|c|c|}
\hline & & 2 & 3 & 4 & & & 7 & V8 & V9 & 10 & 11 & 12 & 3 & 14 & 15 & 116 & 17 & 18 & 19 & $\mathrm{V20}$ & V21 & V22 & $\mathrm{V} 23$ & $\mathrm{V24}$ & $\mathrm{V} 25$ \\
\hline 11 & & & & & & & & & 5 & & & & & & & & & & & & & 21 & 95 & 3 & 0,022 \\
\hline 2 & & & & & & & & & & & & & & & & & & & & & & & & & 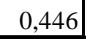 \\
\hline V3 & & & & & & & & & & & & & & & & & & & & & & & & & \\
\hline V4 & & & & & & & & & 457 & & & 1,448 & & ,011 & 435 & & & &, 72 & 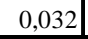 & 398 & 208 & & &, 556 \\
\hline V5 & & & & & & 047 & & & & & &, 86 & & & & & F & 10 & &, 09 & & .523 & 30 & &, 78 \\
\hline V6 & & & & & & & & & & & & $-0,0$ & & & & & & & & & & & & & 990 \\
\hline V7 & & 0 & 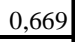 & 198 & 28 & 113 & 1,0 & 7 & ,066 & 4 & & $-0,522$ & & & 056 & 303 & & & 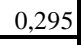 & & & & & & 08 \\
\hline V8 & & & 454 & 314 & 74 & 250 & 0,2 & 0 & 0,119 & & 445 & $-0,692$ & & 414 & 069 & 394 & 144[ & 71 & ,681 & $0+27$ & 07 & 584 & 0. & & 0,674 \\
\hline V9 & 075 & & & & & & 0 & & 1,00 & & &, 231 & & & & & & & & & & 420 & & & $\underline{0,22}$ \\
\hline V10 & & & & & & & & & 0,302 & & & 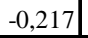 & & & $4+4$ & & & & & & & & & & 0,471 \\
\hline V11 & & - & 0, & 0 , & 0 & & 0,3 & 0,445 & $-0,159$ & 35 & 1,0 & $-0,158$ & 0,571 & 157 & $-0,449$ & 11 & 4 & 0,4 & 40 & 00 & 10 & 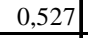 & & & 0,291 \\
\hline $\mathrm{V} 12$ & 295 & 720 & 394 & 448 & 866 & 389 & 2 & . & 0,231 & & & 1,000 & , & & 15 & 24 & 21 &, 66 & 01 & 96 & & 0,686 & & & $-0,724$ \\
\hline V13 & & & & & & & & & 0,2 & & &, 446 & &, 305 & 40 & & & & & & &, 747 & & & 0,61 \\
\hline V14 & & 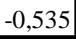 & - & 011 & &, 298 & 379 & 4 & $-0,29$ & & $-0,1$ & 0,260 & J & 001 & 334 & $-0,0$ & & |,074, & $-0,174$ & $-0,526$ & 33 & $-0,459$ & $-0,6$ & & $-0,166$ \\
\hline $\mathrm{V} 15$ & 000 & 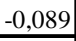 & -0 & & & 186 & 0,0 & & 0,093 & 44 & 199 & $-0,315$ & -0, & & & & & 87 & 44 & 69 & 59 & 117 & & & 0,312 \\
\hline V16 & & & 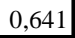 & & & & & & 611 & & &, 404 & & & & & & & & & & & & & 0,654 \\
\hline V17 & & & & & & & & & 0,79 & & 4 & $-0,552$ & & & & & & 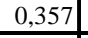 & & & 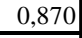 & 4 &, 2 & & 0,461 \\
\hline V18 & & 0 & 0 & & & & 0,8 & &, 011 & & & $-0,665$ & 0 & & & 01 & & 0 & & & & & & & 0,883 \\
\hline V19 & 087 & 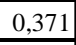 & 0,634 & 70 & 0,629 & 0,052 & 0,295 & 0,680 & 0,360 & &, 146 & $-0,601$ & 0,618 &, 174 &, 444 & & 481 & 0,673 & 00 & 46 & & 413 & & & 0,717 \\
\hline $\mathrm{V} 20$ & & & & & (5) & & & & 264 & 4 &, 408 & $-0,196$ & 22 & 526 & 0,169 & & & 00 & 440 & 1,000 & $-0,031$ & ,424 & 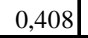 & & 0,144 \\
\hline V21 & 0 & & 0 & & & 0,0 & 0,2 & 0,0 & $\pi$ & &, 17 & $-0,405$ & 0, & $-0,0$ & & & 4 & , 2 & & $-0,031$ & 1,000 & 0,507 & & & 0,417 \\
\hline $\mathrm{V} 22$ & & 0,666 & 0,49 & & & & 0,463 & 0,0 & $0, \pi$ & & & $-0,686$ & & & & & & & & & & & & & 0,748 \\
\hline $\mathrm{V} 23$ & ,295 & 0 & 482 & & 367 & 094 & 0,157 & 66 & 0,300 & & & $-0,462$ & 0,622 & 87 & 114 & 17 & 38 & 546 & 91 & 08 & 20 & 734 & 00 & & 0,760 \\
\hline $\mathrm{V} 24$ & 300 & & & & & 0 & & & 0 & & & $-0,213$ & & . & -0 & & & 540 & 06 & 70 & & 81 & & & 0,54 \\
\hline $\mathbf{v 2 5}$ & 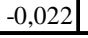 & & & & & & & & & & & $-0,7$ & & & & & & & & & & 07 & & & 1,00 \\
\hline
\end{tabular}


